\title{
Sergei Prokofiev's Third Piano Sonata, OP. 28: Stylistic Analysis and Performance Suggestions
}

\author{
YOUNGJU LEE \\ WVU,yl0024@mix.wvu.edu
}

Follow this and additional works at: https://researchrepository.wvu.edu/etd

Part of the Music Performance Commons

\section{Recommended Citation}

LEE, YOUNGJU, "Sergei Prokofiev's Third Piano Sonata, OP. 28: Stylistic Analysis and Performance Suggestions" (2020). Graduate Theses, Dissertations, and Problem Reports. 7905.

https://researchrepository.wvu.edu/etd/7905

This Dissertation is protected by copyright and/or related rights. It has been brought to you by the The Research Repository @ WVU with permission from the rights-holder(s). You are free to use this Dissertation in any way that is permitted by the copyright and related rights legislation that applies to your use. For other uses you must obtain permission from the rights-holder(s) directly, unless additional rights are indicated by a Creative Commons license in the record and/ or on the work itself. This Dissertation has been accepted for inclusion in WVU Graduate Theses, Dissertations, and Problem Reports collection by an authorized administrator of The Research Repository @ WVU.

For more information, please contact researchrepository@mail.wvu.edu. 
YOUNGJU LEE

Follow this and additional works at: https://researchrepository.wvu.edu/etd

Part of the Music Performance Commons 


\title{
SERGEI PROKOFIEV'S THIRD PIANO SONATA, OP. 28: STYLISTIC ANALYSIS AND PERFORMANCE SUGGESTIONS
}

\author{
Youngju Lee \\ Research Project submitted to the College of Creative Arts at \\ West Virginia University \\ in partial fulfillment of the requirements for the degree of \\ Doctor of Musical Arts \\ in Piano Performance
}

Peter Amstutz, D.M.A., Chair and Research Advisor

William Haller, D.M.A.

Andrea Priester Houde, M.M.

Matthew Heap, D.M.A.

Soo Cheol Jeong, D.D.S.

School of Music

Morgantown, West Virginia 2020

Keywords: Prokofiev, Performance Suggestions, Sonata

Copyright 2020 Youngju Lee 


\section{ABSTRACT \\ SERGEI PROKOFIEV'S THIRD PIANO SONATA, OP. 28: STYLISTIC ANALYSIS AND PERFORMANCE SUGGESTIONS \\ Youngju Lee}

Sergei Prokofiev (1891-1953) was one of the greatest Russian pianists and composers of the twentieth century. He established his own musical style by combining classical form and modern compositional techniques. He composed a variety of piano music including nine piano sonatas. This paper is a study of the third piano sonata in A minor, op. 28.

Prokofiev's music can be classified into three periods: a Russian Period, a Foreign Period, and a Soviet Period. It is possible to identify Prokofiev's compositional styles by studying his piano sonatas because he composed piano sonatas during the entire course of his life. In this document, a review of Prokofiev's life and music and a brief survey of his nine piano sonatas precede an analysis of Prokofiev's Piano Sonata no. 3, op. 28. This sonata is the composer's most popular sonata for piano recitals.

In chapter IV, performance suggestions follow a stylistic analysis. It is valuable to analyze stylistically in order to perform successfully. Pianists will require a high level of technique to play this piece. There are many kinds of performance suggestions. This paper contains some helpful suggestions for pianists with regard to pedaling and fingering, and regarding what Prokofiev called his "modern line" and his "toccata line." 
Table of Contents

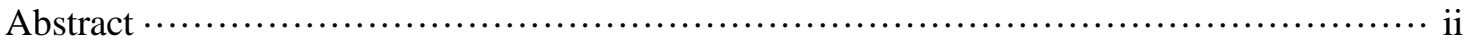

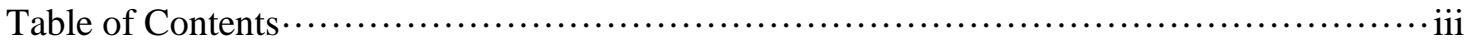

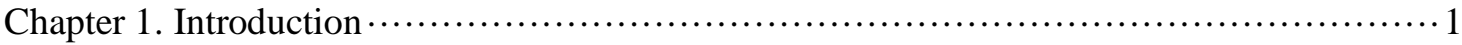

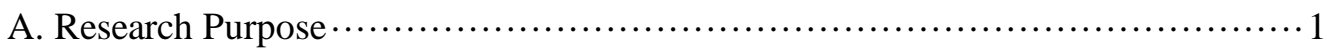

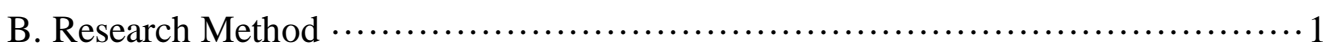

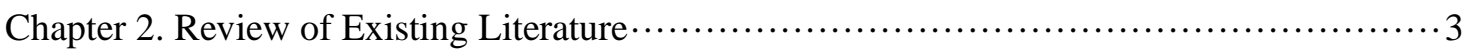

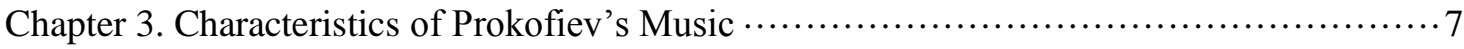

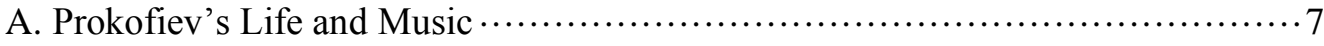

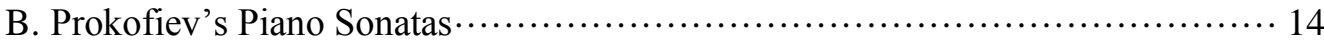

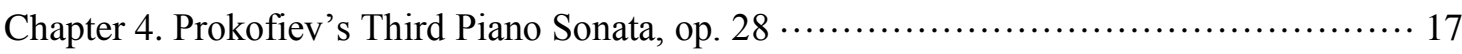

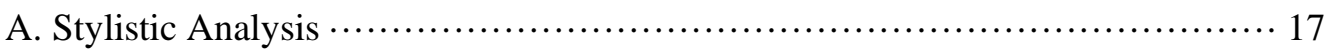

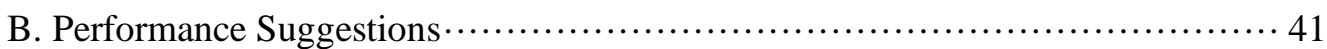

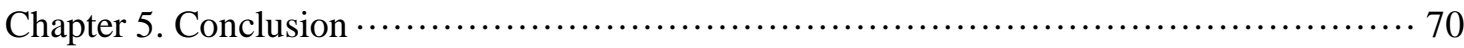

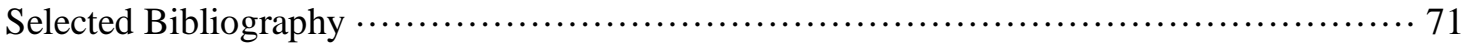




\section{Chapter 1: Introduction}

\section{A. Research Purpose}

Sergei Prokofiev (1891-1953) was one of the greatest Russian pianists and composers in the 20th century. He composed nine piano sonatas, in addition to many other works that included symphonies, concertos, and smaller works. The Third Piano Sonata, op. 28, was composed in 1917. It is a single-movement work and the shortest among his piano sonatas. He used sonata-allegro form for this work, presenting his own musical style and character within a traditional structure. Piano Sonata no. 3 also bears the subtitle "From Old Notebooks," indicating that the material originates from compositional sketches that he had made while still a student.

In a letter to Miaskovsky on June 26, 1907, Prokofiev wrote about Piano Sonata no. 3: "It will remain...in one movement: pretty, interesting, and practical." ${ }^{1}$ This sonata reveals most of the traditional sections in a sonata-form, within which Prokofiev employs his own blend of nineteenthcentury Russian and twentieth-century characteristics.

Prokofiev's Third Piano Sonata is frequently performed on piano recitals. Pianists will require a high level of technique to play this piece. Analyzing the work stylistically can be a significant help towards achieving a successful performance of the work. Toward this goal, this paper offers suggestions that can be valuable to pianists who perform or teach this work.

\section{B. Research Method}

Although reviewing all the published material about Prokofiev's life and music would far exceed the scope of this paper, several sources have been significantly helpful towards understanding his musical characteristics, including several theses and dissertations that touch in some way on the Third Sonata. This study begins with general characteristics of Russian music and an overview of Prokofiev's works, which multiple authors divide within several musical periods that are delineated

\footnotetext{
${ }^{1}$ Sergei Prokofiev. Prokofiev by Prokofiev: A Composer's Memoir. ed. David H. Appel, trans. Guy Daniels (Garden City, NY: Doubleday, 1979), 199.
} 
by his country of residence at the time of composition. It continues with a brief survey of his piano sonatas, before focusing on the Third Sonata with analysis and performance suggestions. 


\section{Chapter 2: Review of Existing Literature}

As indicated above, the bibliography about Prokofiev and his piano music is overwhelmingly vast. Thus, the current review of literature pertaining to this topic will focus on several of the most valuable sources consulted.

The Music of Sergei Prokofiev by Neil Minturn² has been extremely helpful. This book contains theoretical analyses of selected pieces by Prokofiev. In Chapter 1, Minturn discusses Prokofiev's education and biography. He describes Prokofiev as an early twentieth-century composer who was influenced by Romanticism. He trained as a composer and pianist in Russia, eventually returning to his homeland after lengthy stays in the United States and France. Minturn discusses some key points about the perception of Prokofiev's music, including the concept of the "wrong note" as a characteristic feature of his music. ${ }^{3}$ We see many fascinating interactions between intentional "wrong notes" and the traditional background of Russian nationalism and nineteenth-century Russian musical culture.

In Chapter 2, Minturn provides an analysis by Prokofiev himself, in which he identifies and discusses five "lines" in his music, including musical examples for each of these five lines. This concept helps us understand the composer and his music. ${ }^{4}$ These "five lines" are Prokofiev's selfidentified five musical characteristics: the lyrical line, the grotesque line, the classical line, the modern line, and the toccata line. Prokofiev also includes an outline of the constant features and the changing characteristics in his music.

Minturn's Chapter 3 develops Chapters 1 and 2, exploring precise concepts and analytical categories, along with collections of analyses which are organized by genre, presenting material chronologically within each chapter. Minturn reaches five significant conclusions about Prokofiev's musical characteristics:

\footnotetext{
${ }^{2}$ Neil Minturn, The Music of Sergei Prokofiev. (New Haven and London: Yale University, 1997).

${ }^{3}$ Ibid., xi.

${ }^{4}$ Ibid., xii.
} 
1. The surface of Prokofiev's music differs from the surface of traditionally given music.

2. Triads alone do not constitute the recurring characteristic sonorities of any given music.

3. The individuality of a given piece is usually defined by a small number of set classes which occur often and prominently, and which include non-triadic collections.

4. If triads are present in the music, they usually occur with added notes.

5. Some single structure or some single process often drives different aspects of the music. ${ }^{5}$

Minturn's Chapter 4 is about Prokofiev's piano music, which gives the best overview of his evolution as a composer, because works for piano are so central to his output. For the piano, he composed nine piano sonatas, short character pieces, concertos, and transcriptions. Especially the third sonata and the fourth sonata were recycled from the sketches he had kept in notebooks during his conservatory years. Piano Sonata no. 3 appears in one-movement sonata-allegro form.

In Chapter 5, Minturn discusses the first movements of three symphonies as examples of Prokofiev's orchestral works. Chapter 7 explores three concertos and Chapter 8 is about vocal music.

Another helpful source is the book entitled Prokofiev by Prokofiev - A Composer's Memoir, by Sergei Prokofiev. This is an interesting source that describes Prokofiev's life, beginning from his childhood. It is excellent for understanding Prokofiev's human characteristics as well as his educational background in music, providing valuable insights into his life and his complex inner world. His works are often harsh, cruel, and anxiety-ridden, reflecting the darkening of light and joy so often experienced in the twentieth century. Those characteristics relate to the chaotic world circumstances of the time in which he lived. This book is truly useful for figuring out the specific and unique factors of his music and life.

Twentieth-Century Music, by Robert Morgan, ${ }^{6}$ also provides valuable material for this study, containing an entire section on Prokofiev. Morgan provides an overview of the many diverging musical movements of the twentieth century, helping the reader to see the context for each composer in regard to musical characteristics, as well as a summary of their life.

\footnotetext{
${ }^{5}$ Ibid., p. 54.

${ }^{6}$ Robert P. Morgan, Twentieth-Century Music. (New York: W.W. Norton \& Company, 1991).
} 
Prokofiev's music was widely performed during his lifetime, attracting considerable public attention and even enjoying the distinction of being denounced by conservative critics as "ultramodernist." From his earliest years, Prokofiev was influenced both by Romanticism and by antiRomanticism and anti-emotionalism. A sort of "Classicism" seems eventually to have become one of his defining characteristics. He said: ${ }^{7}$

Therefore, I think the desire which I and many of my fellow composers feel, to attain a more simple and melodic expression, is the inevitable direction for the music of the future.... In the field of instrumental or symphonic music... I want nothing better, nothing more flexible or more complete than the sonata form, which contains everything necessary to my structural purpose.

Prokofiev discussed the idea of writing a work evoking the style of Haydn. ${ }^{8}$ This inclination is called Neo-Classicism. Notwithstanding an obvious risk of oversimplifying, Prokofiev's writing styles could be defined in three words: whimsical, laughing, and mocking. ${ }^{9}$ Several early piano works like Diabolic Suggestions and Sarcasms expressed this personality. His later music shows a more open, relaxed lyricism and a new expressive warmth. ${ }^{10}$ Prokofiev was a composer with both a traditional orientation and his own innovative twentieth-century composing style.

The dissertation by David Westfall, entitled "Three One-Movement Sonatas of The Russian Silver Age: A Comparative Study,"11 includes an overview of the arts, politics, and music during the Russian silver age. He analyzes three one-movement sonatas, by Nicolas Medtner, Aleksander Skryabin, and Sergey Prokofiev, respectively. In Chapter 4, he provides a biography of Prokofiev and an analysis of the Piano Sonata no. 3 in a minor. Westfall analyzes by observing the sonata from three viewpoints: melody, structure and thematic development, and harmony. He describes some of the compositional techniques that Prokofiev uses in this work, including augmentation, mirroring, stretto, juxtaposition of themes, sequence and repetition, and imitation.

\footnotetext{
${ }^{7}$ Ibid., p. 240.

${ }^{8}$ Ibid.

${ }^{9}$ Ibid., p. 241.

${ }^{10}$ Ibid., p. 244.

${ }^{11}$ David Westfall, "Three One-Movement Sonatas of The Russian Silver Age: A Comparative Study.” (D.M.A. diss., University of Hartford, West Hartford, 2008).
} 
Also useful is the thesis by Eun Hee Lee, entitled "An Analytic Study on the Sergei Prokofiev Piano Sonata no. 3, op. 28."12 It discusses Prokofiev's life and musical characteristics and it analyzes the Piano Sonata no. 3, also offering performance suggestions. In Chapter 2, she considers five characteristics of Prokofiev's music: classical, innovative, toccata, lyrical, and grotesque. The last chapter provides analysis as well as performance suggestions. In my opinion, more content about performance suggestions would have been welcome.

My study will emphasize performance suggestions regarding fingering, rhythmic playing, percussive technique at the piano, and effective pedaling for Prokofiev's music, along with theoretical analysis.

\footnotetext{
${ }^{12}$ Eun Hee Lee, "An Analytic Study on the Sergei Prokofiev Piano Sonata No. 3, Op. 28." (M.M. Thesis,
} Hanyang University, Seoul, 2009). 


\section{Chapter 3. The Characteristics of Prokofiev's Music}

\section{A. Prokofiev's Life and Music}

Sergei Prokofiev (1891-1953) was born in a small Russian town, Sontsovka, on April 23rd in 1891. His mother was an amateur pianist who could play music by Beethoven and Chopin. She did her best to provide every cultural advantage for Sergei that she could. Prokofiev was deeply affected by his mother and she helped him learn famous piano literature like that of Beethoven, Anton Rubinstein, and Chopin.

Prokofiev also showed remarkable talent. He composed Indian Galop at age 5 and, between the ages of 9 and 10, an opera, The Giant, with piano accompaniment, and an unfinished opera, On Desert Islands. Prokofiev started music lessons with the Ukrainian Post-Romantic composer Reyngol'd Moritsevich Gliere (1875-1956), studying fundamental Music Theory, Harmony, and Orchestration. In 1904, he entered St. Petersburg Conservatory by recommendation of composer Alexander Glazunov (1865-1936), who was a professor there. He learned Applied Harmony and Composition from Anatole Lyadov and Nikolai Rimsky-Korsakov for ten years, Piano from Anna Esipova, and Conducting from Nikolay Tcherepnin. ${ }^{13}$

In 1908, at the age of 17, Prokofiev made his debut by performing seven piano pieces in the "Evenings of Contemporary Music" series. His avant-garde composing style was welcomed at the performance. In 1910, he gained a reputation as a pianist as well as a composer with his Piano Concerto no. 1, op. 10. He published Piano Sonata no. 1, op. 1, in 1911, through Urgenson Publication in Moscow. In 1914, Prokofiev graduated from St. Petersburg Conservatory, along with winning the Rubinstein Competition, playing his own Piano Concerto no. 1, op. 10 in the final round.

In 1917, Prokofiev left Russia through Siberia and Japan to escape the Bolshevik Revolution, and he entered exile in the United States. Between 1917 and 1936, he worked primarily in the United States and France, earning a reputation throughout the world as a pianist and composer. From 1920 to

\footnotetext{
${ }^{13}$ Anthony Leonard, A History of Russian Music, (New York: The Macmillan Company, 1957), pp. $295-296$.
} 
1921, when he was based mainly in France and Canada, the ballet music Chout, op. 21, had its famous premiere in Paris. During the same year, he completed what many regard as his greatest masterpiece, the Piano Concerto no. 3, op. 26. In Paris, he met with Igor Stravinsky, Francis Poulenc, Darius Milhaud, and Maurice Ravel. He was influenced by Neoclassical elements in each of their styles.

In 1933, Leningrad Conservatory requested that Prokofiev compose music for a concert in the Soviet Union, although he was exiled in the U.S. For this event, he composed Night of Egypt and Romeo and Juliet. After a three-year transition period, he decided to return to his own country, Russia, in 1936.

That year, he returned to Russia with his family, receiving a hero's welcome. At that time, many artists had been oppressed by socialist realism. Prokofiev was not an exception and he chose to compose music that would not trigger the censors. He composed short piano pieces, Peter and the Wolf for children (1936), and Romeo and Juliet in 1938. In 1939, he composed the original soundtrack of the movie named "Alexander Nevsky," which has a patriotic theme; this was a new challenge for him. He also wrote the three "War Sonatas": Piano Sonata no. 6, op. 82 (1939); Piano Sonata no. 7, op. 83 (1942); and Piano Sonata no. 8, op. 84 (1944). Piano Sonata no. 7, op. 83, was called a masterpiece among piano sonatas and it won the Stalin Prize for Prokofiev.

After the breakdown of his marriage in 1940, he continued composition with the opera War and Peace, op. 91. In 1944 he created Symphony no. 5, op. 100, and Piano Sonata no. 8, op. 84. Symphony no. 5, op. 100, was also awarded the Stalin Prize.

In 1945 he experienced an accidental fall which included a concussion. His health declined from that point, as did his rate of composition. However, by the time of his death in 1953, of cerebral hemorrhage, he had still managed to compose The Tale of the Stone Flower, op. 118; Symphony no. 7; and the Symphony-Concerto for Cello and Orchestra in E minor, op. 125.

Prokofiev spent most of his life outside Russia. He moved to the U.S. and later spent several years in Paris shortly after World War I. He lived during the stormy times from the late nineteenth century to the early twentieth century. His work can be classified into three periods: The Early Period in Russia (1891-1918), the Middle Period in America and France (1918-1936), and the Late Period in 
the Soviet Union (1936-1953). In his autobiography he mentions that the five categories, or "lines" as he called them, in his compositions are the classical, the modern, the toccata, the lyrical, and the grotesque. ${ }^{14}$ Prokofiev said that the Classical line could be traced back to his early childhood and the Beethoven sonatas he heard his mother play. This line sometimes takes a neo-classical form (e.g., sonatas, concertos), sometimes imitates the 18th century (gavottes, the "Classical" Symphony, part of the Sinfonietta. ${ }^{15}$ Prokofiev employs sonata-allegro form for the first movements of all his piano sonata. He used Alberti-bass accompaniment (derived from $18^{\text {th }}$-century style) and traditional classical cadences (e.g., ii-V-I).

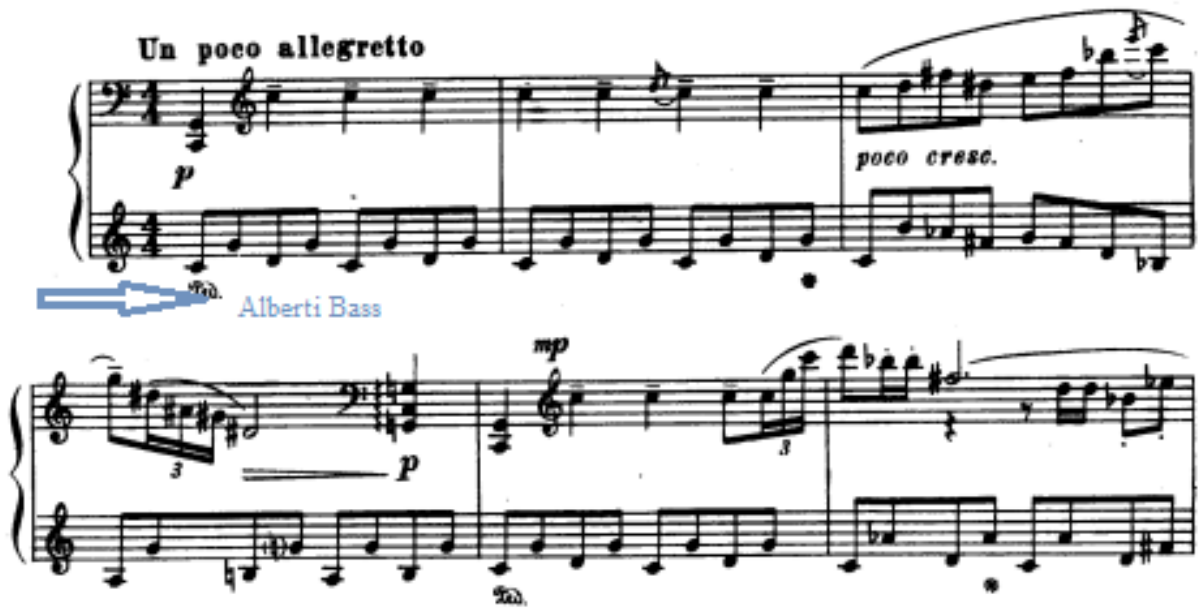

Example 1: Piano Sonata no. 5, op. 38, 3rd movement, mm. 1-6

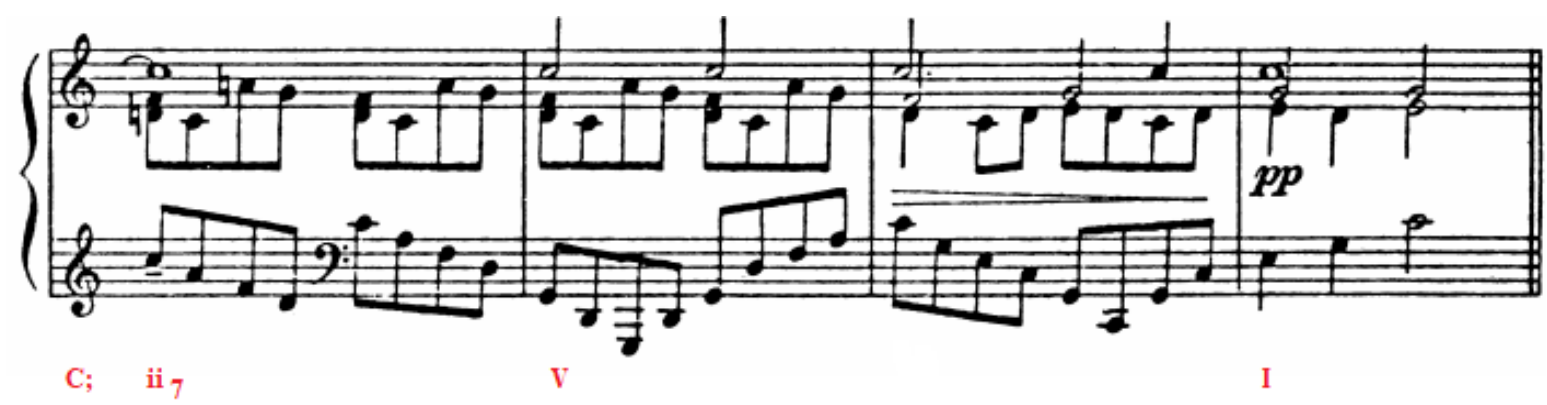

Example 2: Piano Sonata no. 3, op. 28, mm. 90-93

\footnotetext{
${ }^{14}$ Neil Minturn, The Music of Sergei Prokofiev, (New Haven and London: Yale University, 1997), p. 24.

${ }^{15}$ Sergei Prokofiev, Autobiography, in his Soviet Diary 1927 and Other Writings, translated and edited by Oleg Prokofiev (Boston: Northeastern University Press, 1992), pp. 248-249.
} 
His Modern line denotes a nontraditional harmonic vocabulary, especially one which employs daring and unsolved dissonances. Leaving aside the highly experimental examples of Prokofiev's harmonic modernism, we can still point to the Sarcasms, op. 17, some of the Visions Fugitives, op. 22, or the Balmont Songs, op. 36, as pieces in which Prokofiev is carrying on harmonic experimentation. ${ }^{16}$
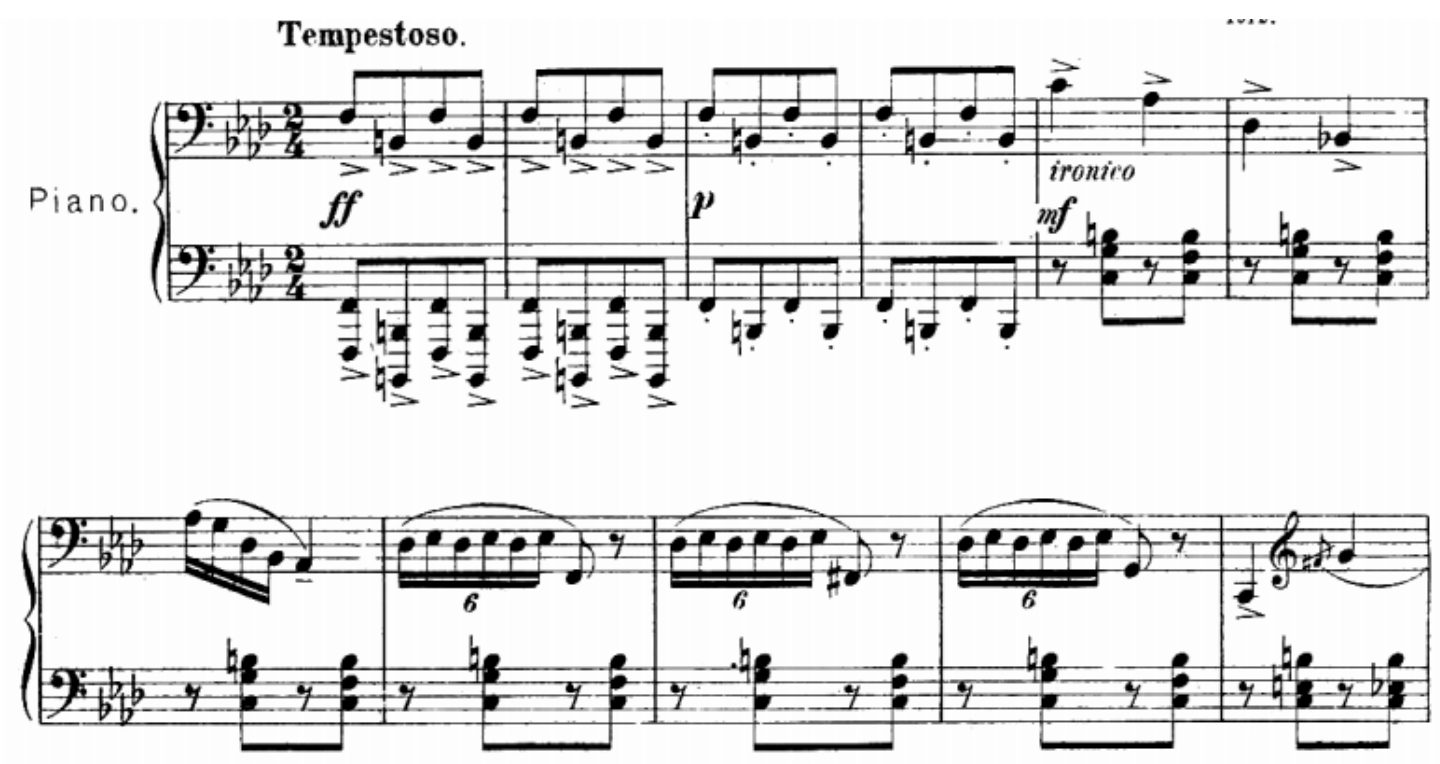

Example 3: Sarcasms, op. $17 \mathrm{~mm} .1-11$

Regarding the Toccata line, given both the association of the toccata with the keyboard and Prokofiev's pianistic career, one would naturally expect piano music to represent the toccata line. Prokofiev's lifelong interest in driving rhythms understandably accounts for a prominent toccata line. For the pianist the relentless sixteenth motion challenges technique and stamina. ${ }^{17}$ Toccata, op. 11 , is an obvious example of this line.

\footnotetext{
${ }^{16}$ Minturn, 28.

${ }^{17}$ Ibid., 25.
} 

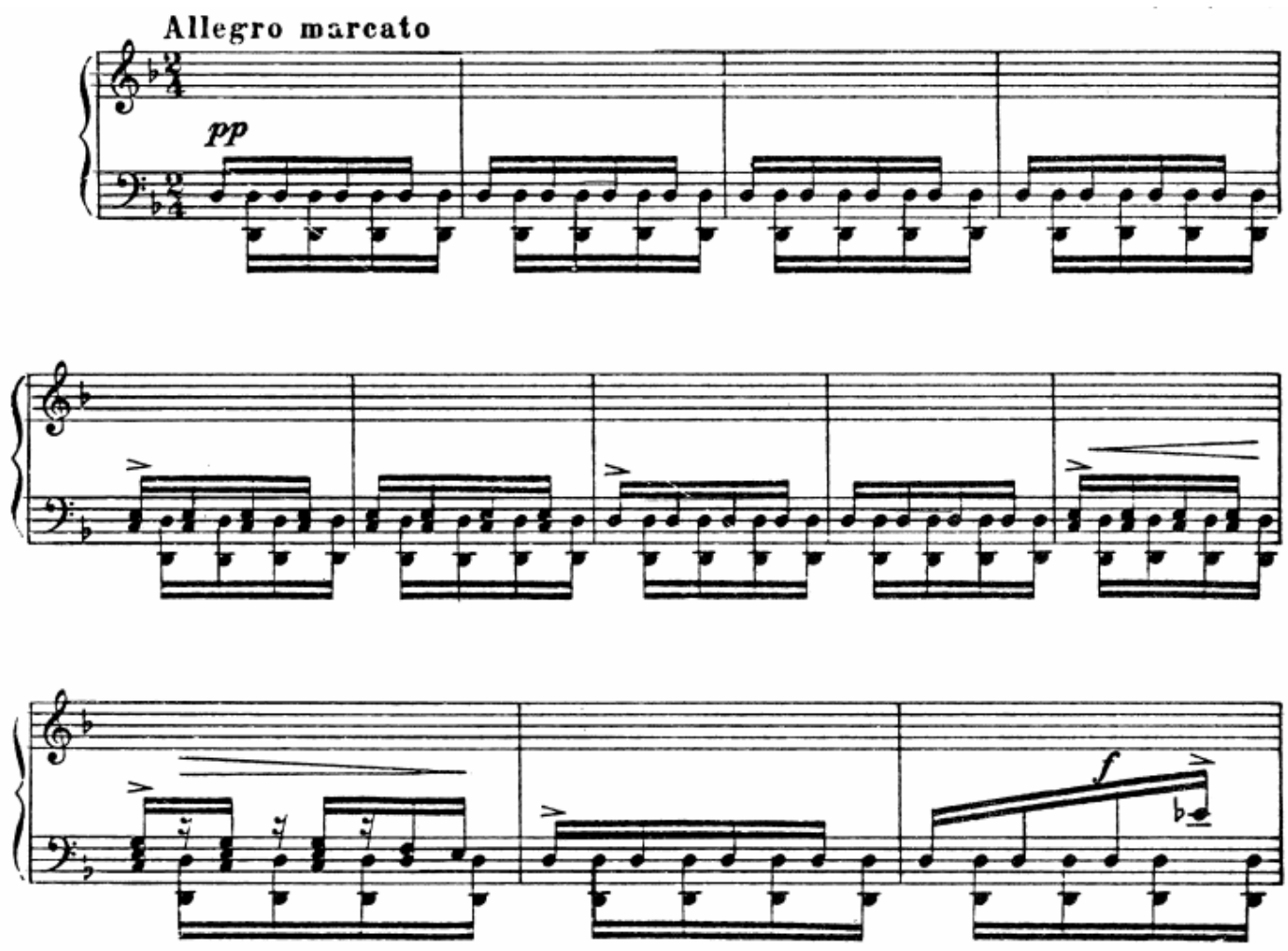

Example 4: Toccata, op. 11, mm. 1-12

For Prokofiev, a strong lyrical line shows a composer with considerable and diverse skills.

He said, "For a long time I was given no credit for any lyrical gift whatever, and for want of encouragement it developed slowly. But as time went on I gave more and more attention to this aspect of my work." 18 One example of the Lyrical line appears in the first movement of Piano Sonata no. 2, op. 14, as shown in Example 5:

${ }^{18}$ Ibid. 


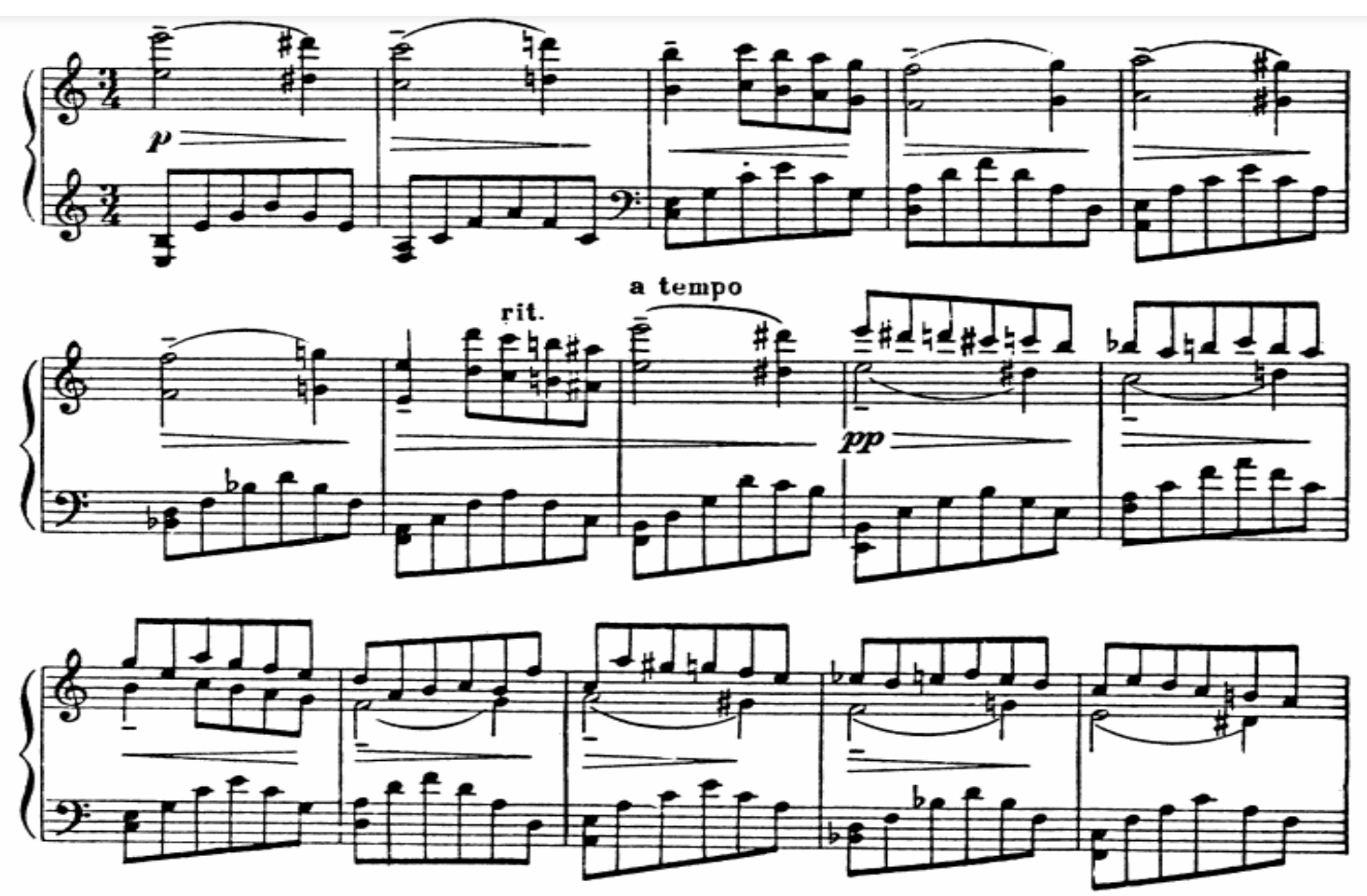

Example 5: Piano Sonata no. 2, op. 14, 1st movement, mm. 65-79

In describing the Grotesque line, Prokofiev wanted his music to be characterized as "scherzo-ish" in quality, or perhaps by three words that describe various degrees of "scherzo" quality: whimsicality, laughter, and mockery. "Grotesque" implies the distortion or caricature of a basic model. Prokofiev's traditional genres - including the marches, gavottes, and waltzes which he so often composed — provide both the model (the type) and its grotesque interpretation. ${ }^{19}$ March from Love for Three Oranges, op. 331, Suggestion Diabolique, op. 4, no. 4, and parts of Piano Sonata no. 6, op. 82, provide characteristic examples of the grotesque line.

${ }^{19}$ Ibid., 30. 

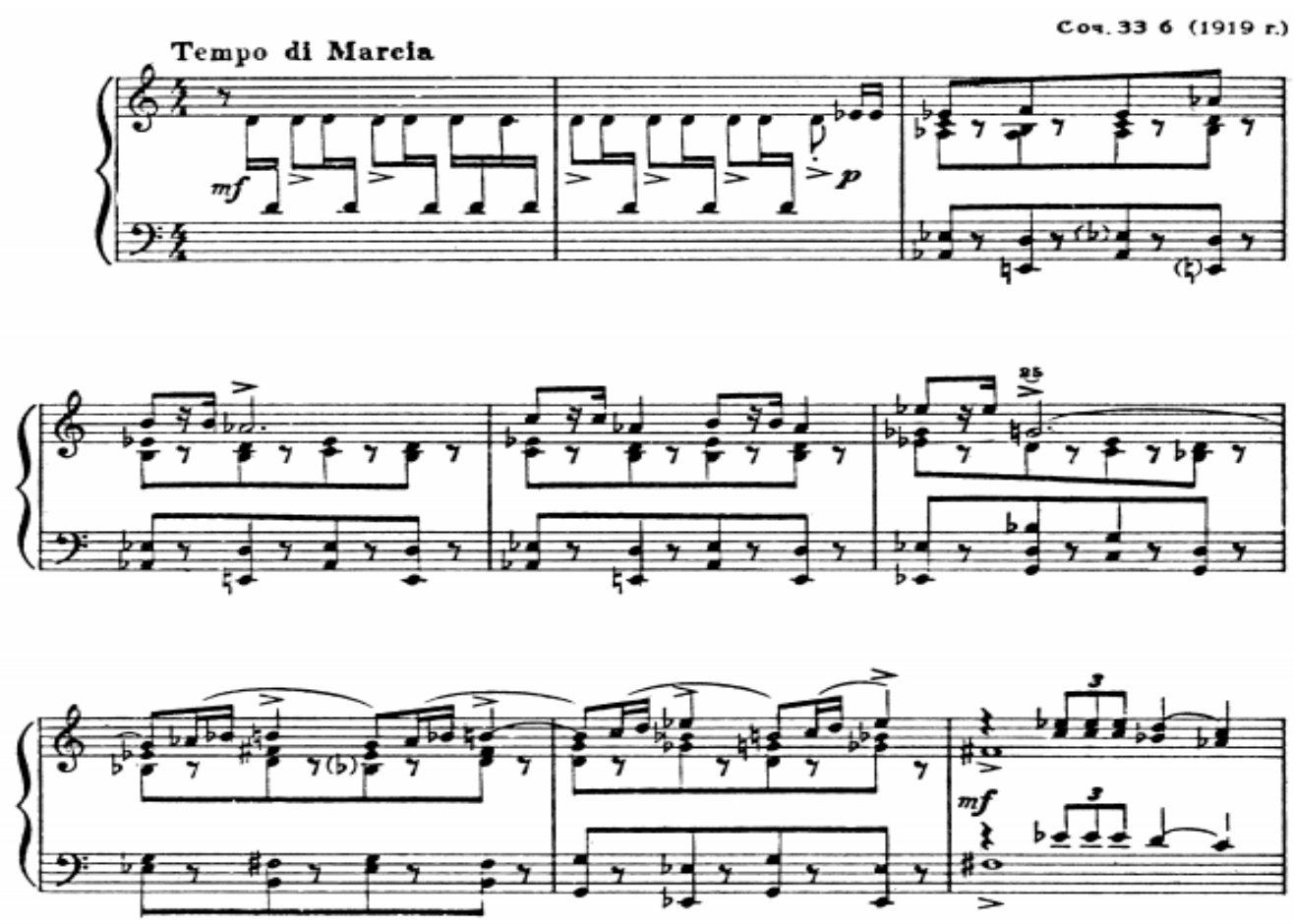

Example 6: March from Love for Three Oranges, op. 331, mm. 1-9

Prestissimo fantastico.
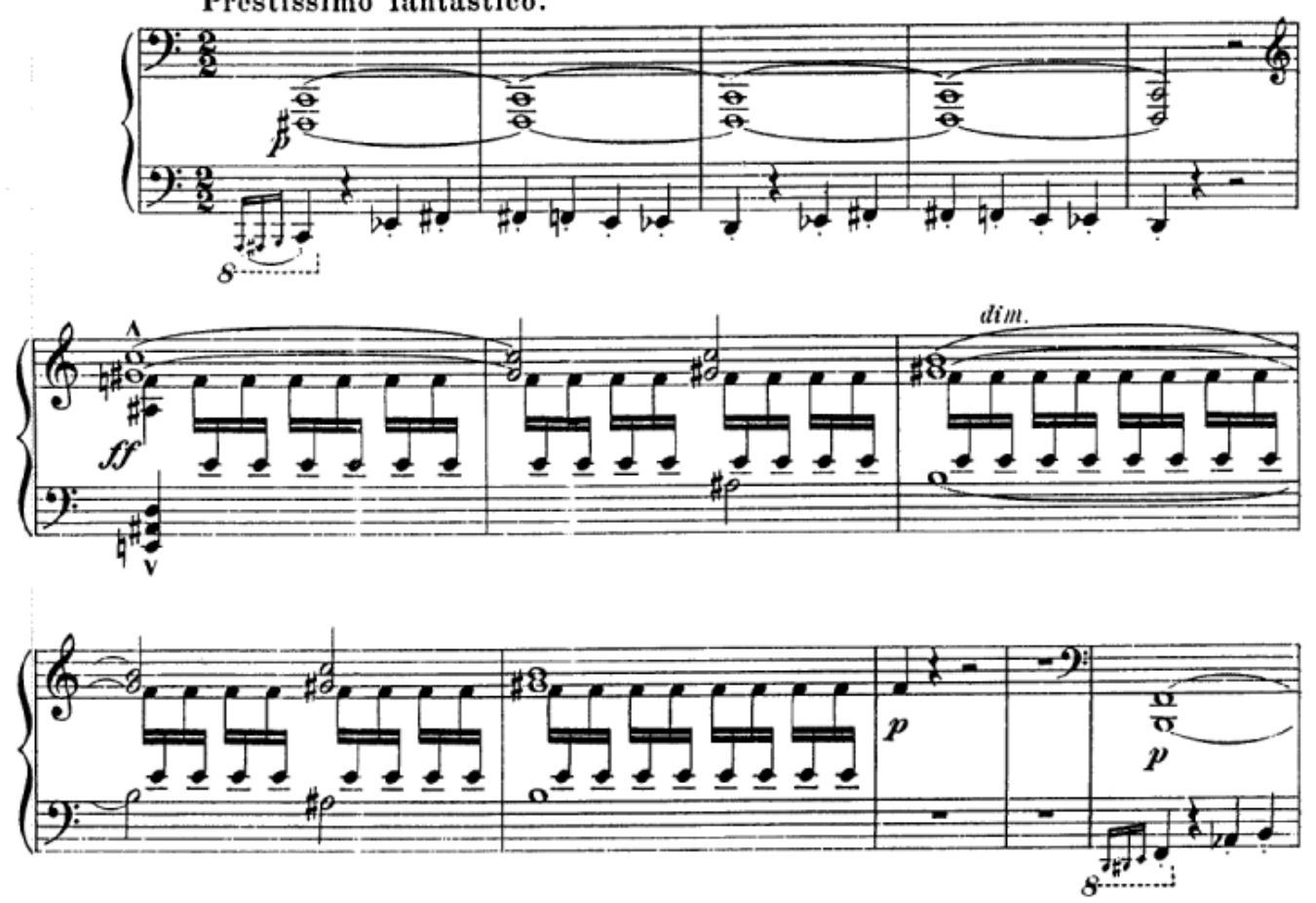

Example 7: Suggestion Diabolique, op. 4, no. 4 mm. 1-13 

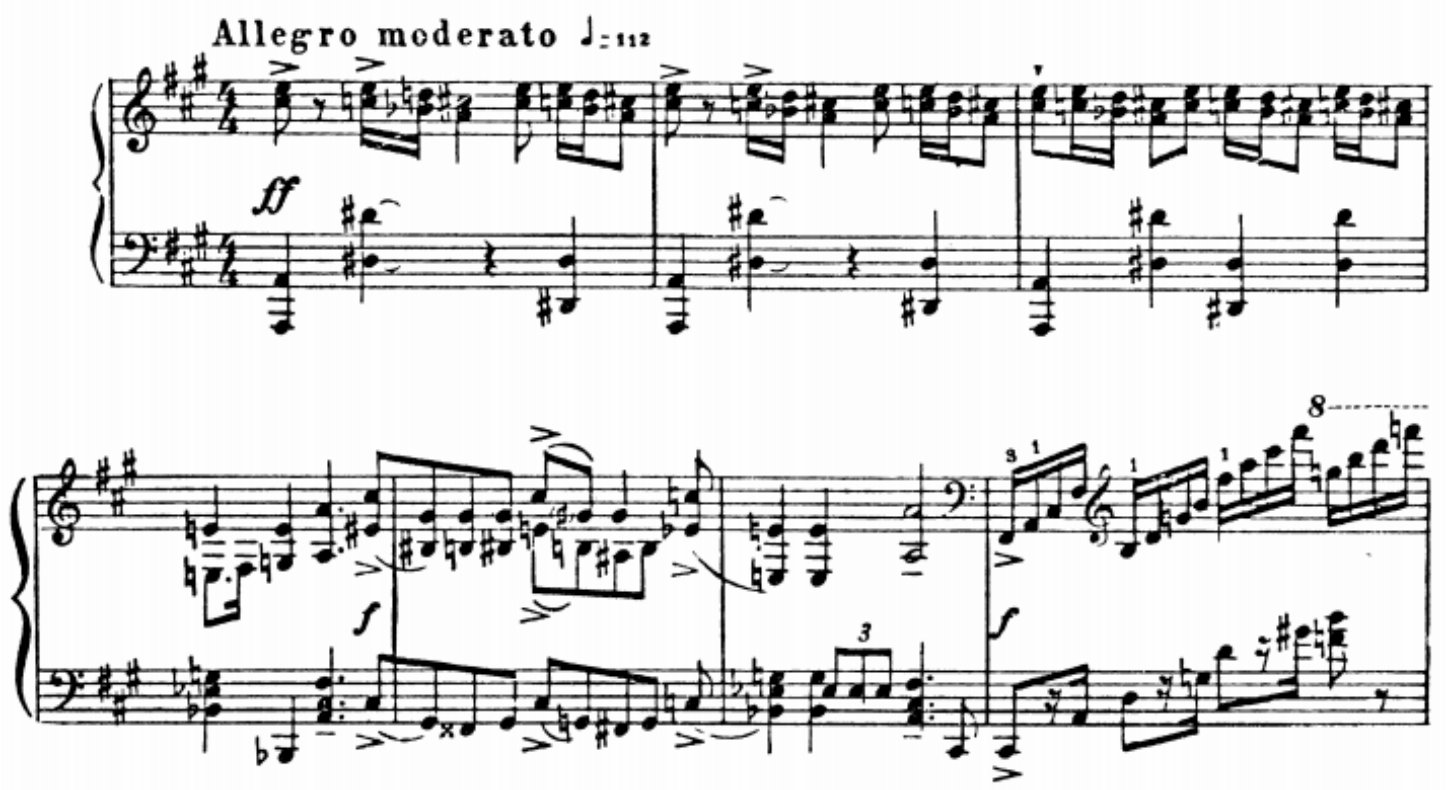

Example 8: Piano Sonata no. 6, op. 82, mm. 7-13

\section{B. Prokofiev's Piano Sonatas}

Prokofiev completed nine piano sonatas and he began a tenth sonata that was never finished.

The nine complete sonatas are among the most important repertoire in piano literature of the twentieth century. They represent twentieth-century musical techniques along with sonata-allegro form, expressed in Prokofiev's own harmonic language. The first four sonatas can be classified as representing the early period, the fifth sonata comes from the middle period, and the last four sonatas (no. 6-9) represent Prokofiev's last period.

\section{The Early Period (1891-1917)}

The first sonata in F minor, op. 1, was written in 1907 while he studied in St. Petersburg; it is comprised of one movement. He revised the work in 1909. It displays nineteenth-century postRomantic style, including diatonic scales and Romantic harmony throughout the piece. This work is influenced by Schumann, Rachmaninoff, and Scriabin.

Prokofiev wrote his second sonata in 1912, also while he studied in St. Petersburg. The Romantic elements are coordinated with modern harmony and strict rhythms. In the second sonata, Prokofiev composed a lyrical first movement, a humorous and satirical second movement, a mysterious third movement, and a toccata-style fourth movement that is a tarantella based on a 
melody from the first movement. Many dissonances appear throughout each movement. The second sonata is different from the first sonata in part because its rhythms feel cheerful and the chordal writing has an aspect of freshness. It shows Prokofiev's unique musical language.

The third sonata was begun in 1908 and completely revised in 1917. It is the shortest among the nine sonatas and is composed in one single movement. Passionate and dramatic melodies alternate with calm, lyrical lines throughout the whole piece. Intense rhythmic drive is a dominant characteristic of this sonata.

The fourth sonata consists of three movements. The first and second movements are dark, heavy, and quiet. The third movement presents a classical-style Alberti-bass pattern in the left hand. It is animated and raging. The second movement was a favorite of Prokofiev's, as reflected in part by his decision to orchestrate the music. While it follows strict classical form, it presents a Romantic mood.

\section{The Middle Period (1918-1936)}

The fifth sonata consists of three movements. It was the only sonata that Prokofiev wrote while exiled in the United States and Paris. It has three movements and presents dissonant harmonies, textures, and phrases. He revised and simplified it as op. 135 in $1953^{20}$ because he thought it was too difficult and complex.

\section{The Late Period (1936-1953)}

The next three sonatas were written after Prokofiev returned from exile to his native Russia. Because he created the sixth through eighth sonatas during World War II, they are often referred to as the "War Sonatas." "The sixth, seventh, and eighth sonatas, written at the height of Prokofiev's artistic maturity and command, contain some of his most magnificent, intense and profound music."21

The sixth sonata was written in 1939 and has four movements. It is interesting and diverse in

\footnotetext{
${ }^{20}$ Robert P. Morgan, Twentieth-Century Music. (New York: W.W. Norton \& Company, 1991), p. 242.

${ }^{21}$ Hallow Robinson. Sergei Prokofiev, (Boston: Northeastern University Press, 1987), p. 371.
} 
part because of the characteristics of its four movements. The first movement is wild and energetic. The second movement implies an ironic mood. The third movement is a slow waltz, and the last movement presents a short motive with strong accents. It was premiered by Sviatoslav Richter (prominent Russian pianist, 1915-1997), who praised it highly as a masterpiece that is both concise and structurally perfect. ${ }^{22}$

The seventh sonata contains three movements. Prokofiev uses intense harmonies and ostinatos which represent the horrible reality of war. Prokofiev also employs a complex mixture of percussive virtuosity and lyrical cantabiles.

The eighth sonata was written between 1939 and 1944. It is the last of the "War Sonatas" and is calmer, slower, less intense, and less dissonant than the others. It is the only sonata which starts with a slow first movement, which is also soft and lyrical. The second movement is a slow Andante and the third movement shows its temperament in the frequent use of major chords.

The ninth sonata does not present as strong a sense of tension as the previous three sonatas; by contrast, it displays calmness, introspection, conciseness, and clarity as its characteristics. Prokofiev pursued the principle of simplicity during his last period, as an intentional musical conception. $^{23}$

\footnotetext{
${ }^{22}$ Ibid., 376.

${ }^{23}$ Yumi Park. Piano Literature, (Eumak Chunchu: Seoul, 2014), p. 416
} 
Chapter 4. Prokofiev's Third Piano Sonata, op. 28

\section{A. Stylistic Analysis}

Prokofiev's Piano Sonata no. 3, op. 28, was composed in 1917, based on earlier sketches from 1907, during his early period in Russia. It presents his unique composing skills in blending classical forms with modern characteristics. This sonata contains only one movement, presented in traditional sonata-allegro form: Exposition (mm. 1-93), Development (mm. 94-153), Recapitulation (mm. 154204), and Coda (mm. 204-234).

\section{Exposition (mm. 1-93)}

The Exposition extends from measure 1 to measure 93. Its tempo marking is "Allegro Tempestoso." The tonality is A minor and the time signature is $12 / 8(4 / 4)$. It consists of Theme I in A minor, Transition Theme I and Transition Theme II, Theme II in C Major, and Codetta. The rhythms are simple and there is frequent repetition of regular triplets.

(1) Part I of the Exposition: Theme I (mm. 1-12)

The work begins with fortissimo repeated E-Major triplets, sounding the dominant chord of A minor with a strong downbeat accent. This percussive material introduces the first theme while immediately establishing the energetic character of the movement.

\section{Allegro tempestoso}

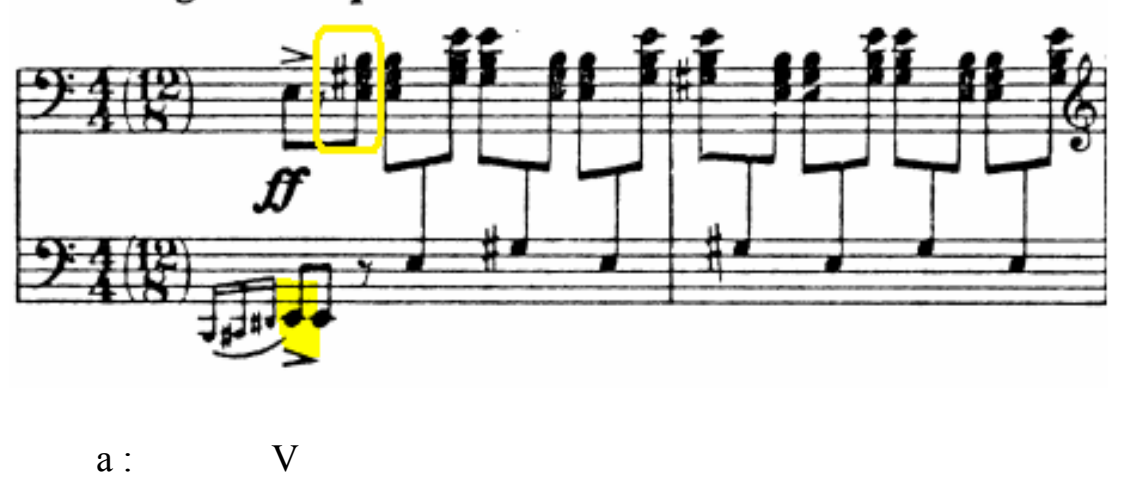

Example 9: mm. 1-2 
The first theme appears in mm. 3-12. It displays contrast between diatonic movement in the right hand and chromatic progression in the left hand. The rhythm of the left hand is consistent triplets that contrast with the lyrical melody in the right hand. The accents in the right hand should be played with a percussive technique. The left hand can be articulated as if non-legato.

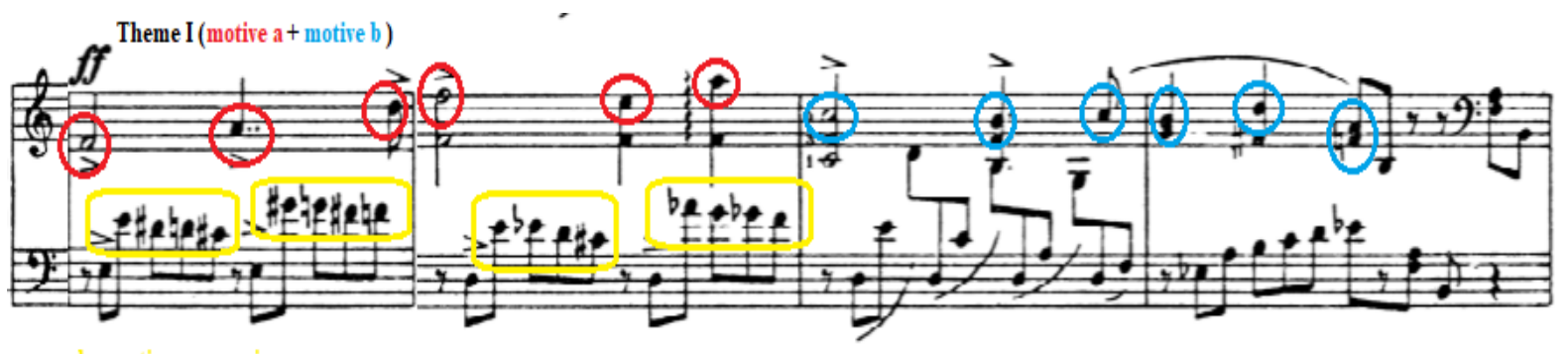

Example 10: mm. 3-6

The contrasts Prokofiev created in the opening of this sonata are characteristic of the "modern" line, among his five self-described compositional characteristics. In mm. 9-12, there is a transformation of the first theme. Prokofiev adds thirds and grace notes to the first theme. A new Eflat pitch appears in the melody, with a long-short rhythm in $\mathrm{m} .12$.

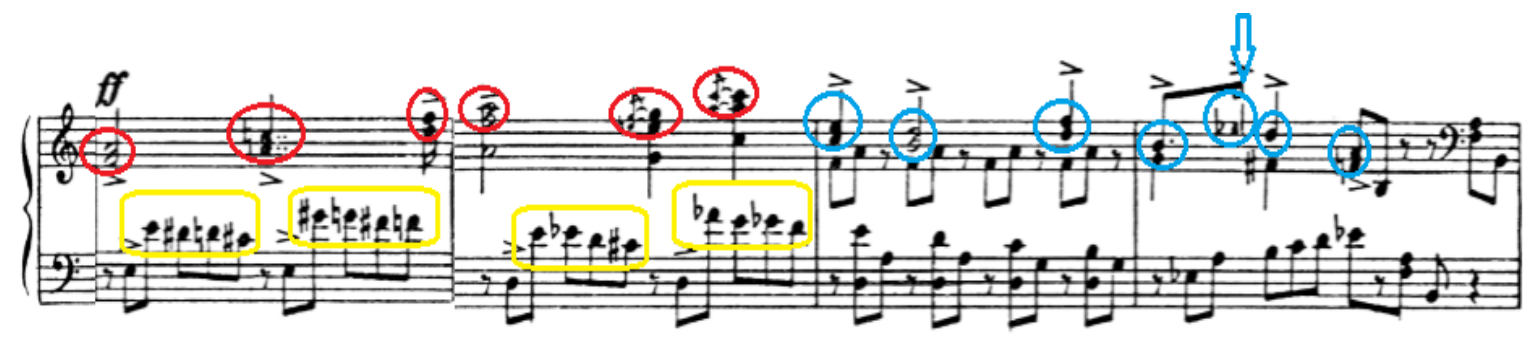

Example 11: mm. 9-12

(2) Part II of the Exposition: Transition Theme I (mm. 13-26)

Transition Theme I presents a more expanded form and length than Theme I. It serves to develop the first theme in a broader way. Transition Theme I appears from measure 13 to measure 26 . Measure 13 restates the introduction from the first theme. Measures 14-15 show its transformation through left hand arpeggios. Measures 13-14 create a sense of anticipation, which continues with diminuendo to the main melody in measures 16-17. 


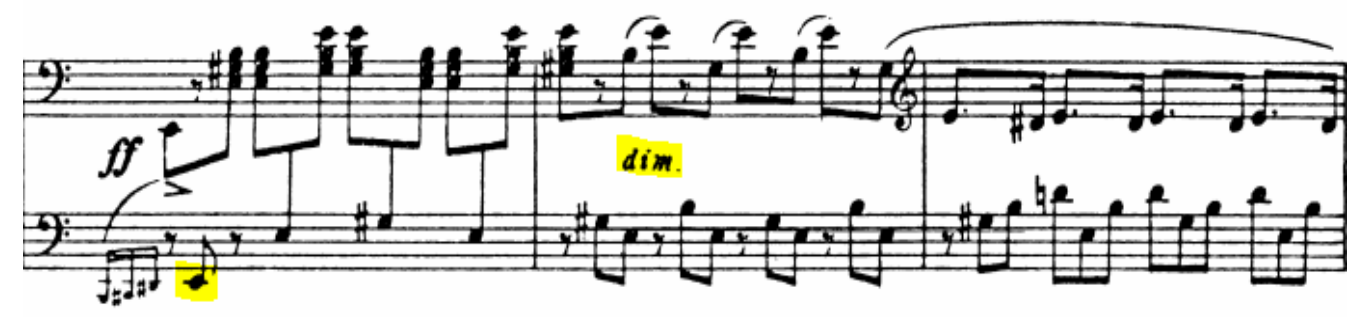

Example 12: mm. 13-15

The melody of Transition Theme I outlines the A-minor tonic chord and establishes the key. Prokofiev gives the dynamic sign $p$, in dramatic contrast to the $f f$ in the previous part. Prokofiev uses a short-long rhythm in the descending seventh intervals in the right hand against left-hand chromatic seconds (F-F\#-G-G\#-A). The melody ascends for two octaves and then descends via two intervals of the seventh. Measure 18 imitates m. 16, at the interval of a fifth. In measures $18-19$, the previous melody appears a perfect fifth lower.

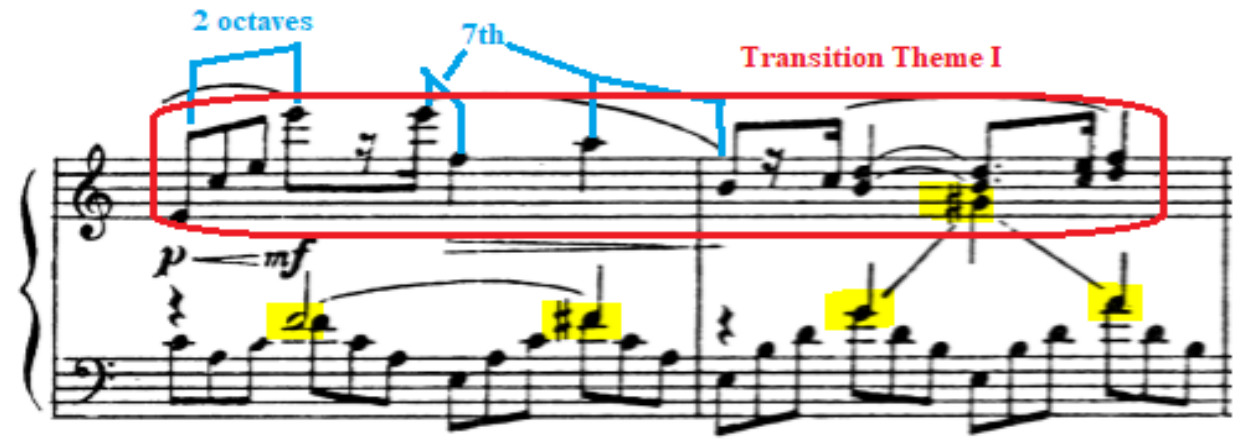

Example 13: mm. 16-17

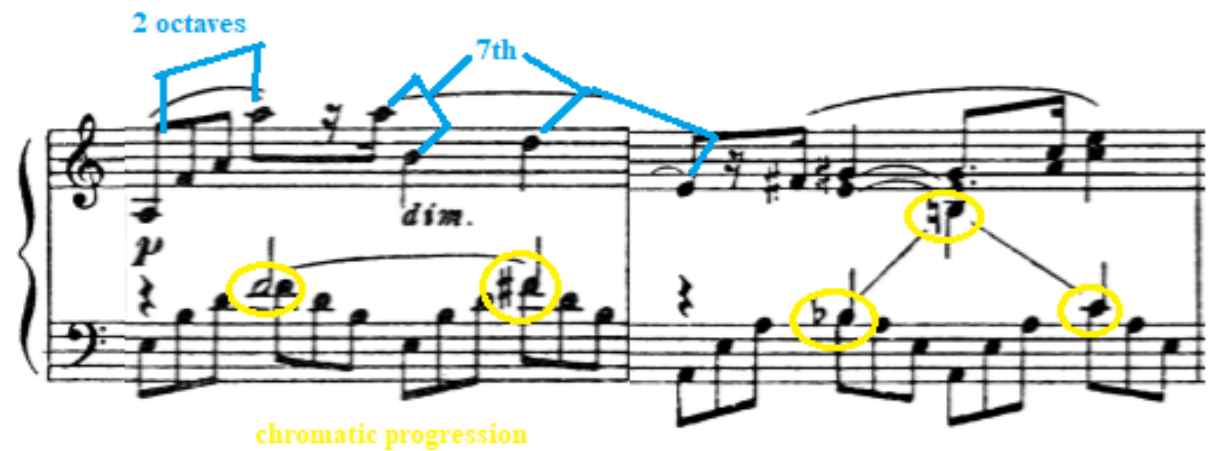

Example $14:$ mm. 18-19 
A transformation of the first theme occurs in measures 20-21, as Prokofiev employs rhythmic diminution of the material. It returns a third lower in measure 22 , and the rhythm is repeated in measure 23. The $f p$ in measures 21,23 , and 25 provides a characteristic example of Prokofiev's modern line technique. ${ }^{24}$ The abrupt dynamics and irregular accents deserve careful attention from the player because they are structural for Prokofiev's "modern line" technique.

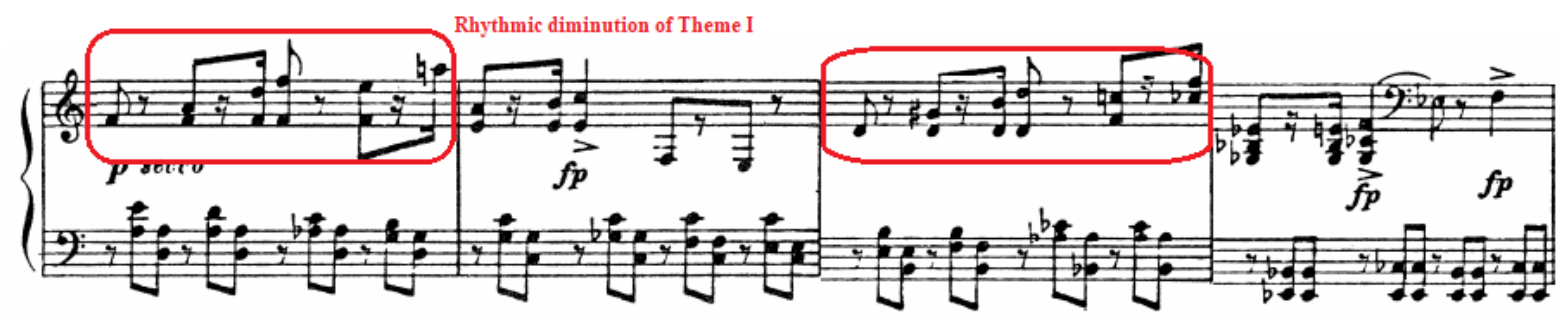

Example 15: mm. 20-24

(3) Part III of the Exposition: Transition Theme II (mm.27-53)

Measures 27-28 lead the listener to Transition Theme II, which appears in measures 29-53. It begins with an ascending pattern of seconds in a triplet rhythm, outlining an A-minor triad with chromatic passing tones. It does appear that the "Transition Theme II" has some developmental qualities deeply rooted in Theme I. The right hand and the left hand move in contrary motion.

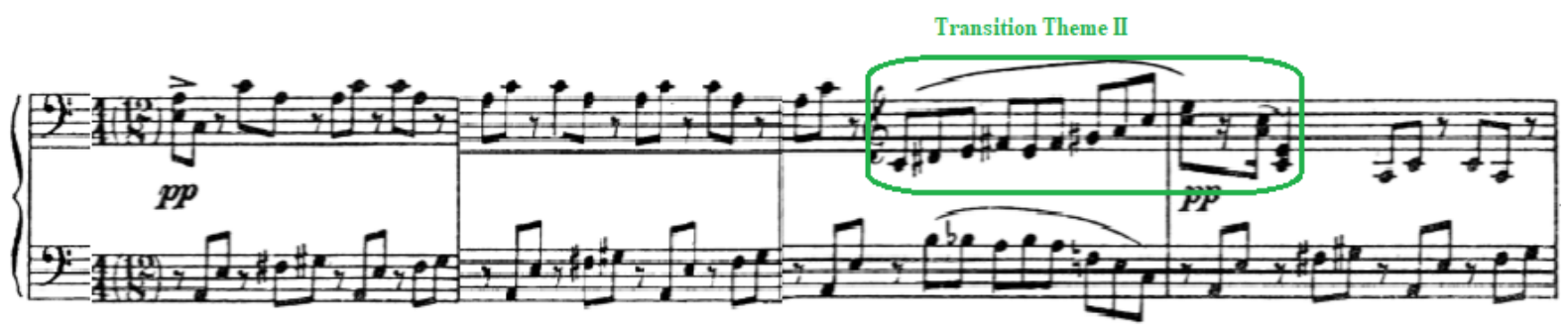

Example 16: mm. 27-30

Chromatic scales in contrary motion lead to the key of C Major in measure 34. In measure 33, F-F\#-G in right hand and A-Ab-G in left hand direct the ear to the second inversion of the tonic chord

\footnotetext{
${ }^{24}$ It is one of five characteristic compositional technique "lines" that Prokofiev mentioned in his autobiography: the classical line, the modern line, the toccata line, the lyrical line, and the grotesque line.
} 
of C Major in measure 34.

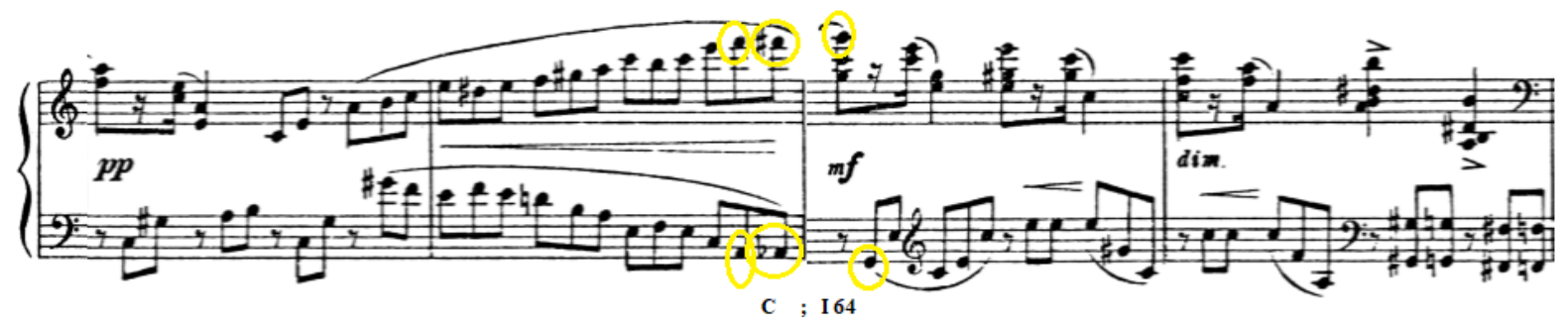

Example 17: mm. 33-35

Measures 36-41 provide a sequential treatment of material from measure 27-31. This is a continued development, all a fourth lower leading next to the key of E.

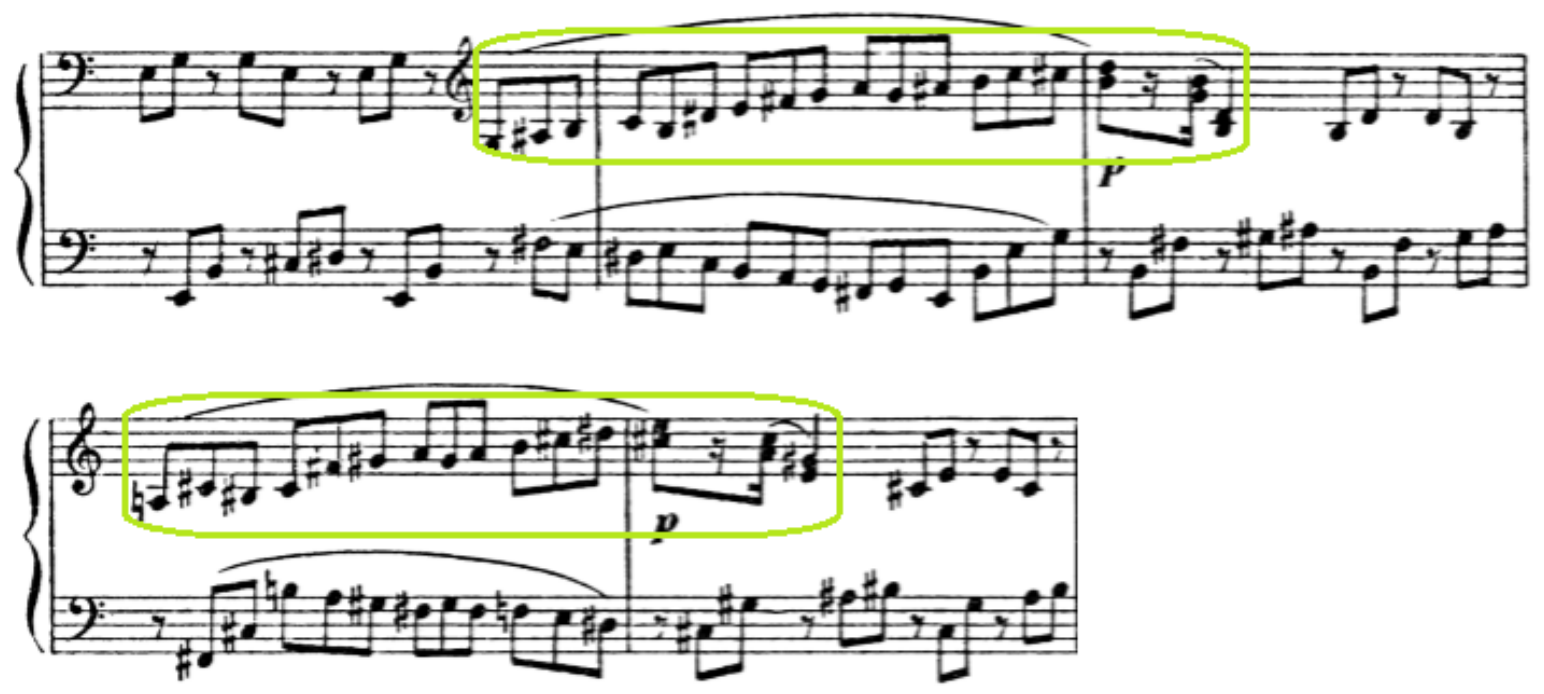

Example 18: mm. 36-41

Measures 45-53 serve as an extension, developing both Transition Theme I and Transition Theme II. This section uses the chromatic motive from Transition Theme I in the left hand and the rhythm of Transition Theme II in the ascending melody. Prokofiev employs frequent key changes: C\# minor (m. 45), F minor (mm. 46-47), and C\# minor (mm. 48-53). In m. 53, the chromatic melody in octaves connects naturally to the following moderato section through poco ritardando. 

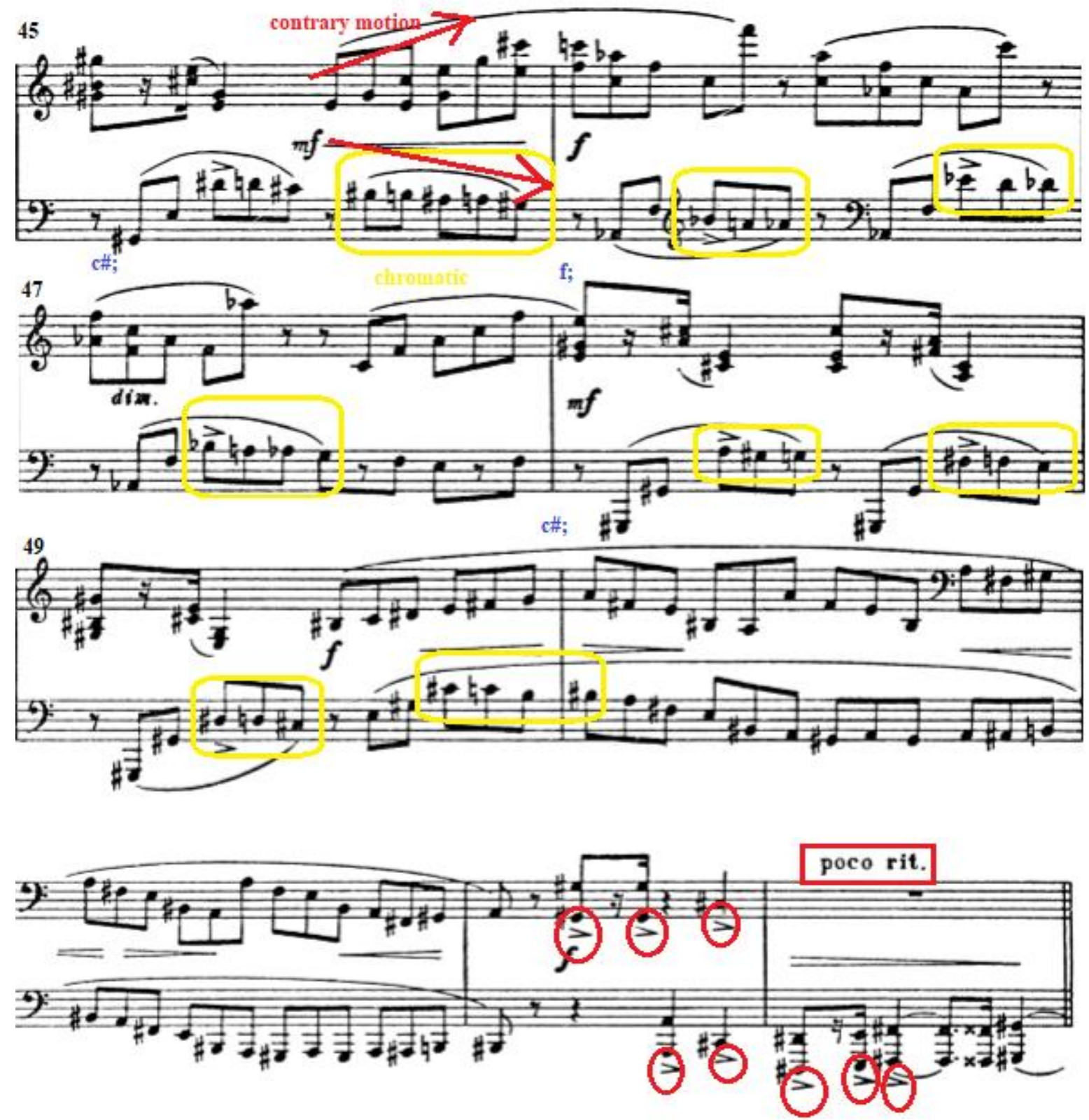

Example 19: mm. 45-53

(4) Part IV of the Exposition: Theme II (mm. 54-77)

The Moderato section has two functions. First, it changes the tonality from $\mathrm{c} \#$ minor to $\mathrm{C}$ major by moving to $\mathrm{G}$ in the bass, then using a strong bass ii-V-I progression from $\mathrm{D}$ to $\mathrm{G}$ in octaves to the $\mathrm{C}$ which supports the melody of theme II in measure 58. Secondly, it introduces the second theme by its use of chromatic steps, now in the rhythm of eighth notes. 


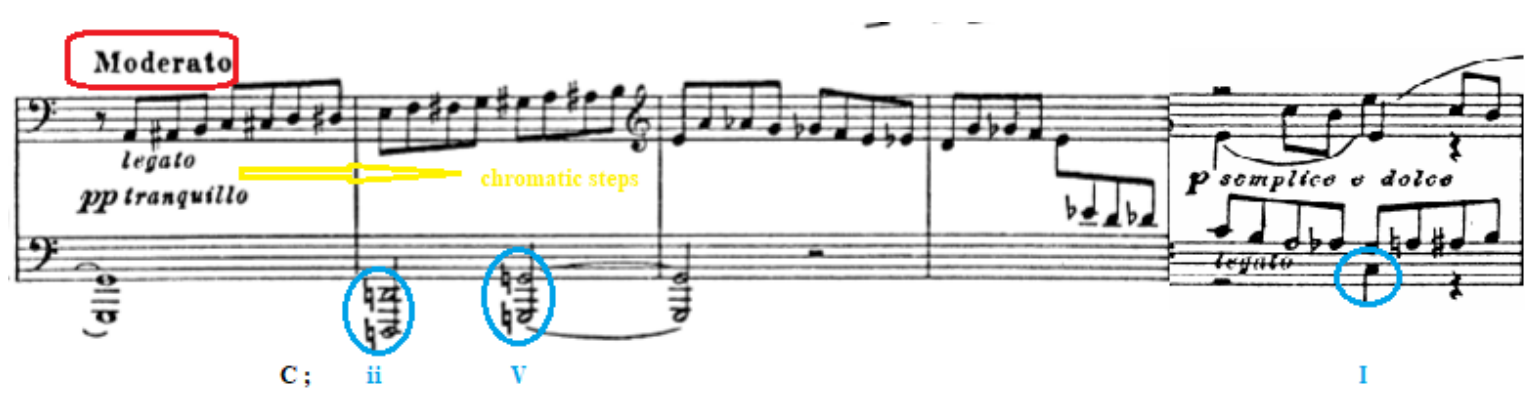

Example 20: mm. 54-58

The second theme arises in $\mathrm{mm} .58-59$ in $\mathrm{C}$ major, the relative major of the first theme. Two measures of left-hand chromaticism in theme two alternate with two measures of stepwise motion in eighths. The right hand of the second theme conveys the flavor of Russian folk music. Its simplicity contrasts with the first theme, which is passionate and dynamic. The dynamic sign is pp, also contrasting with the ff of the first theme. The texture of the second theme is written in four-part counterpoint that employs imitation and contrary motion.

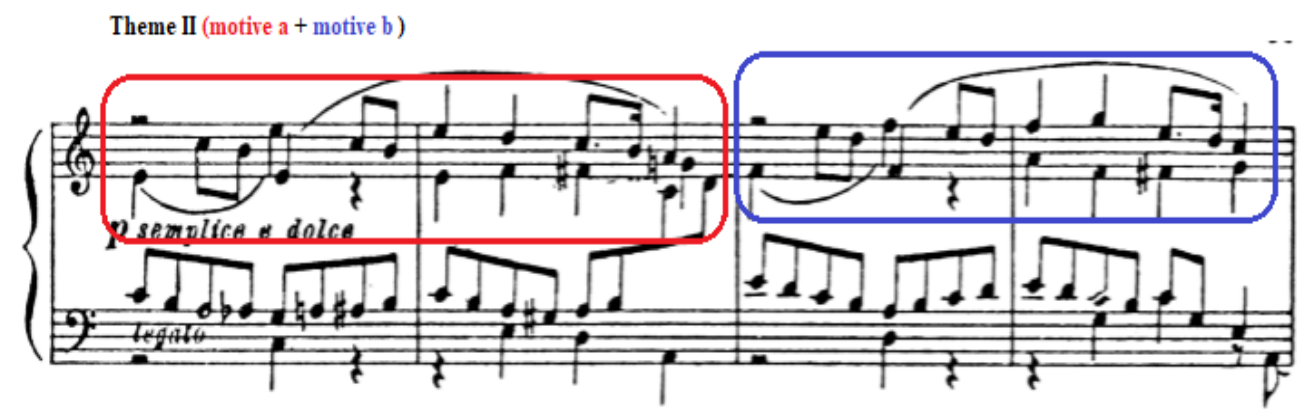

Example 21: mm. 58-61

The second theme continues in measures 62-73, but with transformation. Measures 62-65 are nearly identical to measures 58-61, with the exception of a slight change in the bass voice.

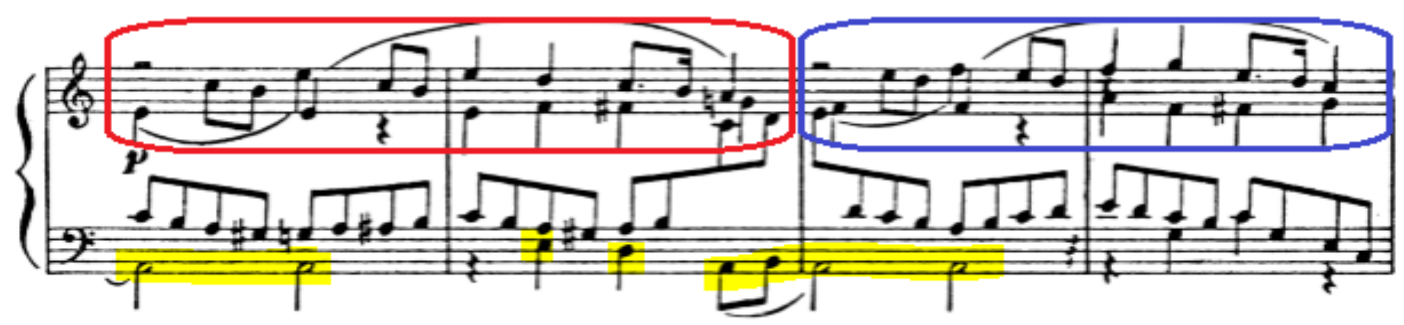

Example 22: mm. 62-65 
In measures 66-67, the second theme appears in the left hand in the key of G\# minor, with an accompaniment in the right hand. In measures $68-69$, Prokofiev enlarged the intervals (G\#-G\# to G\#A\#) with an accompaniment in the left hand, with the same rhythmic pattern. This is followed by a walking bass of D\#-E\#-Fx in measure 69; measure 70 is transposed to A minor. The Alberti-bass accompaniment in the left hand appears in measures $70-73$ with the transformed second theme in the right hand. Measures 74-77 are an exact repetition of mm. 58-61, one octave higher.
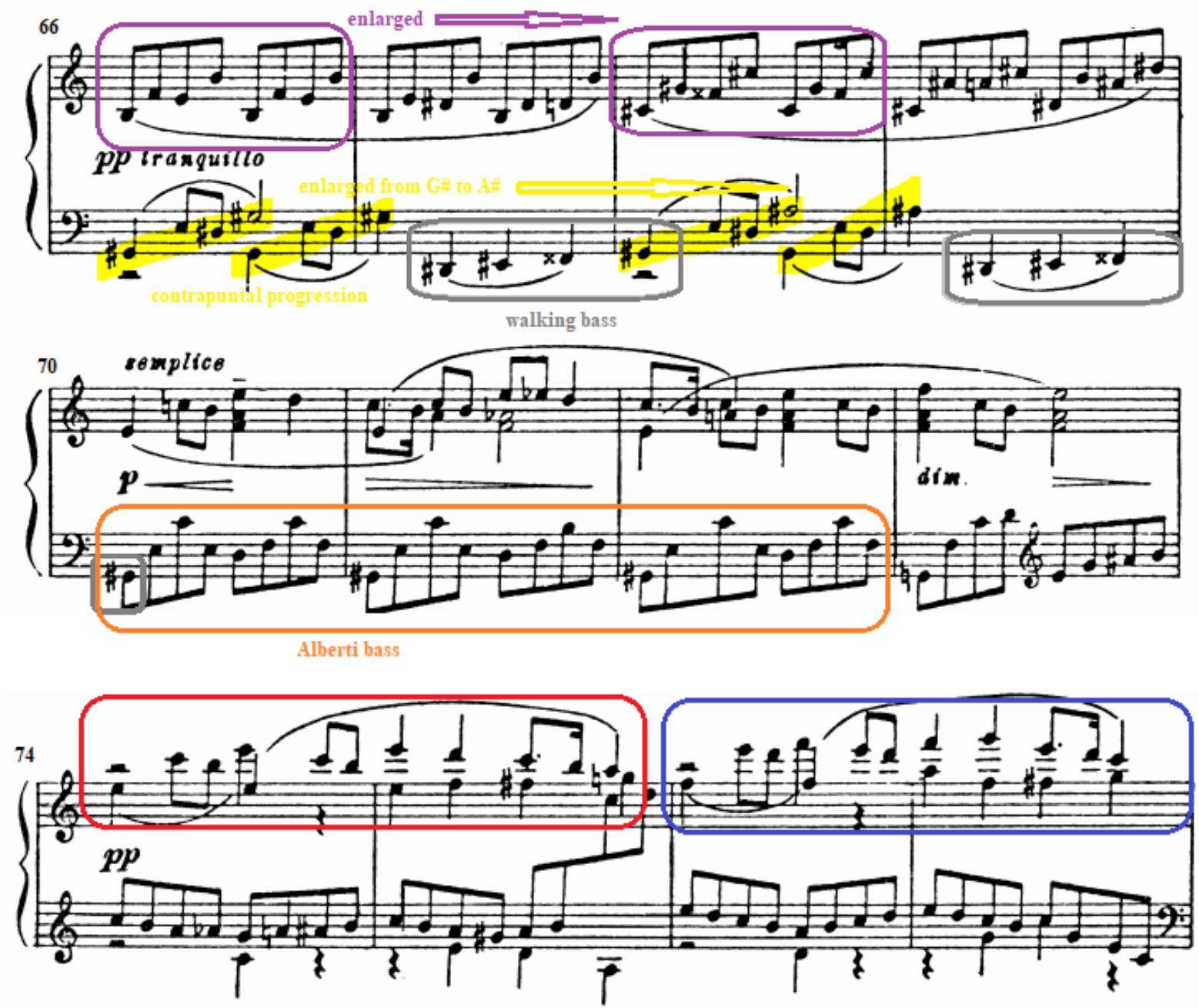

Example 23: mm. 66-77

(5) Part V of the Exposition: Codetta (mm. 78-93)

The codetta stays in the key of C Major. The rhythm of the second theme, which consisted of quarter notes and eighth notes, appears in the left hand in syncopation. The transformed rhythm of the 
second theme appears in the right hand in measures 78-81. The left hand repeats a descending pattern of eighth notes.
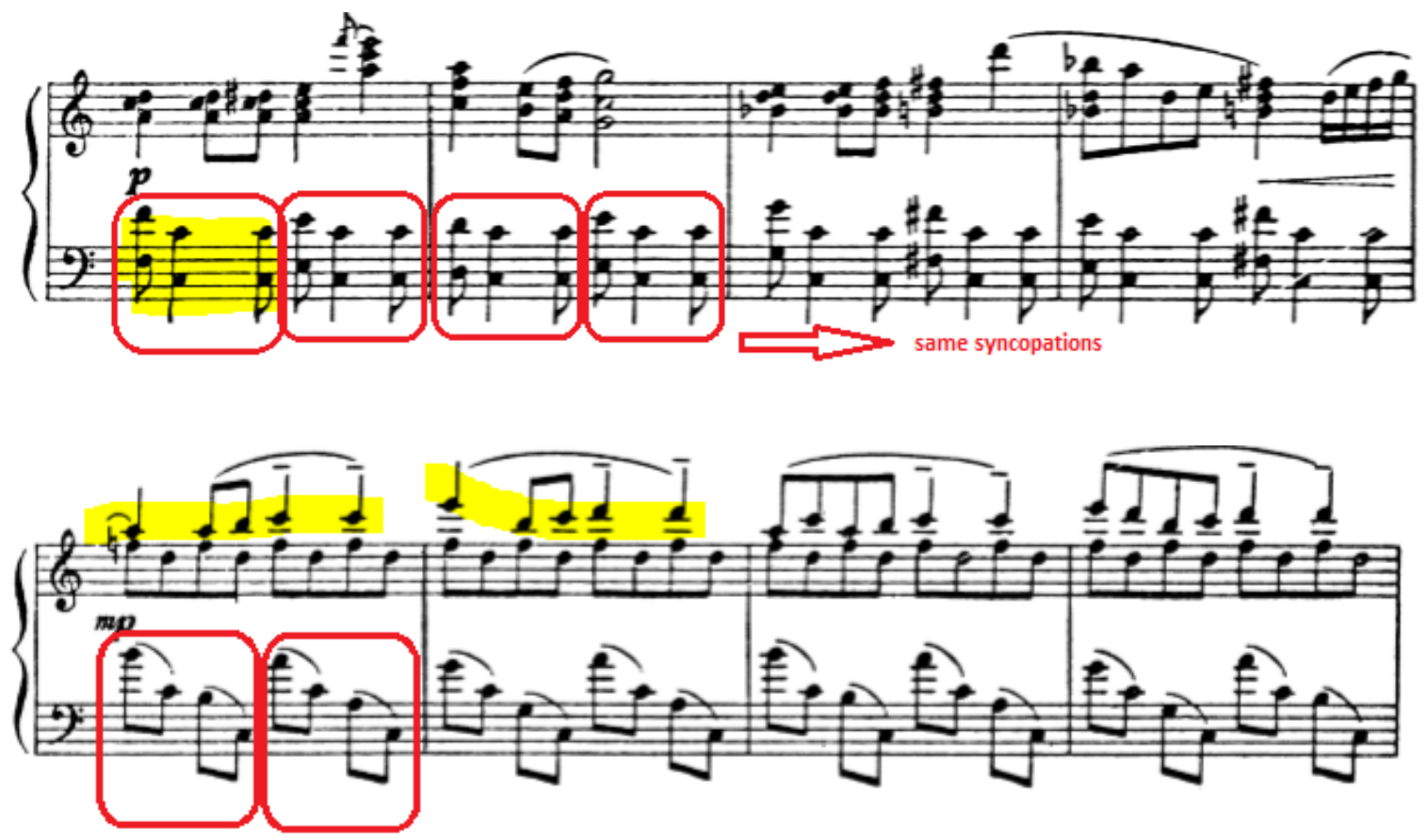

Example 24: mm. 78-85

Measures 86-93 transform the left-hand stepwise motion in $\mathrm{mm}$. $78-85$ to a rising chromatic progression, primarily in octaves. The right hand is written in a classical style of 6 ths and 5 ths in counterpoint with traditional arpeggiated accompaniment. The harmonically simple arpeggiation continues in both hands from mm. 90-93, providing a calm, classical-style ending to the section. The tempo marking in measures $91-93$ is ritardando assai, which guides the change of tempo. It ends with I6-V-I in C Major, although the V chord contains a $\mathrm{C}$ instead of a B. 

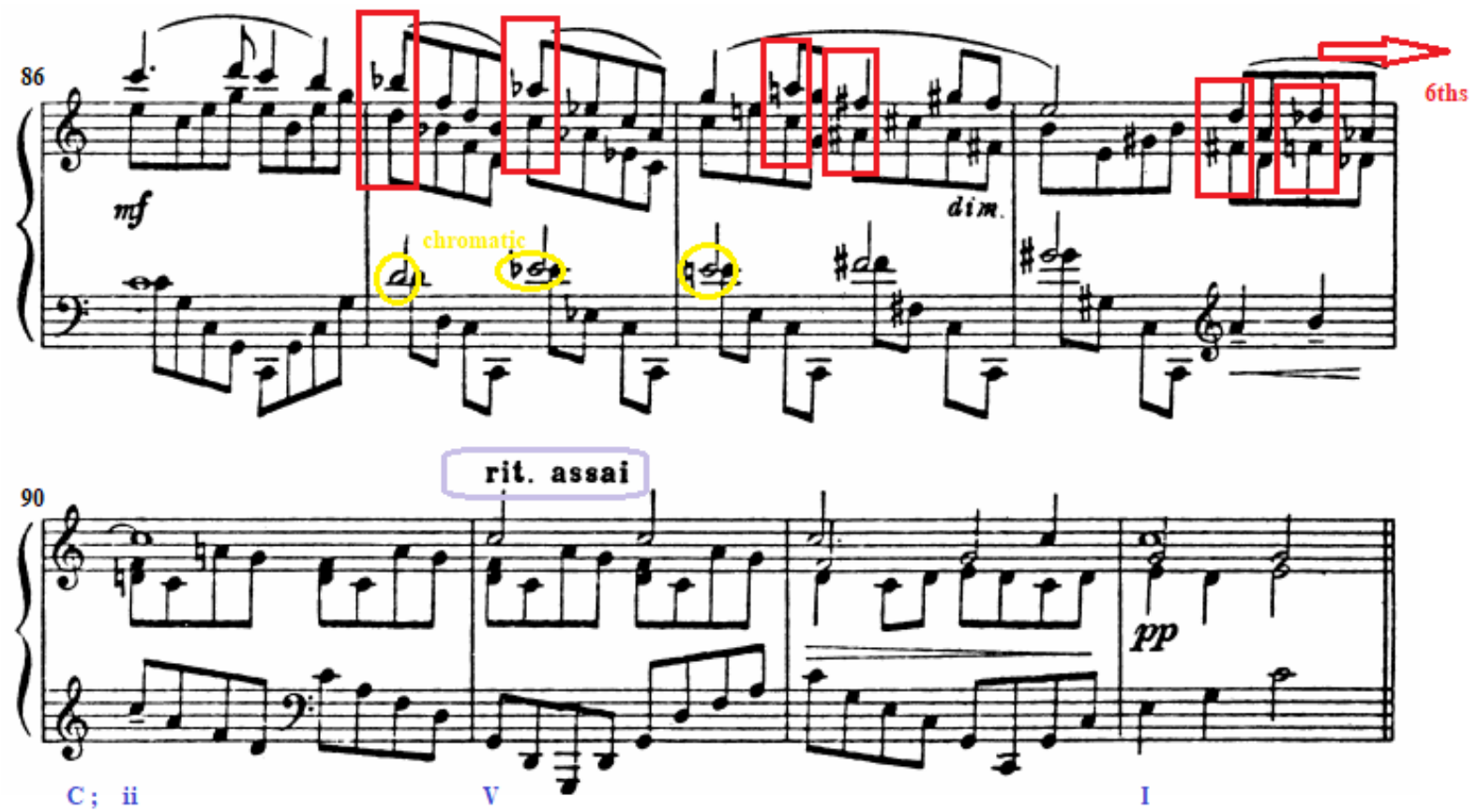

Example 25: mm. 86-93

2. The Development (mm. 94-153)

The Development starts in measure 94 and ends in measure 153. The starting tempo is Allegro Tempestoso (fast and tempestuous) but it includes changes to Moderato, Più lento, and, finally, to Più animato. The first theme and the second theme are developed separately with chromatic progressions and dissonances. The Development is in the key of A minor and has three parts; Part I

(Transformation of Theme I and Theme II, mm. 94-122), Part II (Theme II, mm. 123-145), and Part III (Codetta, mm. 146-153).

(1) Part I: Transformation of Theme I and Theme II (mm. 94-122)

Part I of the Development starts energetically in fortissimo, contrasting dramatically with the pianissimo of theme 2. Minor seconds are featured prominently in the introduction of measures 94-96, as the hands move in contrary motion. The melody of Transition Theme II spans two octaves in each hand and it ends on the subdominant (iv) chord of A minor in $\mathrm{m} .95$. The transformed Theme I incorporates a sequence of hand crossing. 


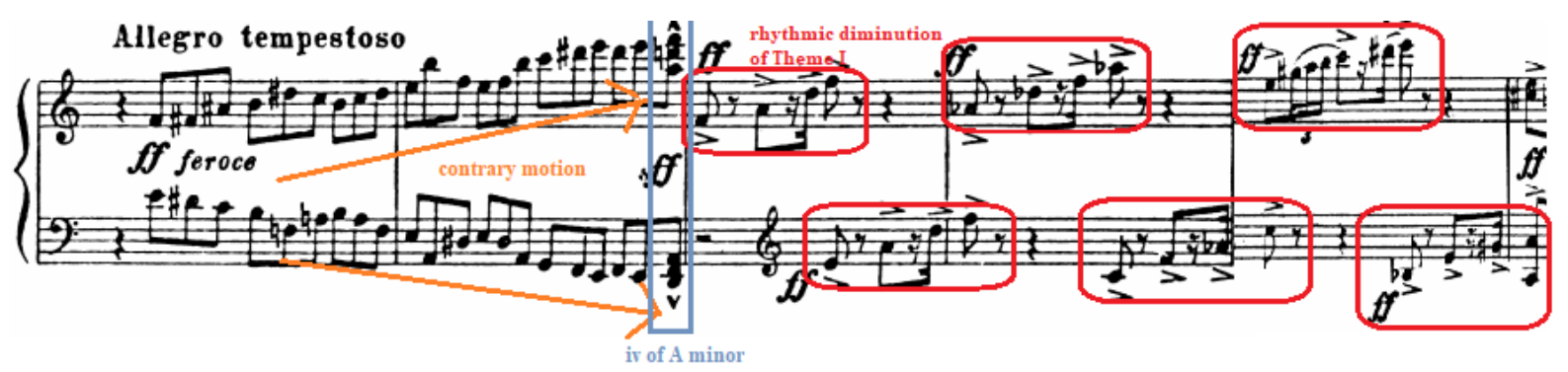

Example 26: mm. 94-99

In measures 103-104, the right hand presents a transformation of the rhythm of Theme II. The left-hand chromatic harmony in minor thirds repeats and strengthens to ff into measure 110. Measures 107-110 are a repetition of measures 103-106, a perfect fourth lower.

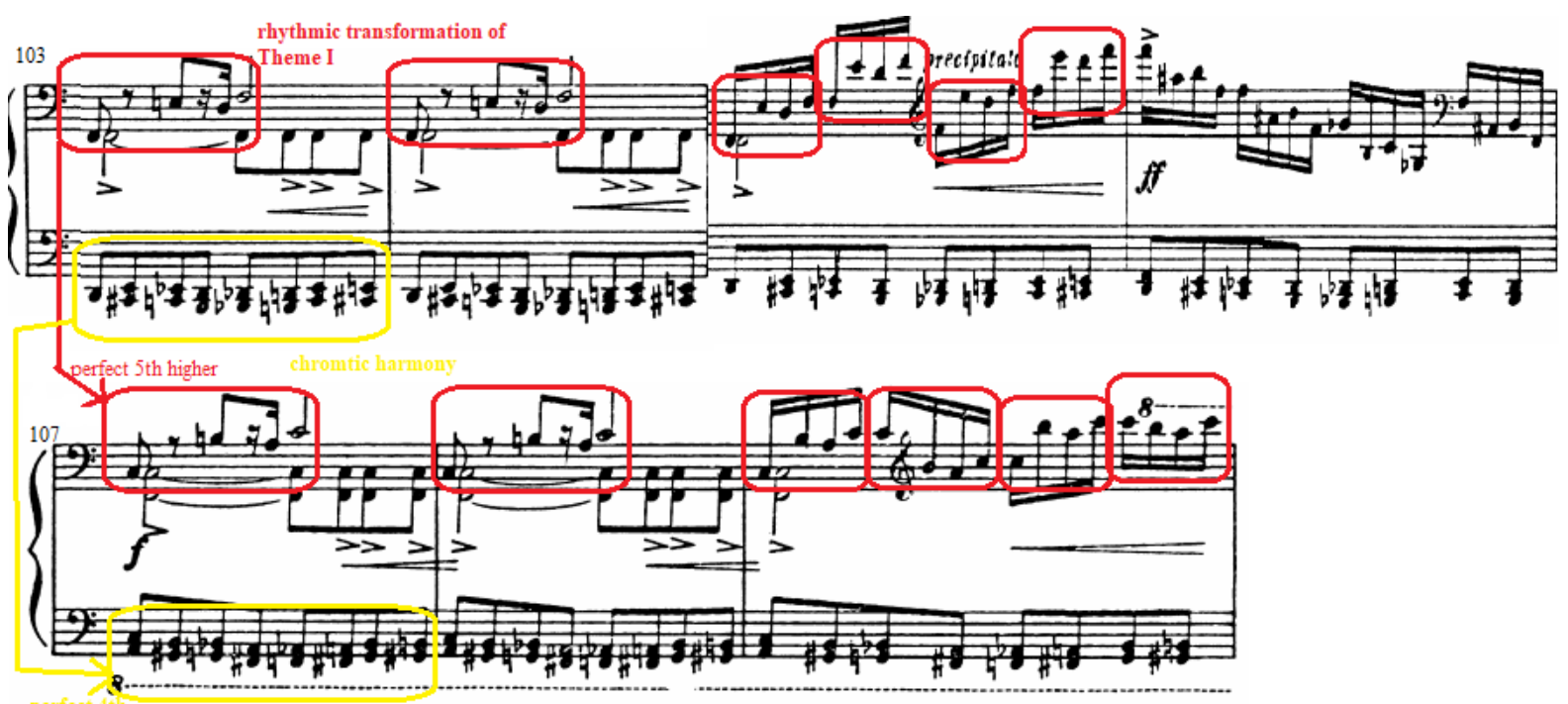

Example 27: mm. 103-109

Measures 110-113 provide tension by the use of repeated C's, alternating C-Db's, and downbeat accents, beginning in $\mathrm{ff}$, conveying a vigorous character. The left hand produces a big acoustic effect through thirds and a chromatic progression of chords that include F-Gb-G-Ab-A. 

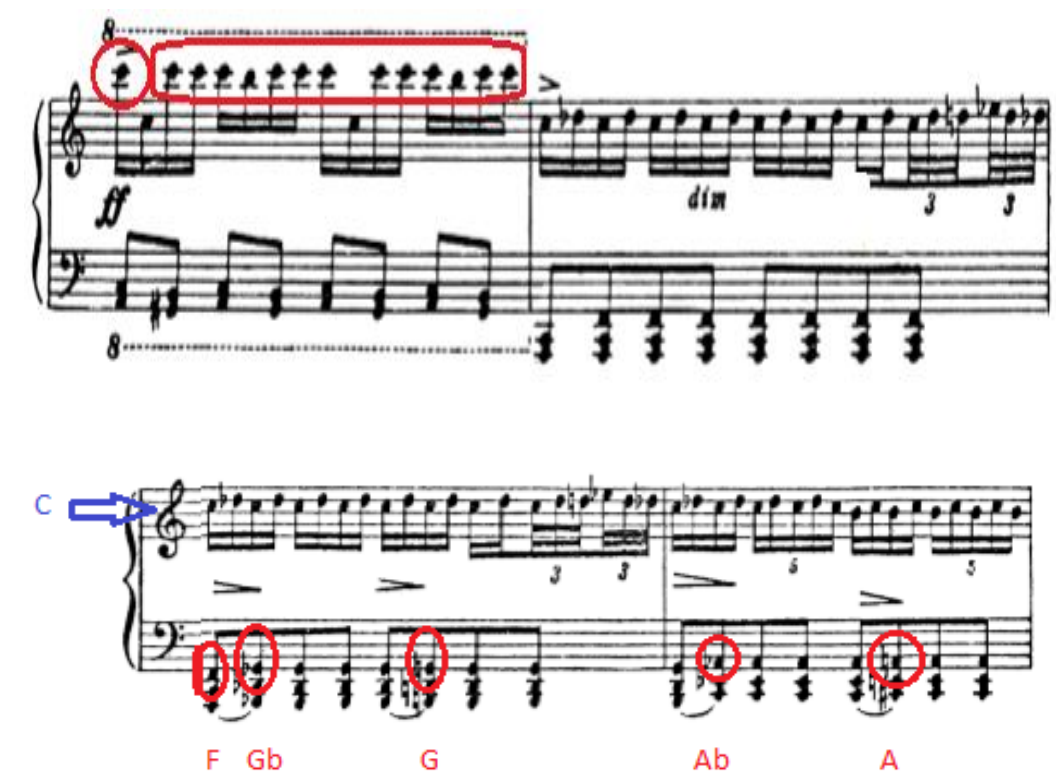

Example 28: mm. 110-113

Rhythmic transformation of Theme II appears in measures 114-117 with sixteenth notes. The bass line traverses a chromatic ascent. The octave melody in the right hand of measure 118 presents a transformation of the rhythm and melody from Transition Theme I. The transformed melody in the right hand of measure 121 joins a snippet of the melody in the left hand, creating a contrapuntal texture.
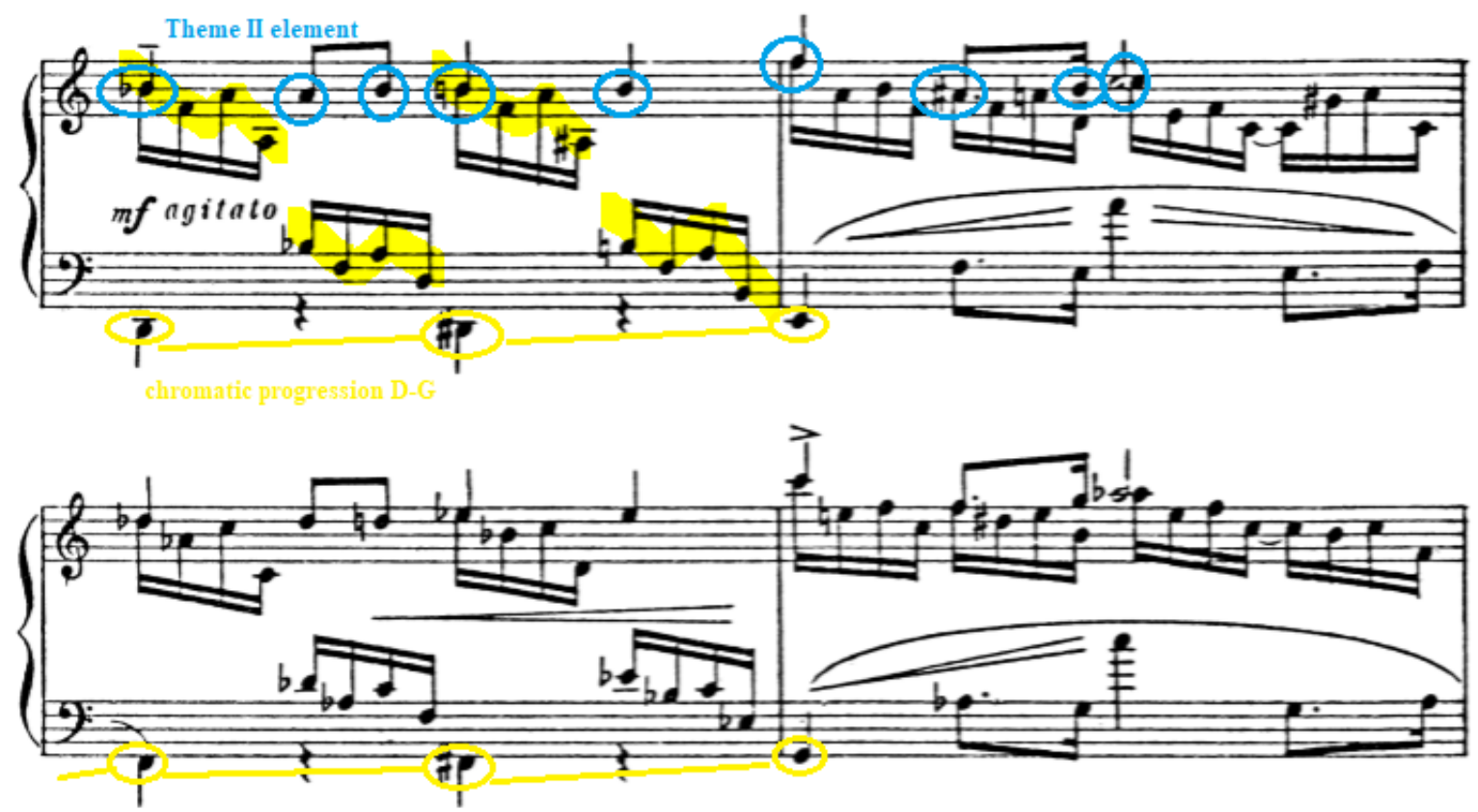


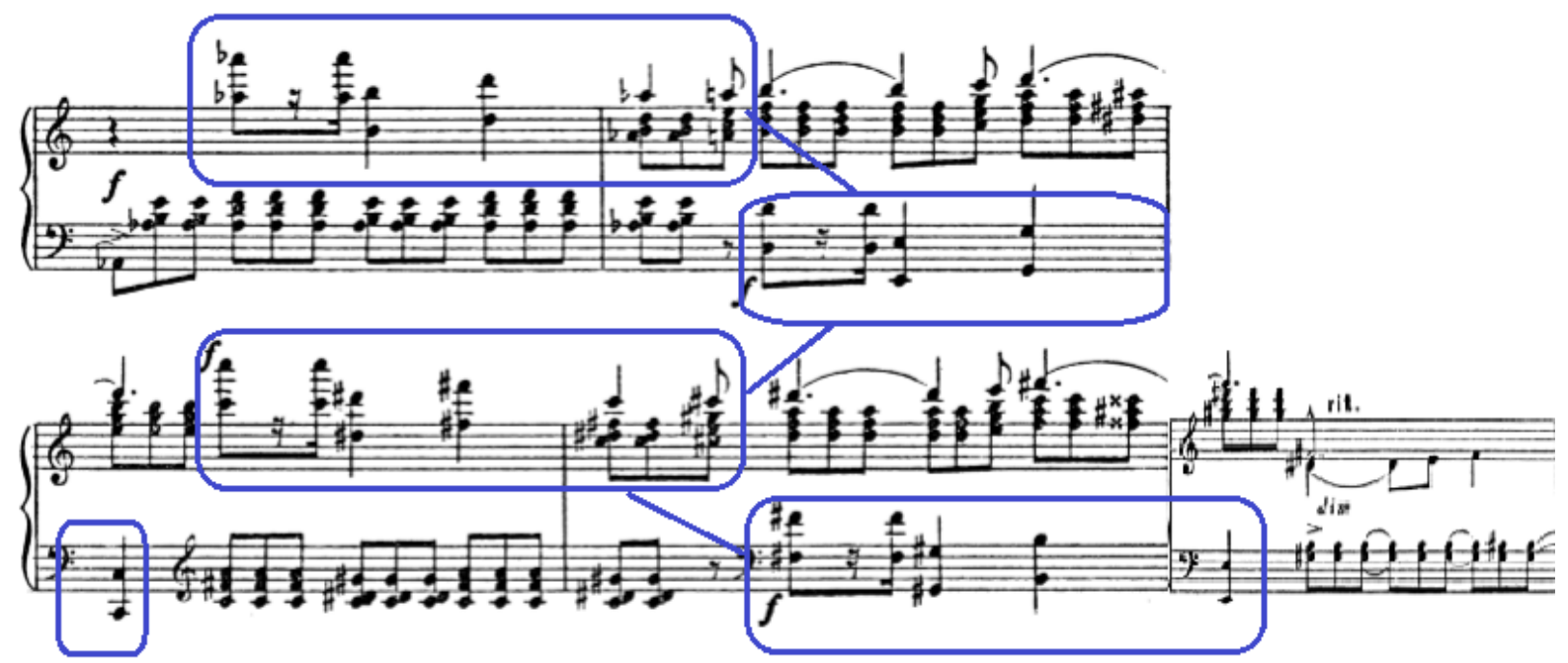

Example 29: mm. 114-122

(2) Part II of the Development: Theme II (mm. 123-145)

In Part II, the tempo changes to Moderato, and the dolce marking contrasts with the vigorous previous section. The lyrical melody of theme 2 has transformed. Theme II appears in the right hand in measures 123-131, and the left hand is a progression of thirds whose rhythm is syncopated. The inner voices display a chromatic ascent and descent in measures 128-131. In contrast to the left-hand chromaticism, Prokofiev writes a rather typical melodic sequence in measures 128-131. The tempo marking of Più lento in measures 128-131 sets up a change to Più animato at measure 132, where the music becomes more active and the tension begins to build. 

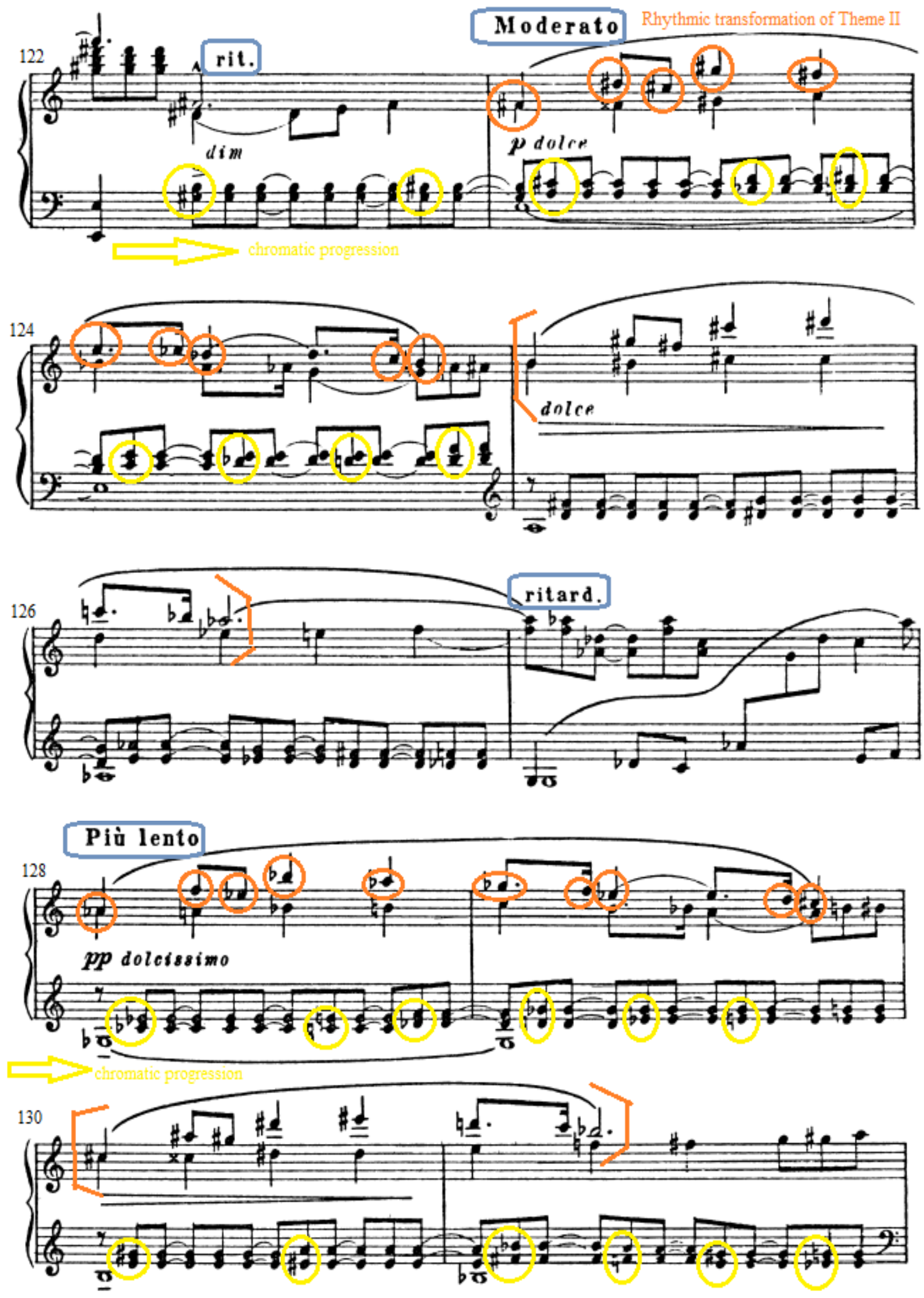

Example 30: mm. 122-131

In measures 132-139, the left hand states the transformed theme II in octaves, and the 
chromatic melody line is developed via right-hand triplet chords. The chromatic melody in the right hand is developed from the descending rhythm of measures 86-90 in the Exposition. It covers a fouroctave range by using wide leaps. It expresses a huge acoustic effect and large-scale dynamic change from pp in $\mathrm{m} .132$ to $\mathrm{fff}$ in $\mathrm{m} .146$.
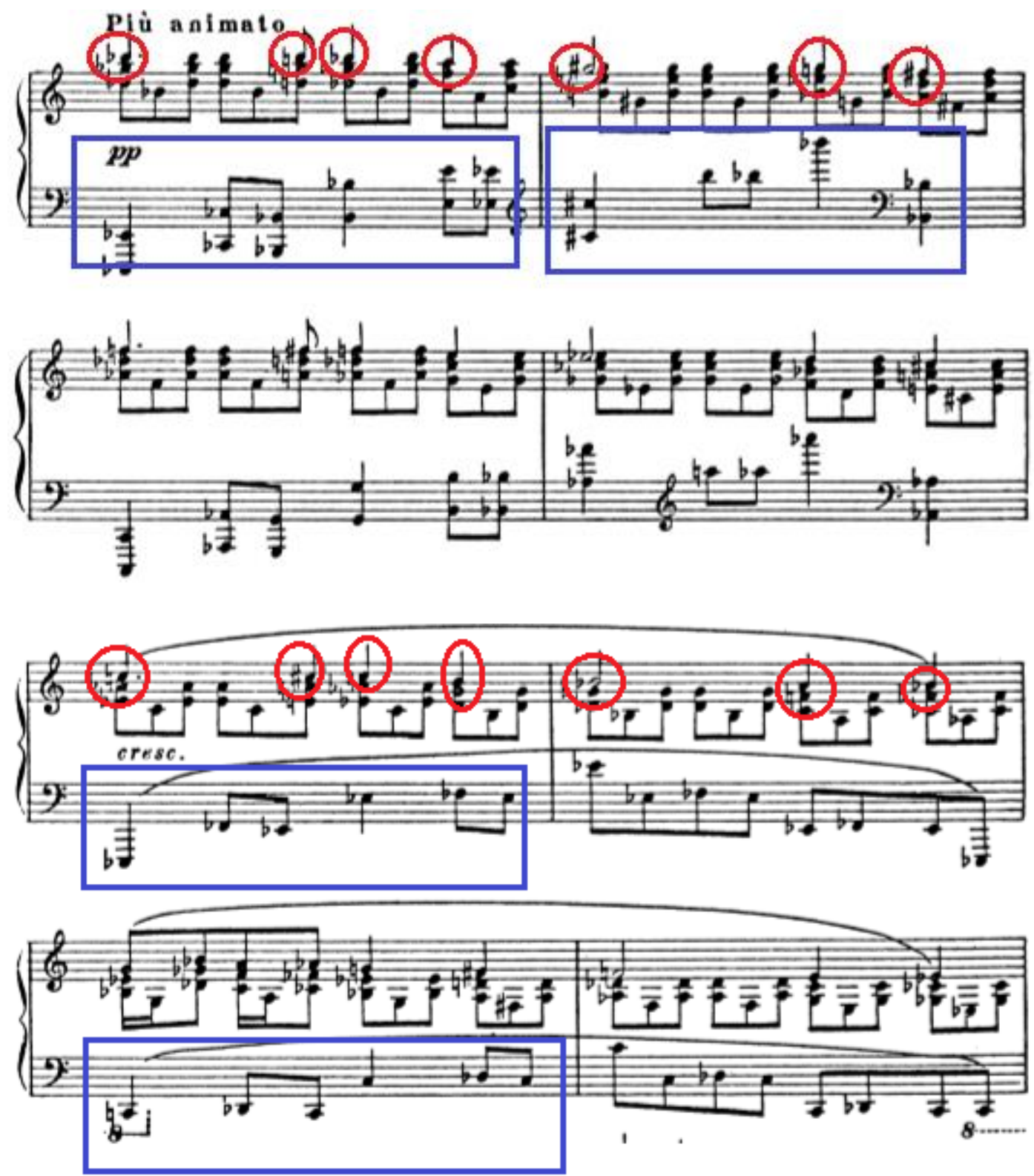

Example 31: mm. 132-139

In measures 140-141, the rhythm of Theme II appears in the right hand, creating dramatic tension through wide leaps and high notes. Prokofiev employs quartal chords in the key of Bb Major 
and syncopated rhythms in the left hand. There is a contrapuntal progression in both hands. Measure 145 creates a natural connection to the Codetta through allargando.
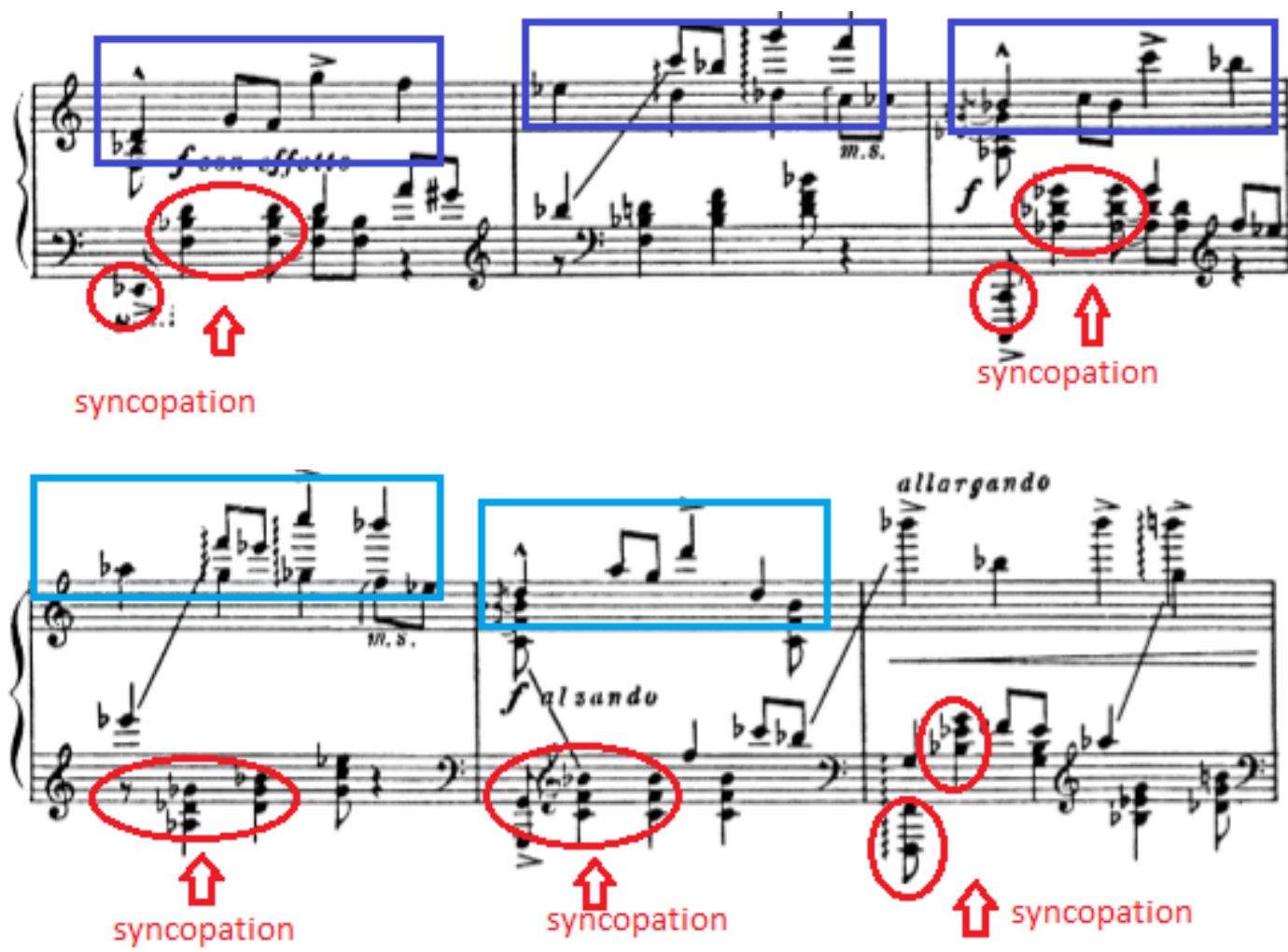

Example 32: mm. 140-145

(3) Part III of the Development: Codetta (mm. 146-153)

The Codetta of the Development section takes place in measures 146 to 153 . It is very active and passionate. The left hand in measures 146-147 covers four octaves with ascending first-inversion chords, and measures 148-149 use descending minor sevenths, where the chromatic thirds on top are most important. The ritardando in measure 151 prepares the ending and the cadence. Prokofiev wrote the final chord in measure 153 as a V9 chord with the natural third, with fermata. The following note, E, is the dominant of A minor, and it implies the arrival of the Recapitulation. 

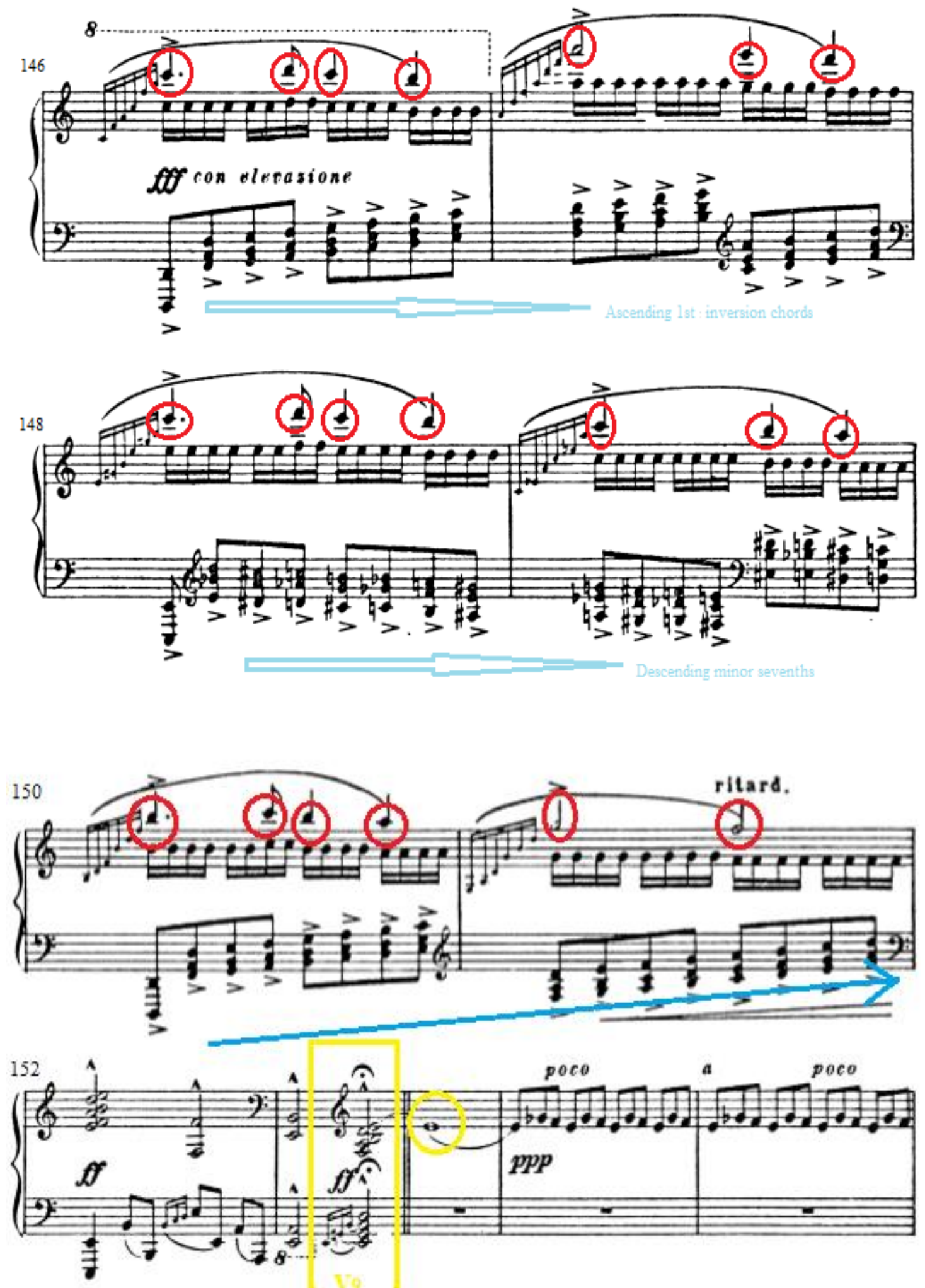

Example 33: mm. 146-156 
The Recapitulation in measures 154 to 234 returns to the key of A minor. Elements of Transition Theme II and Theme II appear. The Recapitulation has three parts: Part I: Transition Theme II (mm. 154-188), Part II: Theme II (mm. 189-204), Part III: Coda (mm. 205-234). The Recapitulation does not present Theme I, marking a departure from the classical sonata-allegro form.

(1) Part I of the Recapitulation: Transition Theme II (mm. 154-188)

Part I of the Recapitulation starts with the single pitch, 'E,' and continues with triplets in a slow tempo and ppp. Poco a poco accelerando for six measures is followed naturally by an Allegro tempo. Measures 154-156 connect between the tension of the Development and the energy of the Recapitulation. The chromatic descending rhythm in measures $157-163$ is a transformation of the same material in measures 27-28 of the Exposition.
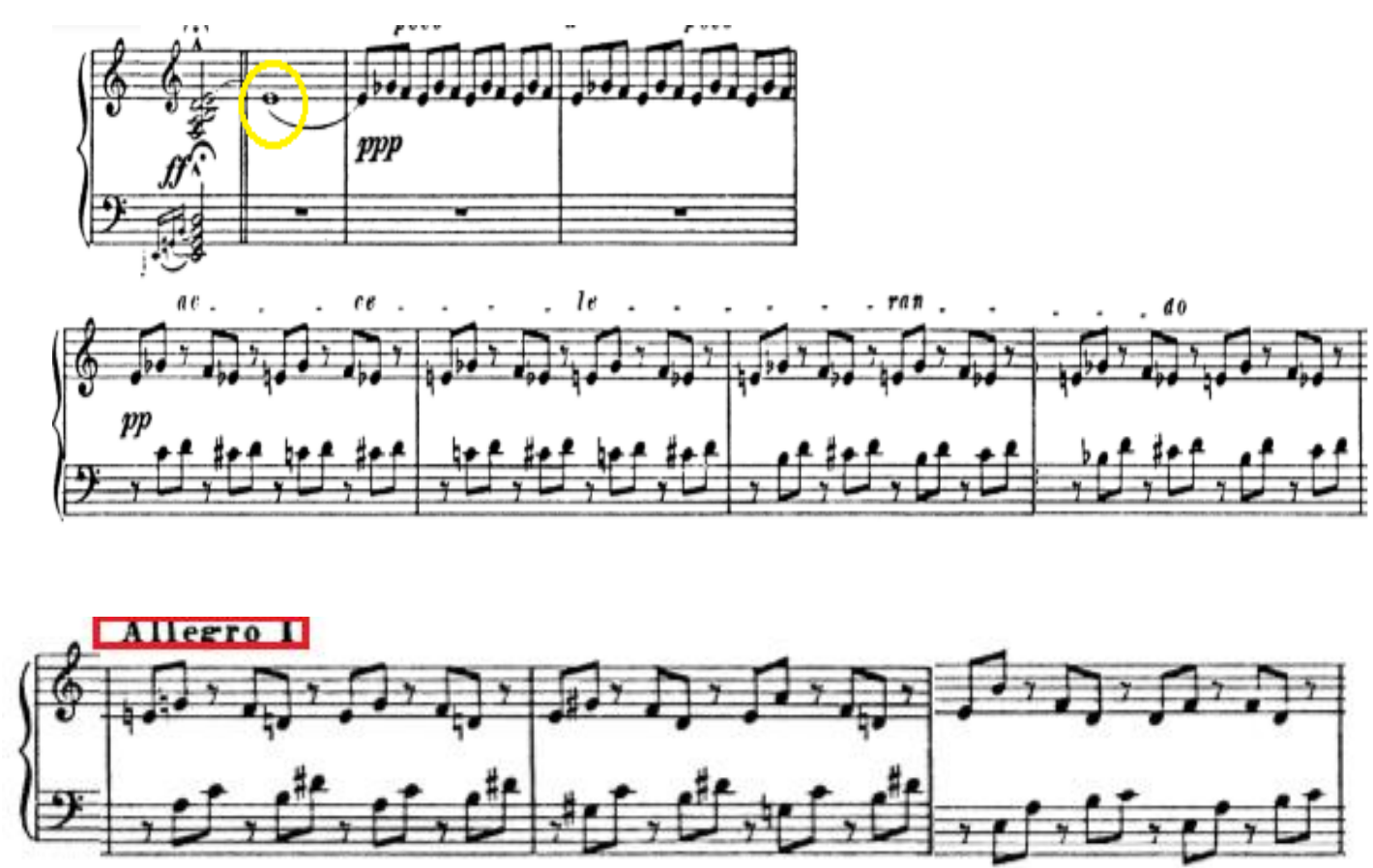

Example 34: mm. 153-163

Measures 164-188 incorporate a transformation of Transition Theme II. In measure 165, the tonic chord of A minor has clearly appeared. The descending right hand and the ascending left hand 
proceed in contrary motion in measures 167-170.
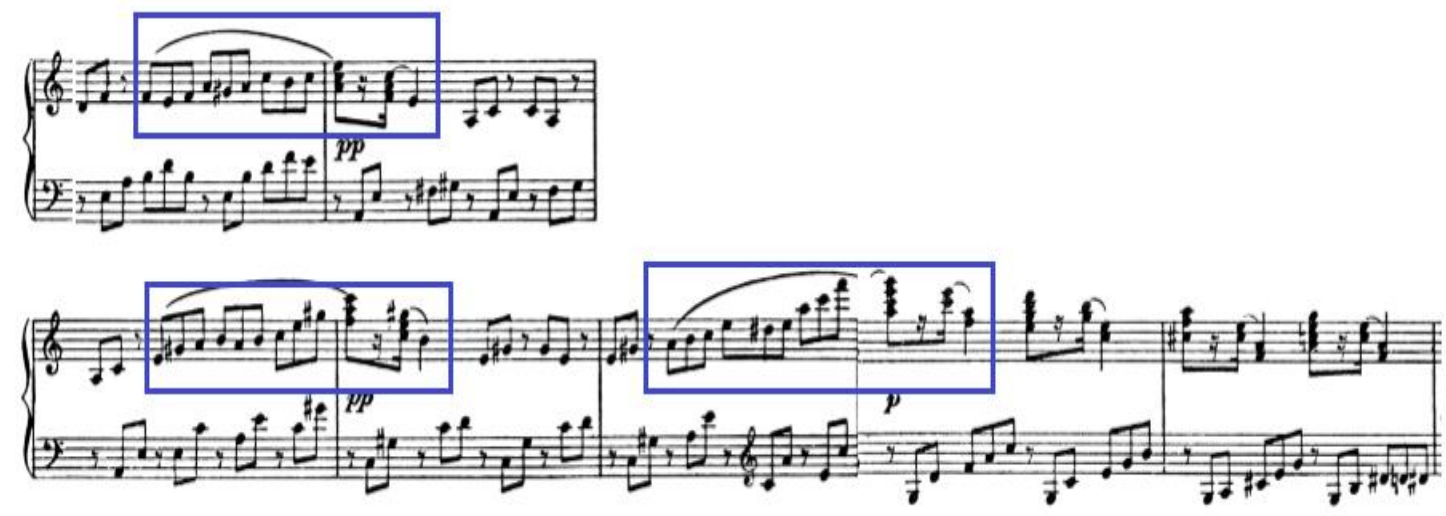

Example 35: mm. 164-170

Measures 181-182 transform Transition Theme II by enlarging it. The melodic pattern that fills the first two beats in the left hand immediately repeats an octave higher. A variety of rhythms which originate from Theme I appear with chromaticism in measures 181-186. Prokofiev writes ascending triplets in the left hand that arrive at an A-minor chord in measure 189.
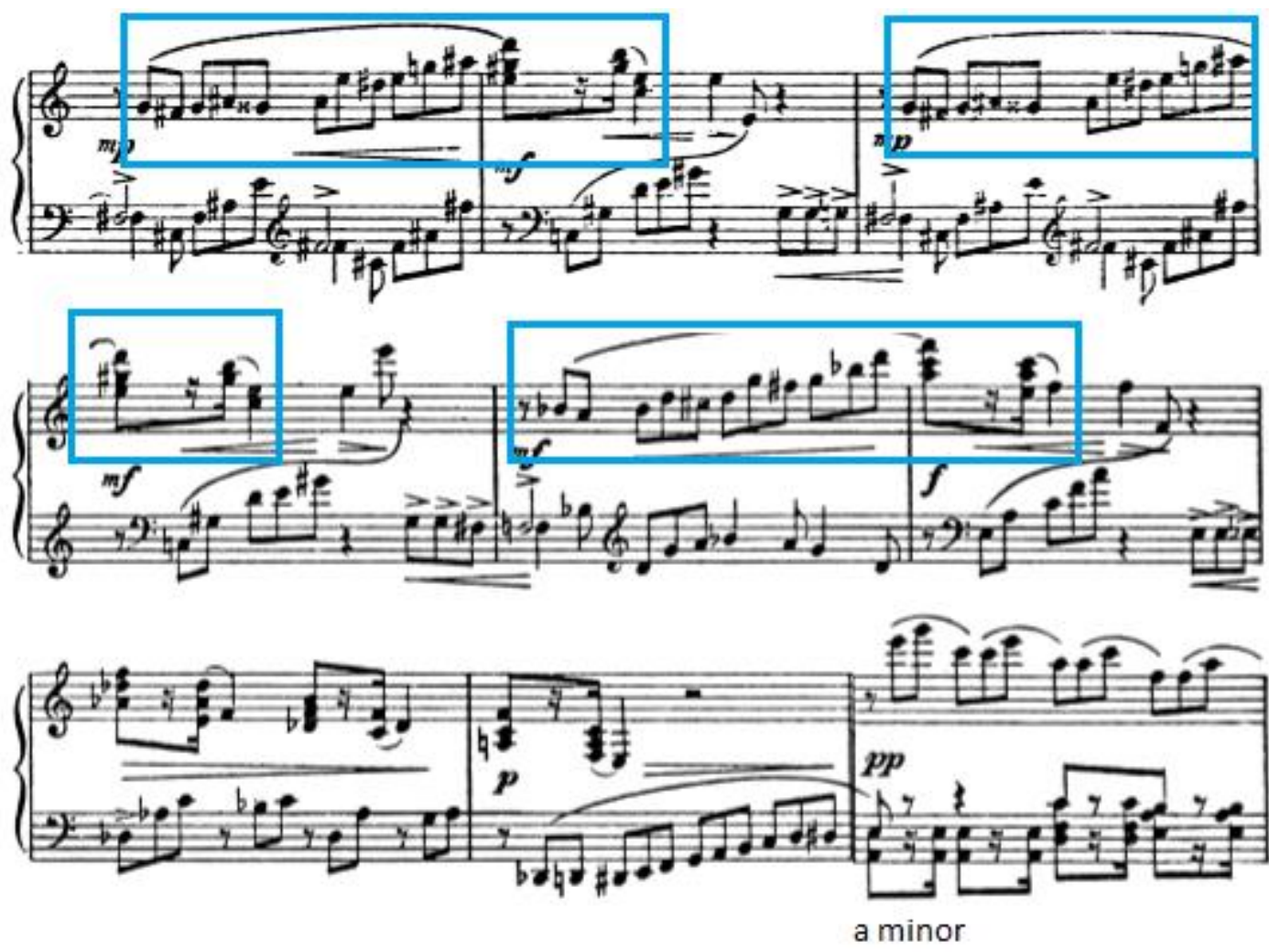

Example 36: mm. 181-189 
(2) Part II of the Recapitulation: Transformation of Theme II (mm. 189-204)

The transformed and enlarged Theme II appears in the inner voice of the left hand in measures 189-196. The rhythm has changed to shorter values using rests rather than the rhythm of lyrical theme II. The right hand is a progression of thirds, sixths, and first-inversion chords that span two octaves.

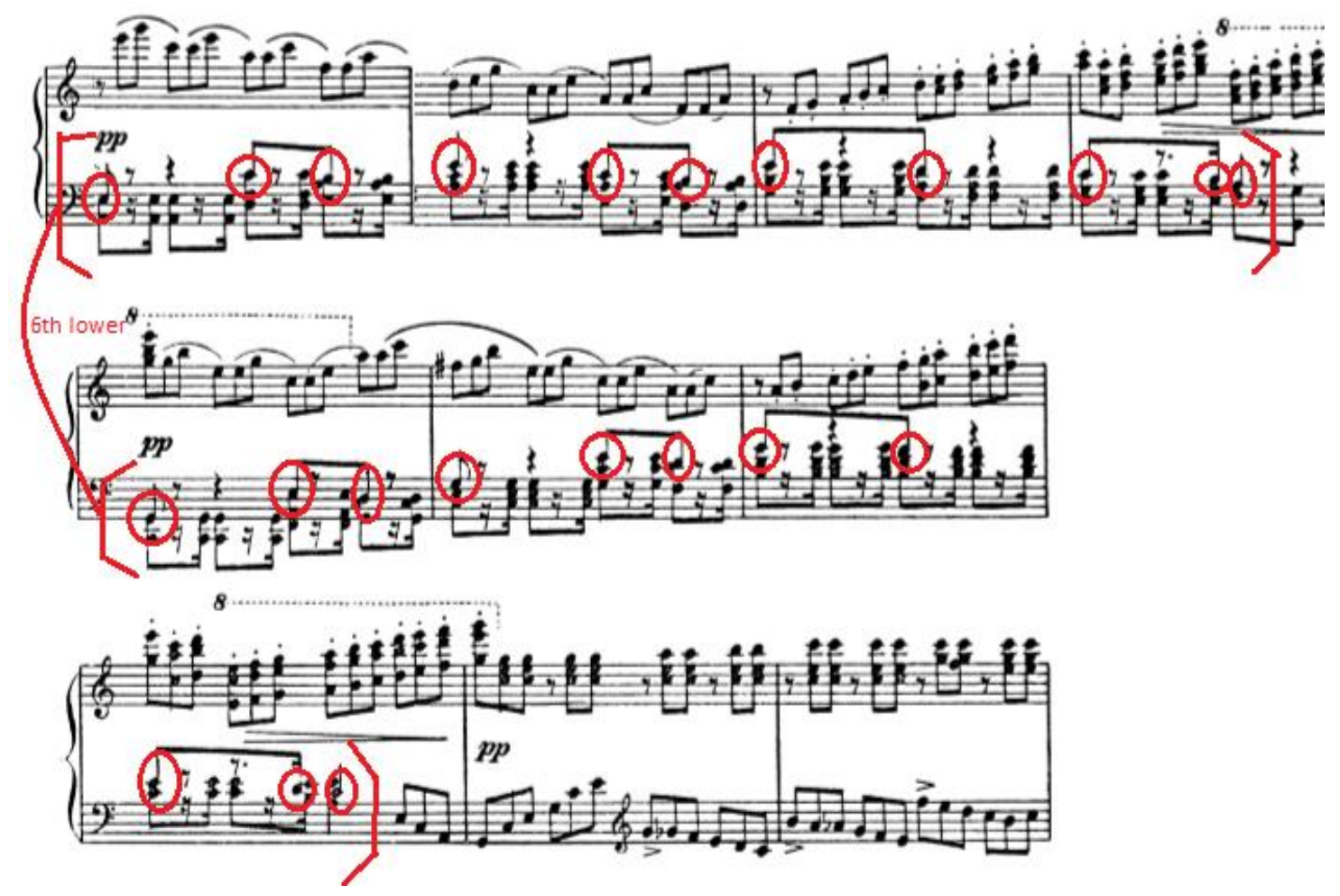

Example 37: mm. 189-198

In measures 196-204, Prokofiev writes many tonal chord progressions. Bb Major and Eb Major are used in measures 201-202, and E Major and D Major occur in measure 203. In measures 201-204, Prokofiev uses rhythmic elements of Theme I. The key of A minor returns in measure 205. 

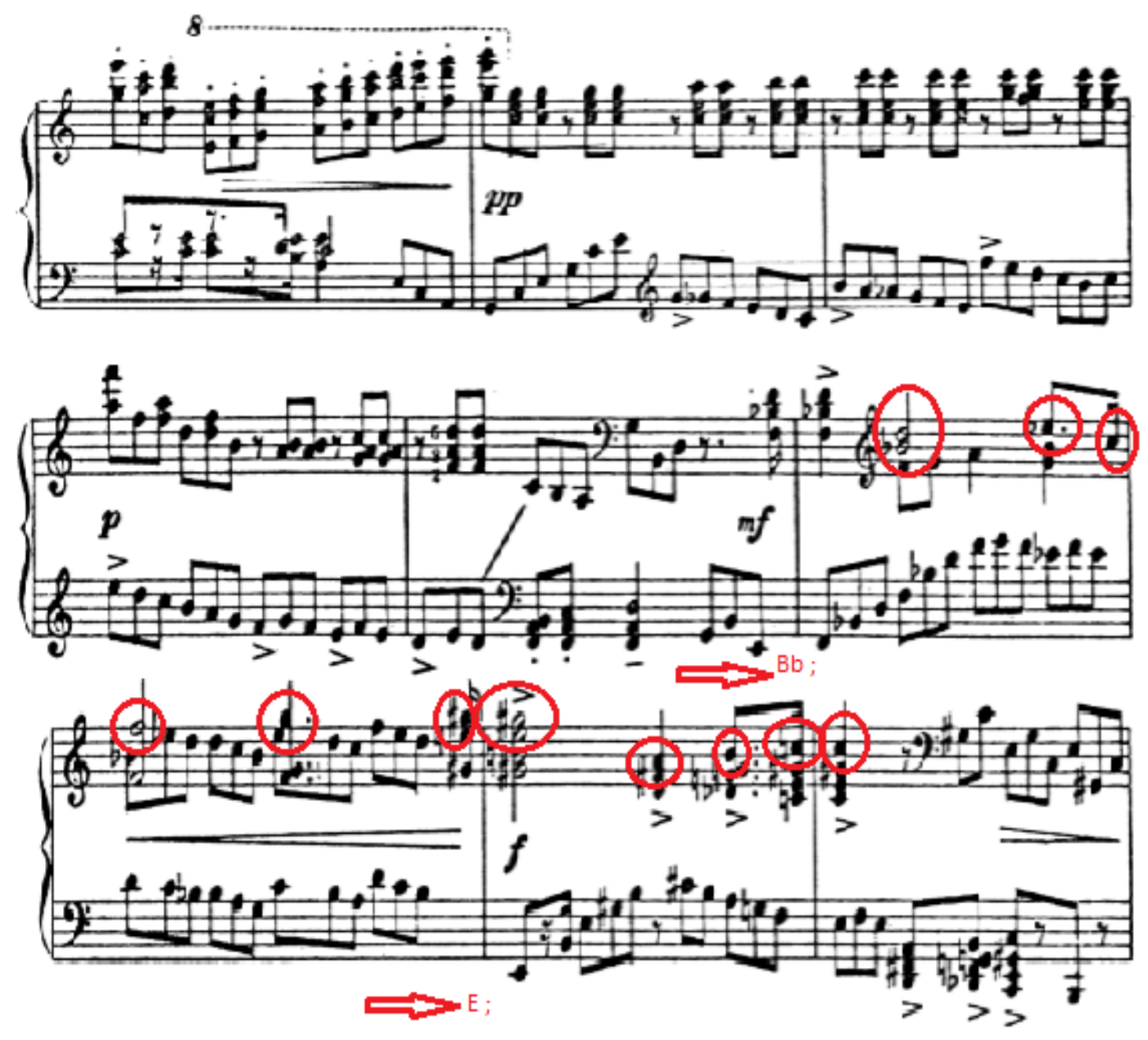

Example 38: mm. 196-204

(3) Part III of the Recapitulation: Coda (mm. 205-234)

The coda starts with the tempo marking "poco più mosso" (a little faster). We see repeated, percussive eighth notes that contrast dramatically with the pp in measures 205 to 213 , moving to ff at measure 217 and maintaining that level throughout most of the ending. The percussiveness and the huge crescendo make the music feel tense and urgent. Measures 205-212 create a climax which features ascending thirds in the right hand and a descending chromatic line in the left hand. The melodic line in measures 205-208 repeats an octave higher in triads from measures 209-212. 

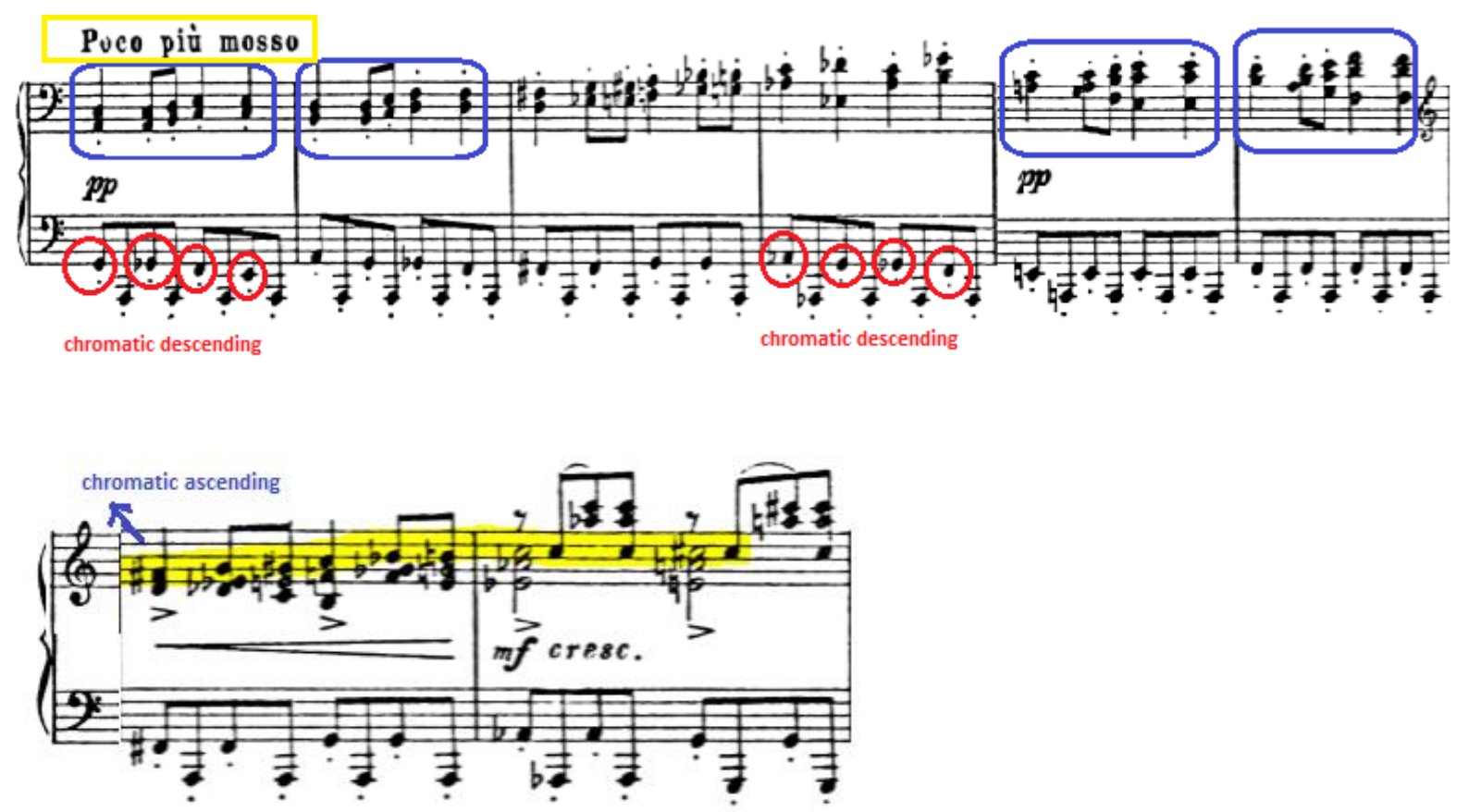

Example 39: mm. 205-212

Measures 213-216 display a progression of chromatic thirds that play the role of connecting directly to the tonic chord of A minor in measure 217. Syncopated accents convey an emphatic rhythm. "Subito pp" in measure 213 grows into "fff" in measure 224.

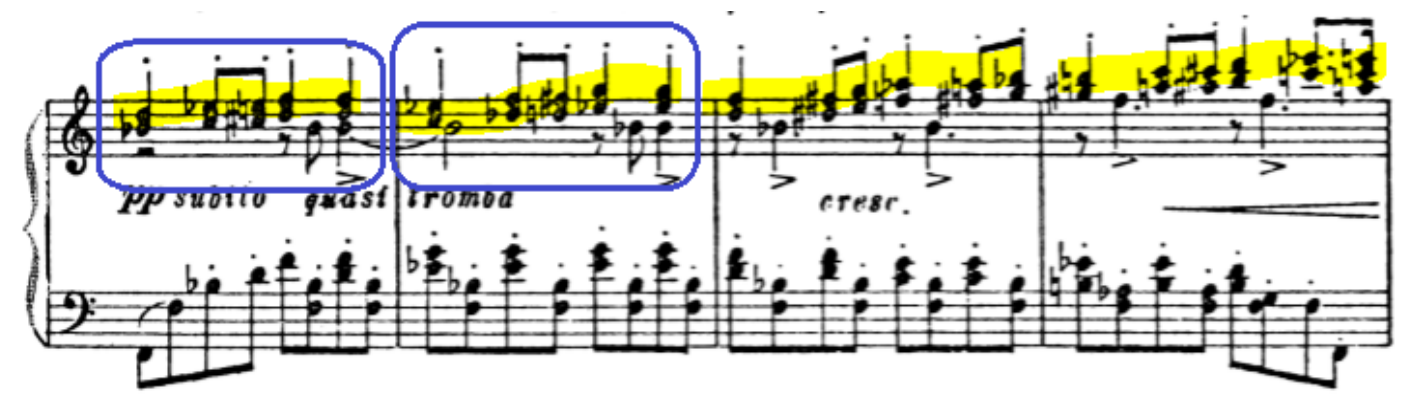

Example 40: mm. 213-216

In measures 217-220, left-hand figures span three octaves while a chromatic descending melody in the right hand appears in contrary motion. The tonic chord of A minor in measure 217 is 
joined by chromatic descending triads through measure 220 , creating tonal ambiguity. The descending chords end with the tonic of A minor, reinforcing the tonality in measure 221. In measures 221-224, the rhythm of theme I appears and the melody ascends. The same rhythm in these two measures, four sets of triplets, appears in contrary motion in measures 225-226.
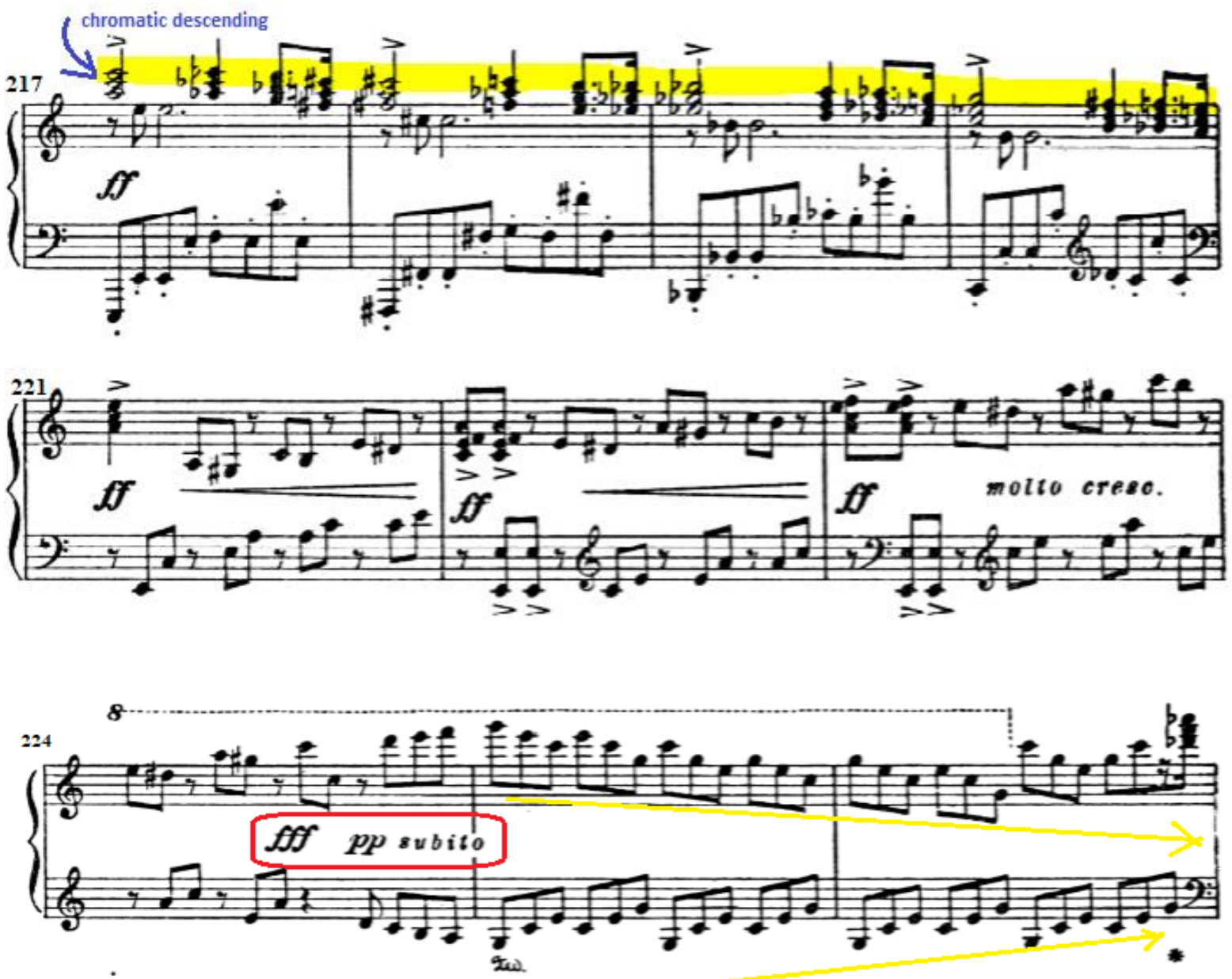

Example 41: mm. 217-226

At the end of measure 228, the E-Major triad acts as the dominant chord of A minor, and the harmony resolves to the tonic chord of A minor in measure 229. Prokofiev employs a Db-Major chord in measure 227 before an E-major chord in the next measure. The rhythm of theme II appears in measures 229-230. In measure 232, the Db-Major chord returns from measure 227. The Db-Major chord is one semitone lower than the subdominant chord of A minor; in this case, its fifth has been removed. This progression is an example of Prokofiev's "modern" characteristic, as he expands the 
final cadence by adding an unexpected chord to a traditional, classical cadence. This technique contributes a change of color. The sonata ends with a dry (secco) chord and octaves in the tonic of A minor in measures 233-234.

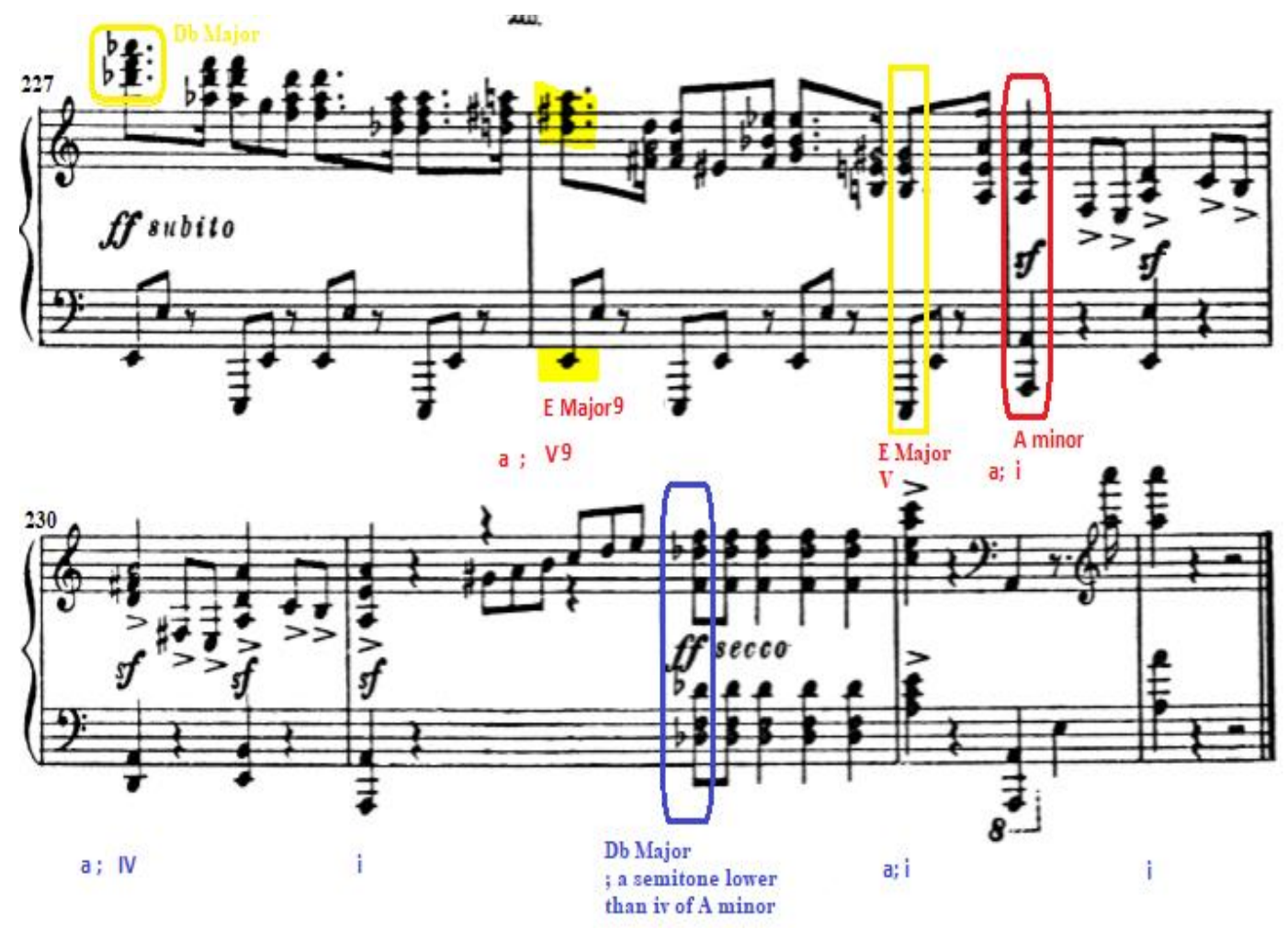

Example 42: mm. 227-234 


\section{B. Performance Suggestions}

Prokofiev's Piano Sonata no. 3, op. 28 treats the piano primarily as a percussion instrument and demonstrates the piano's abundant acoustic abilities by using regular rhythm patterns and a wide range. This sonata contains all five lines of Prokofiev's musical characteristics: the classical line, the toccata line, the modern line, the lyrical line, and the grotesque line. Among these five lines, this paper will focus on both the modern line and the toccata line, related to performance suggestions. The musical examples of this chapter are organized by topic.

\section{The Modern Line}

\section{(1) Percussive Effects}

In respect to the modern line, Prokofiev emphasizes this technique by treating the piano as a percussion instrument. The following are examples of this: In measures 1-2, the pianist should prepare for the first note of the left hand with a breath, roll the wrist for the grace notes, and afterward emphasize the $\mathrm{E}$ with an accent. The following E-Major chords must be played in a percussive style, even though the speed essentially requires a relaxed right wrist.

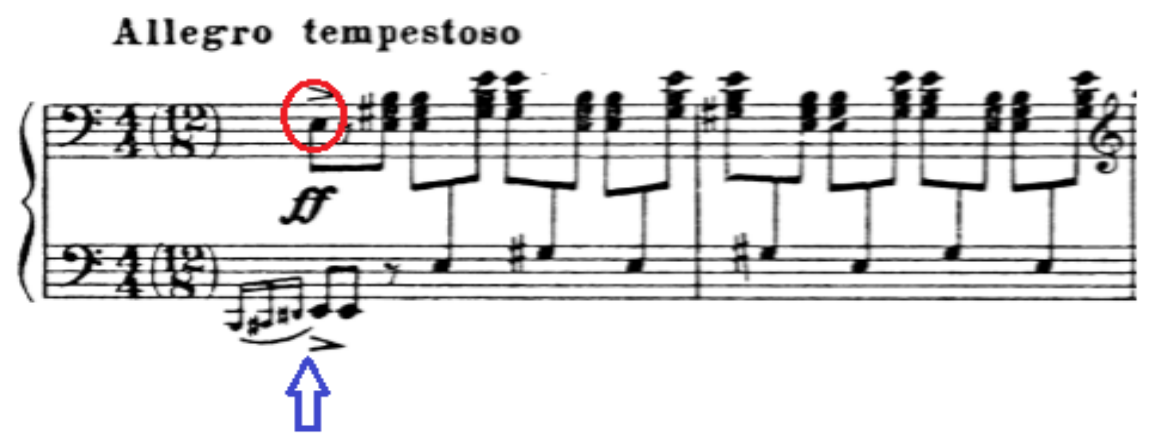

Example 43: mm. 1-2

Measures 103-104 have many bass-clef F's in the alto part; they also suggest a drum. The pitch $\mathrm{C}$ has been added to the F's in measures $107-108$ with accents. In measures $109-110$, the accented notes in the right hand should be played with strong accents and as a single phrase. The right 
wrist and arm should be flexible over the five-octave span. The left hand in measures 110-111 also can be played dry to make a percussive effect. The right hand, in measures $110-113$, presents trills of sixteenth notes, transitioning from forearm rotation (ff) to finger action during the diminuendo.
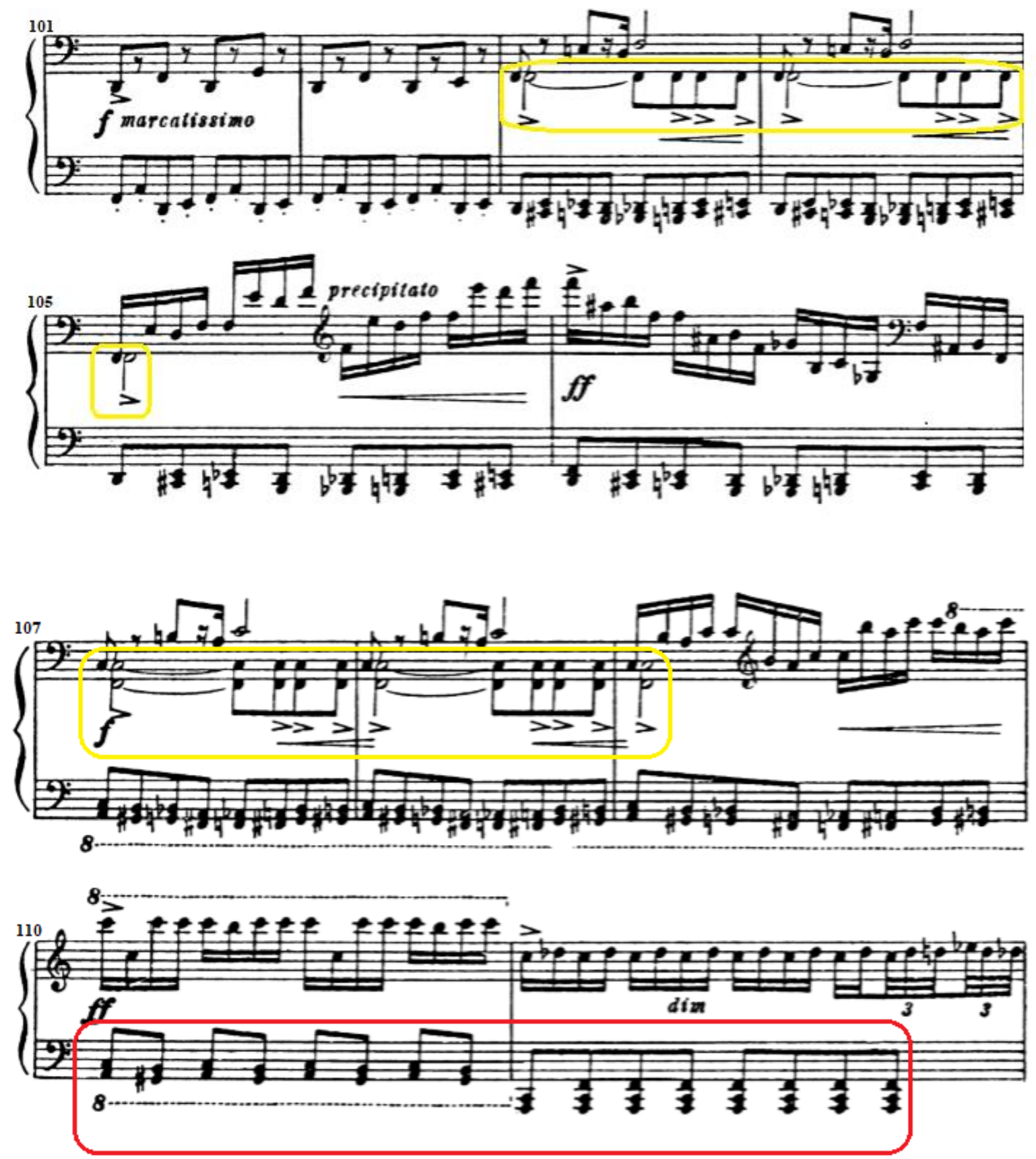

Example 44: mm. 101-113

The left hand in measures 146-151 has ascending first inversions and descending parallel minor thirds with accents. They can be played non-legato with a relaxed arm and wrist. The arpeggio 
in the right hand of this passage, leading to the first note, can be played smoothly, with the focus on the melody in the outer voice. The direction in this passage is "con elevazione," which means "with elevation."
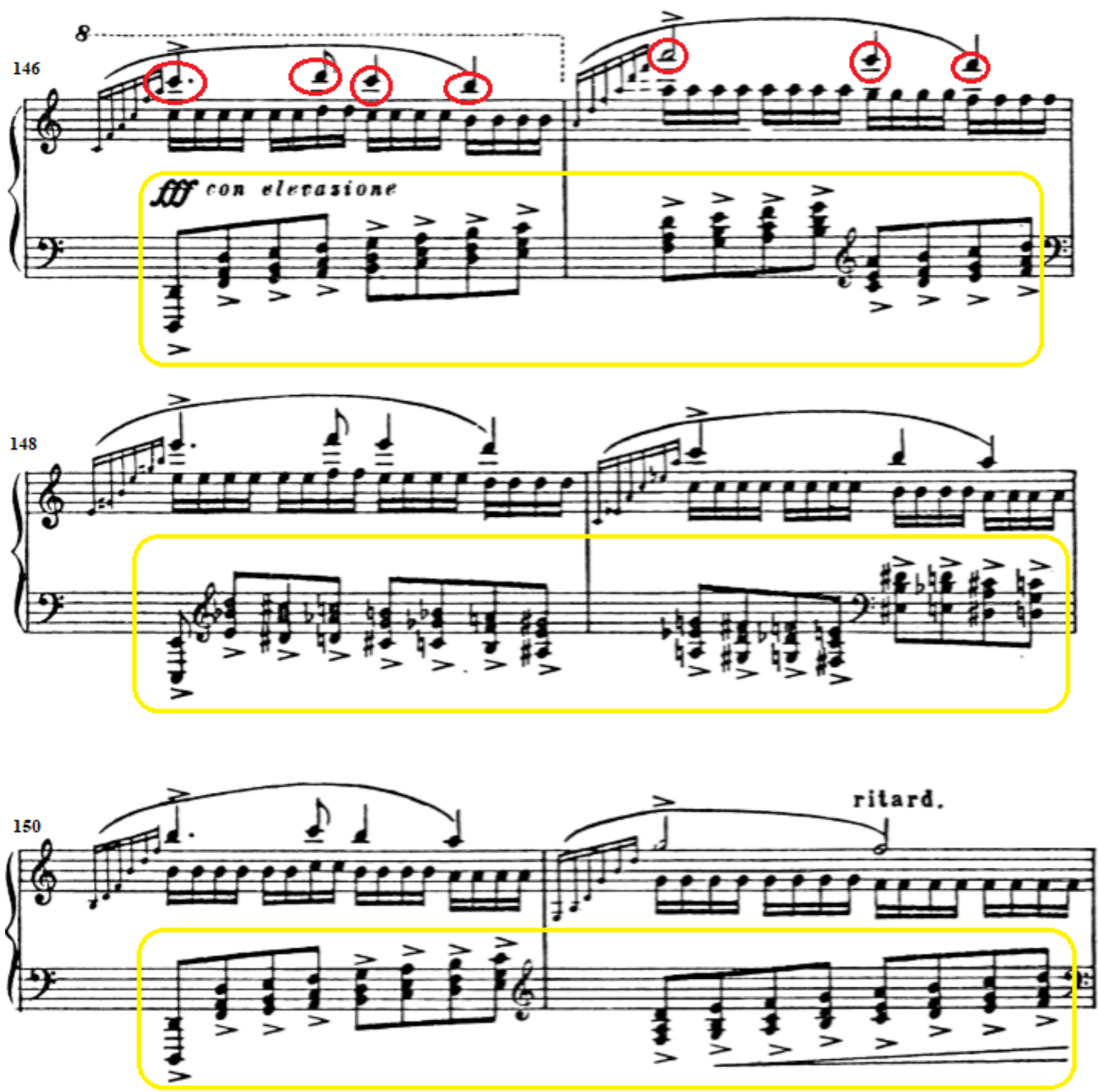

Example 45: mm. 146- 151

In measure 205, the mood and tempo change to poco più mosso. We see only staccatos for both hands until measure 216 for the right hand. The left hand continues with staccato notes from measure 205 to measure 220, imitating a snare drum. 

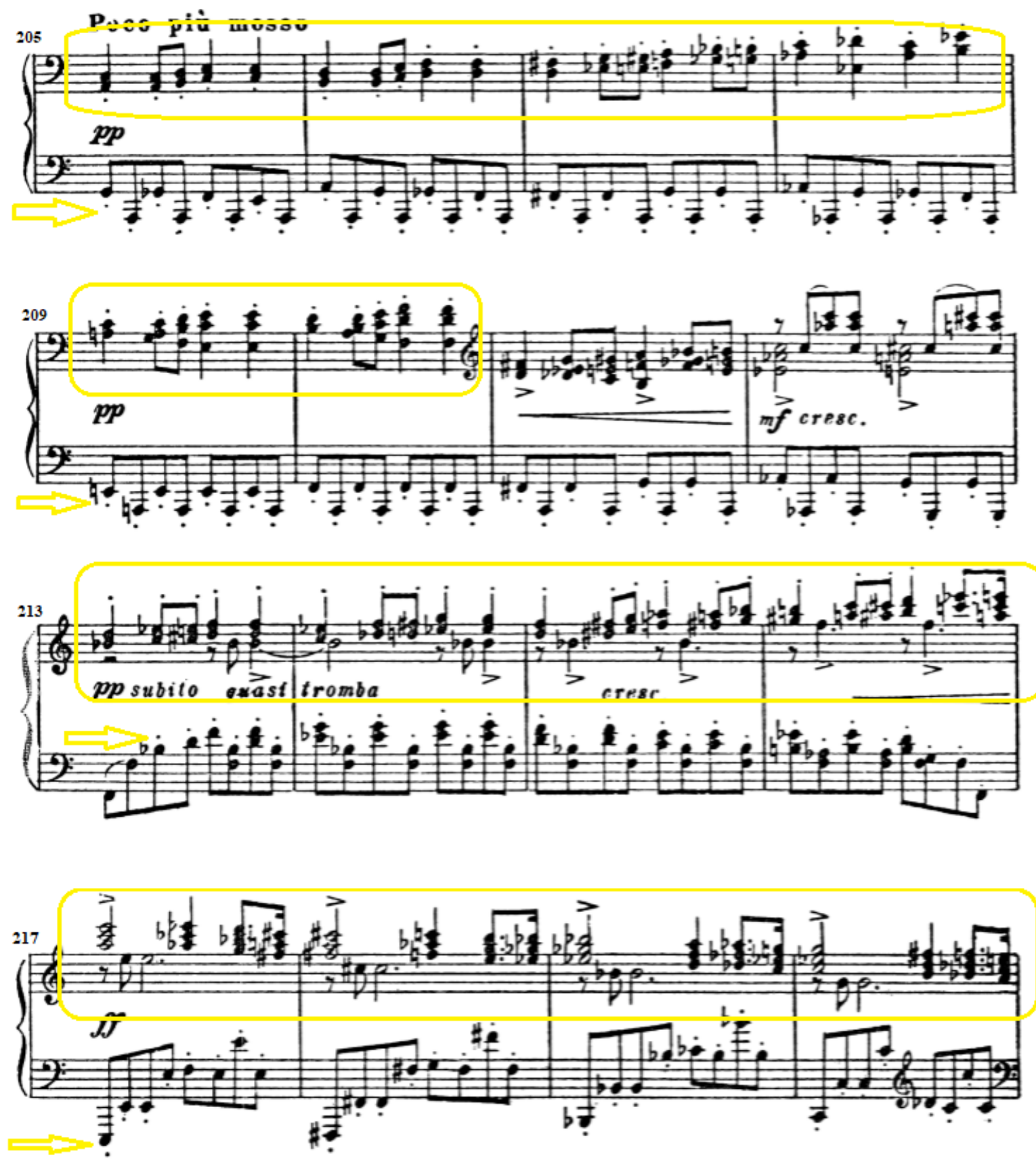

Example 46: mm. 205- 220

(2) Modern Rhythms

Many pieces from this time period include asymmetric rhythms, hemiolas, and emphasis on the offbeats. In order to play these patterns effectively, pianists require a strong sense of rhythm. In this sonata we easily find examples of syncopations and motor rhythms together with irregular 
rhythms. For example, measure 3 has a double-dotted quarter note and a sixteenth note over triplet eighth notes.

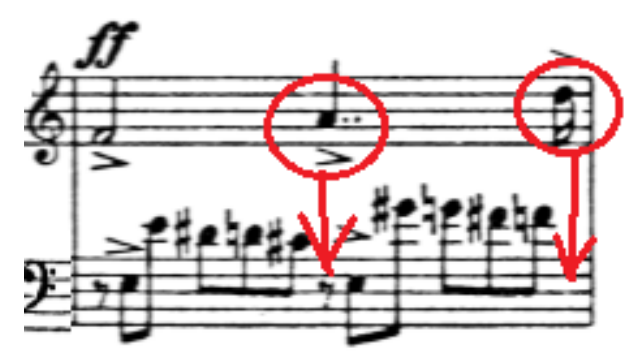

Example 47: measure 3

The sixteenth notes in example 41 are written so that they should follow the third notes of the triplets; however, in order to play in allegro tempestoso tempo, there is a good chance that they will coincide with the last notes of the triplets.

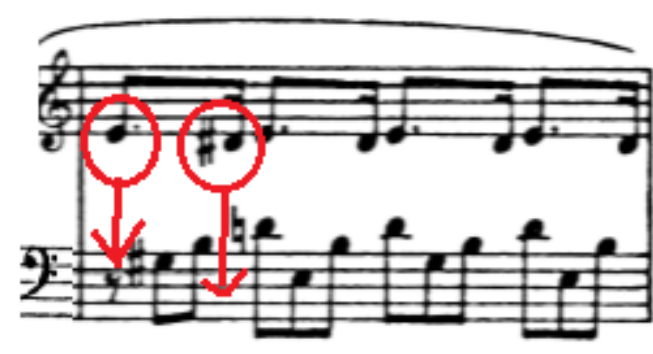

Example 48: m. 15 (Long-short rhythm against triplet )

A new tempo starts in measure 94 . Before playing this part, quickly prepare mentally for the new tempo. During mm. 95-97 one also needs to ready to change the division of the beat from triplets to plain eighth notes. 


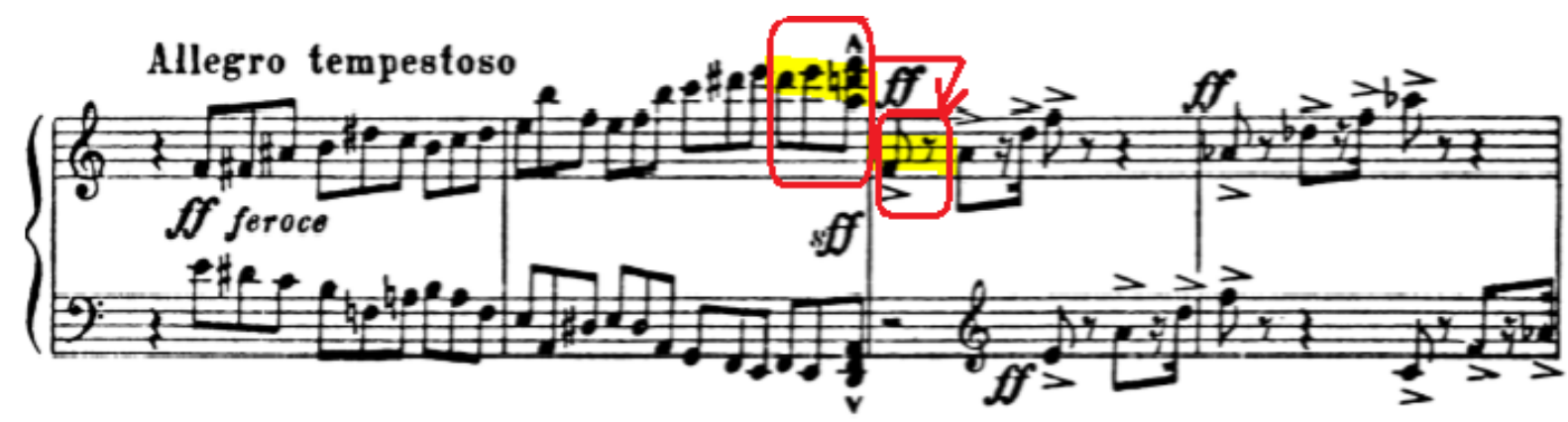

Example 49: mm. 94-97 (Change from triplets to eighth notes)

Another new tempo, moderato, begins in measure 123, following both a ritardando and a diminuendo in the previous measure. We also encounter two-against-three rhythms between the hands. Managing a smooth tempo change along with the 2:3 interference pattern can be challenging, especially as the tied notes create the extra complication of syncopations.

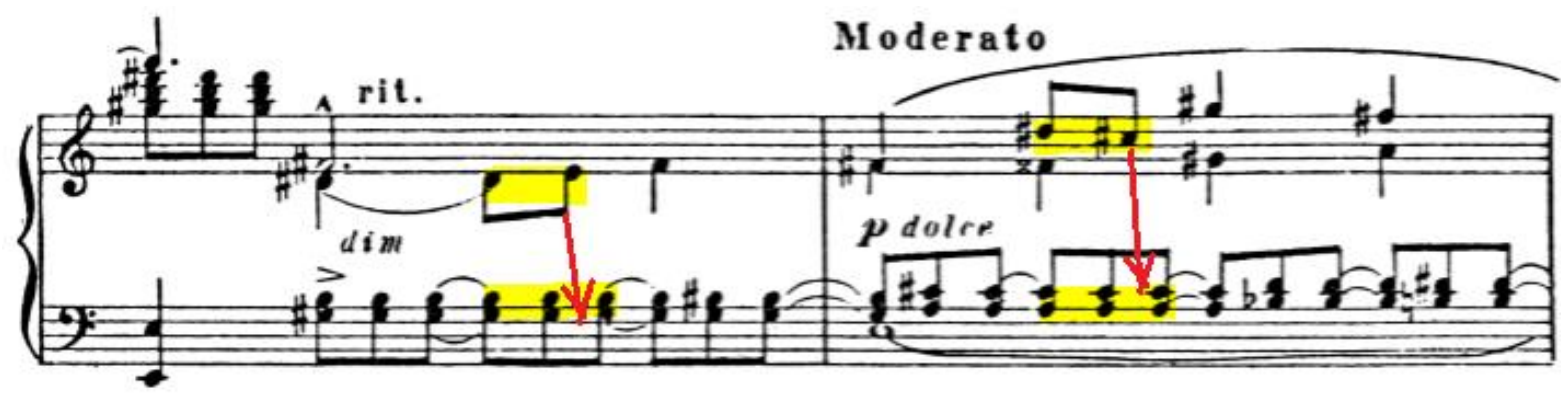

Example 50: mm. 122-123 (eighth notes: triplets, long-short rhythm: triplets)

Più animato appears in measure 132. Again we see $3: 2$ relationships between the hands. The melody in the soprano part needs to be brought out. The left hand moves in octaves and, with hand crossings, the passage spans more than six octaves of the keyboard. 

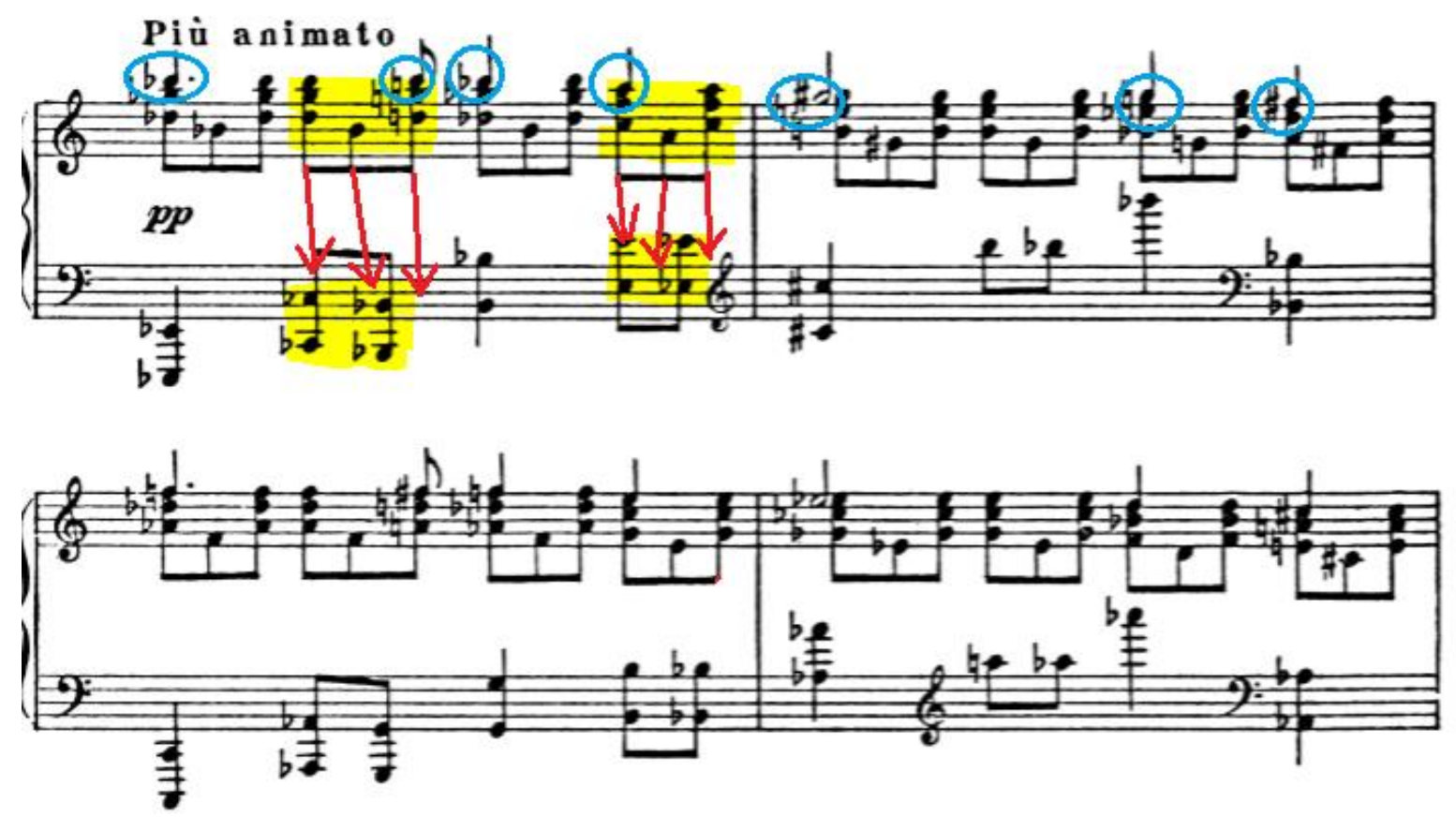

Example 51: mm. 132-135 (Eighth notes: triplets)

Measures 187-192 also display a combination of long-short rhythm and triplets, displaying contrast between the hands. The dynamic mark is pianissimo and the main melody appears in the upper voice of the left hand, presenting a cantabile role for the left thumb.
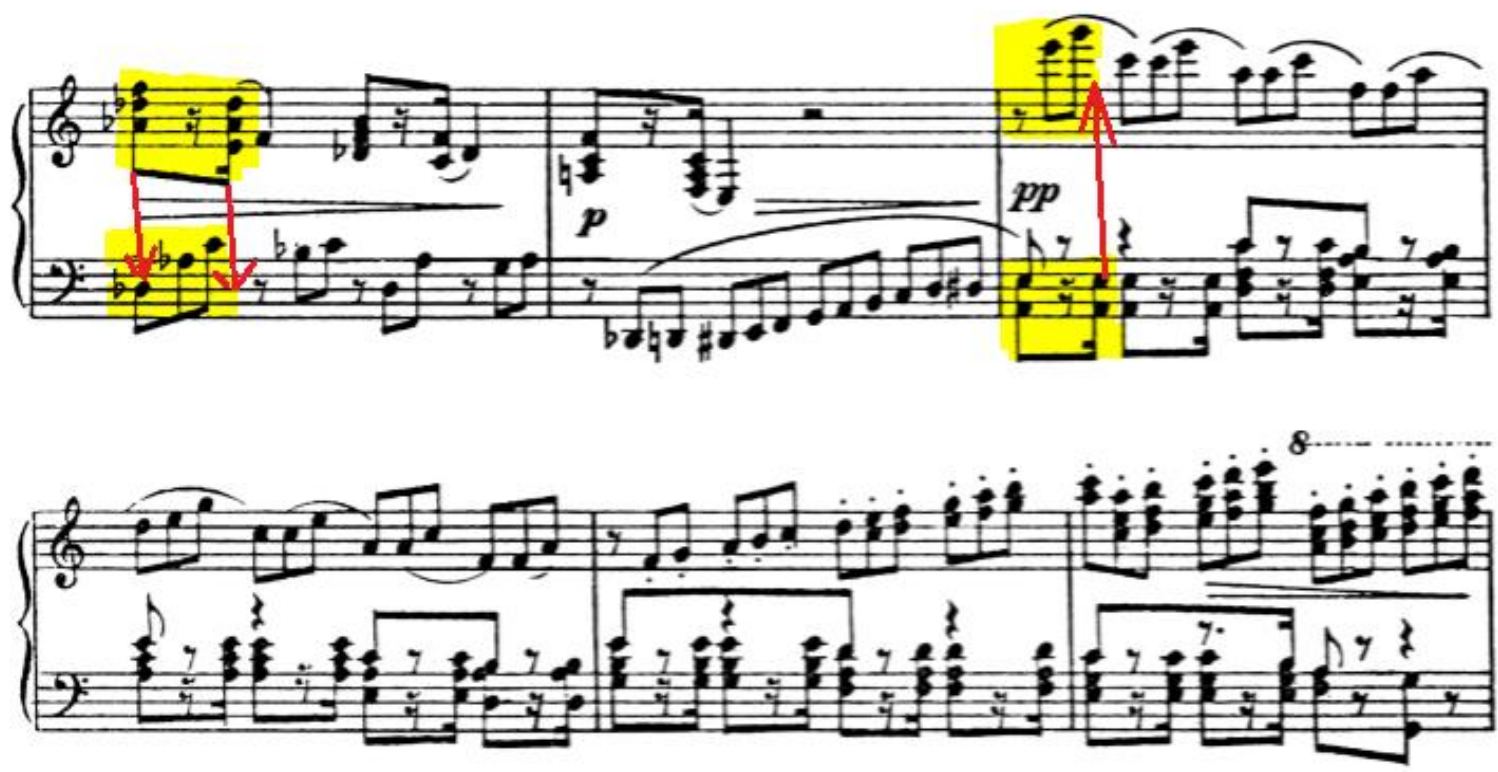

Example 52: mm. 187-192 (Triplets: long-short rhythm) 
Syncopations in the left hand of measures 78-81 can be played lightly, in part so Prokofiev's characteristically lyrical melody can sing out within a relaxed mood.

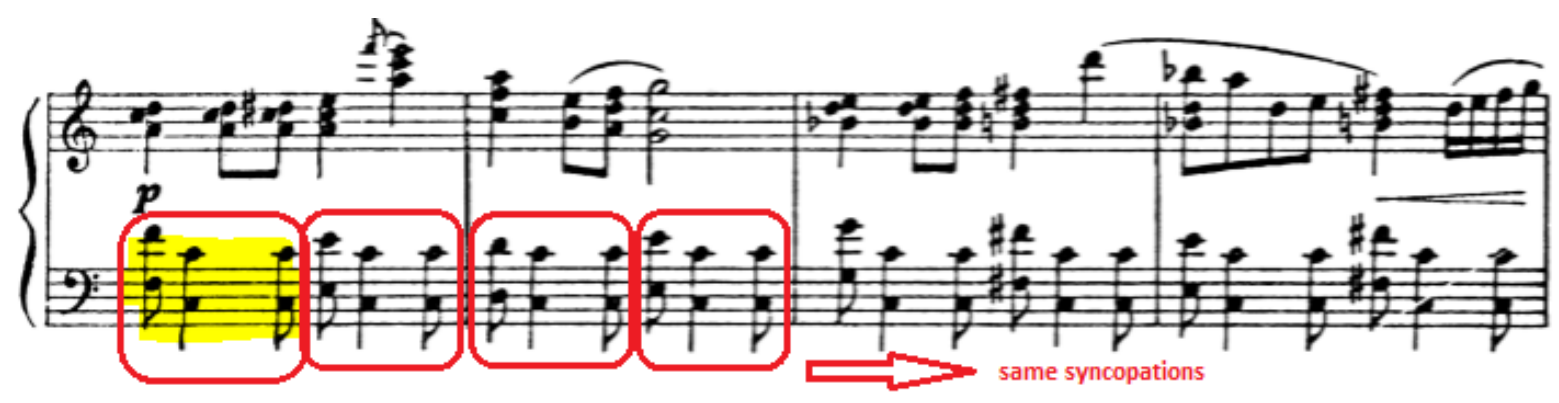

Example 53: mm. 78-81(Syncopations)

Motoric rhythms appear in many places throughout this sonata, beginning with the first two bars of the piece. Just as a motor often powers movement, so this energetic material creates movement towards the appearance and character of Theme I.

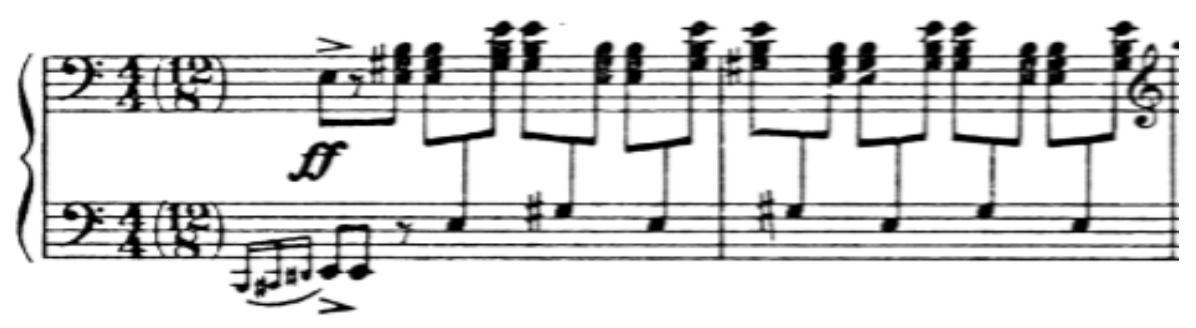

Example 54: mm. 1-2

The left hand in measures 20-23 also displays motoric rhythms. While the right hand presents the diminution of theme I, the left hand plays a continuous motor rhythm. The repeated notes in the left hand can be tricky, as the second note of the repeated pair will not sound unless the first note is sufficiently short. 


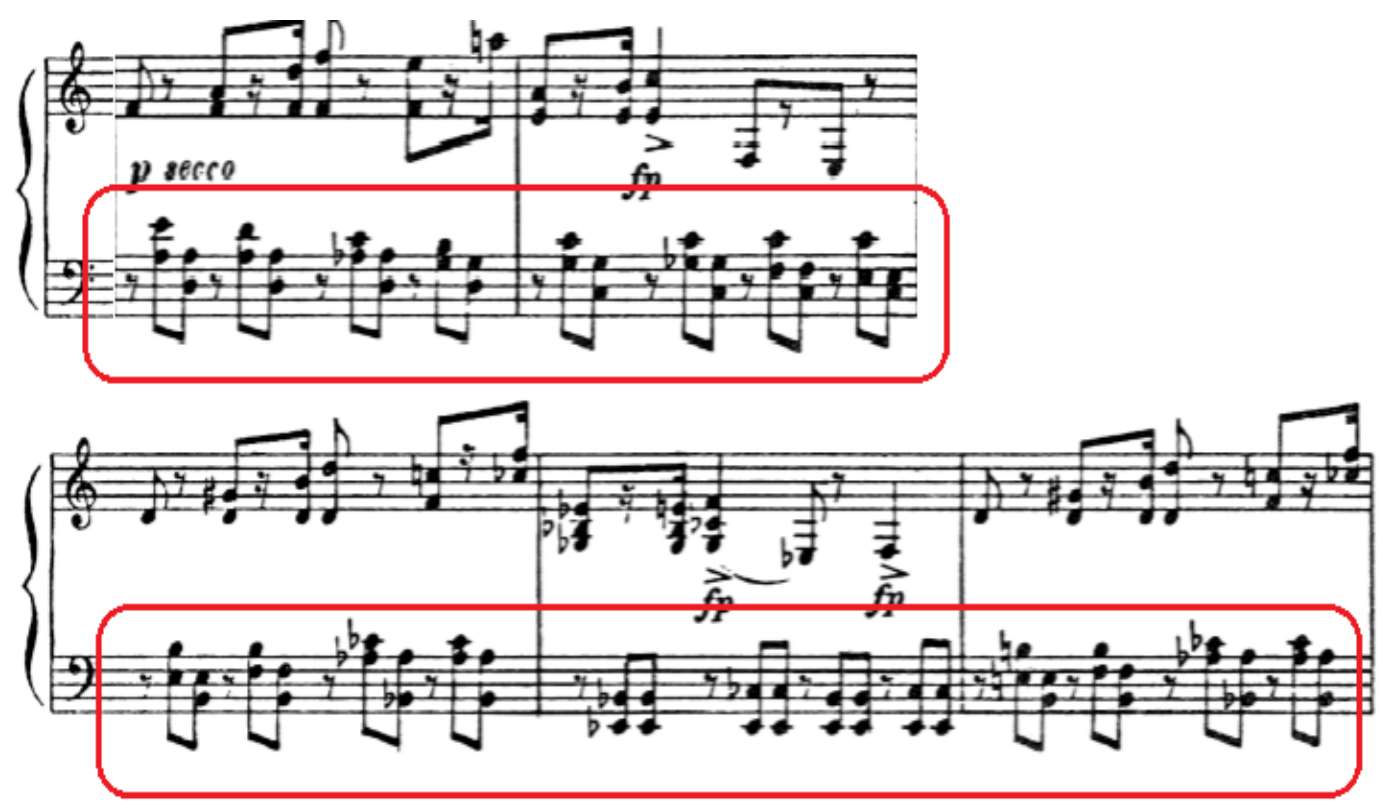

Example 55: mm. 20-23

Measures 101-102 present motoric rhythms in the left hand that we can also call ostinato. The direction marcatissimo means"with very strong accentuation."

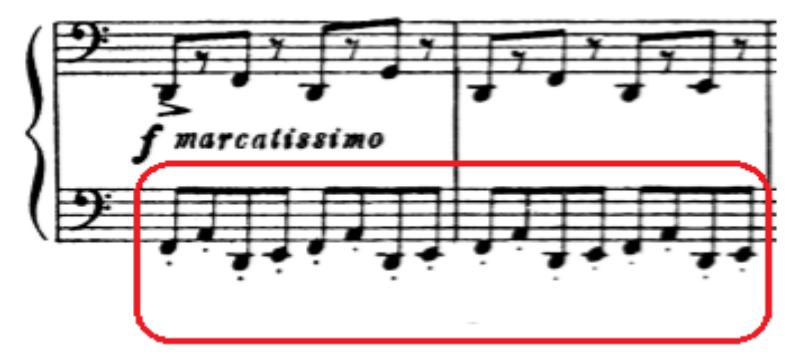

Example 56: mm. 101-102

The first note of the Recapitulation, the long $\mathrm{E}$ in measure 154, should be held for its entire duration. The next measure has a dynamic sign ppp, and poco a poco accelerando starts in this measure, with motoric rhythm in both hands. Effective control of the tempo change is required for a smooth connection between the sections. 

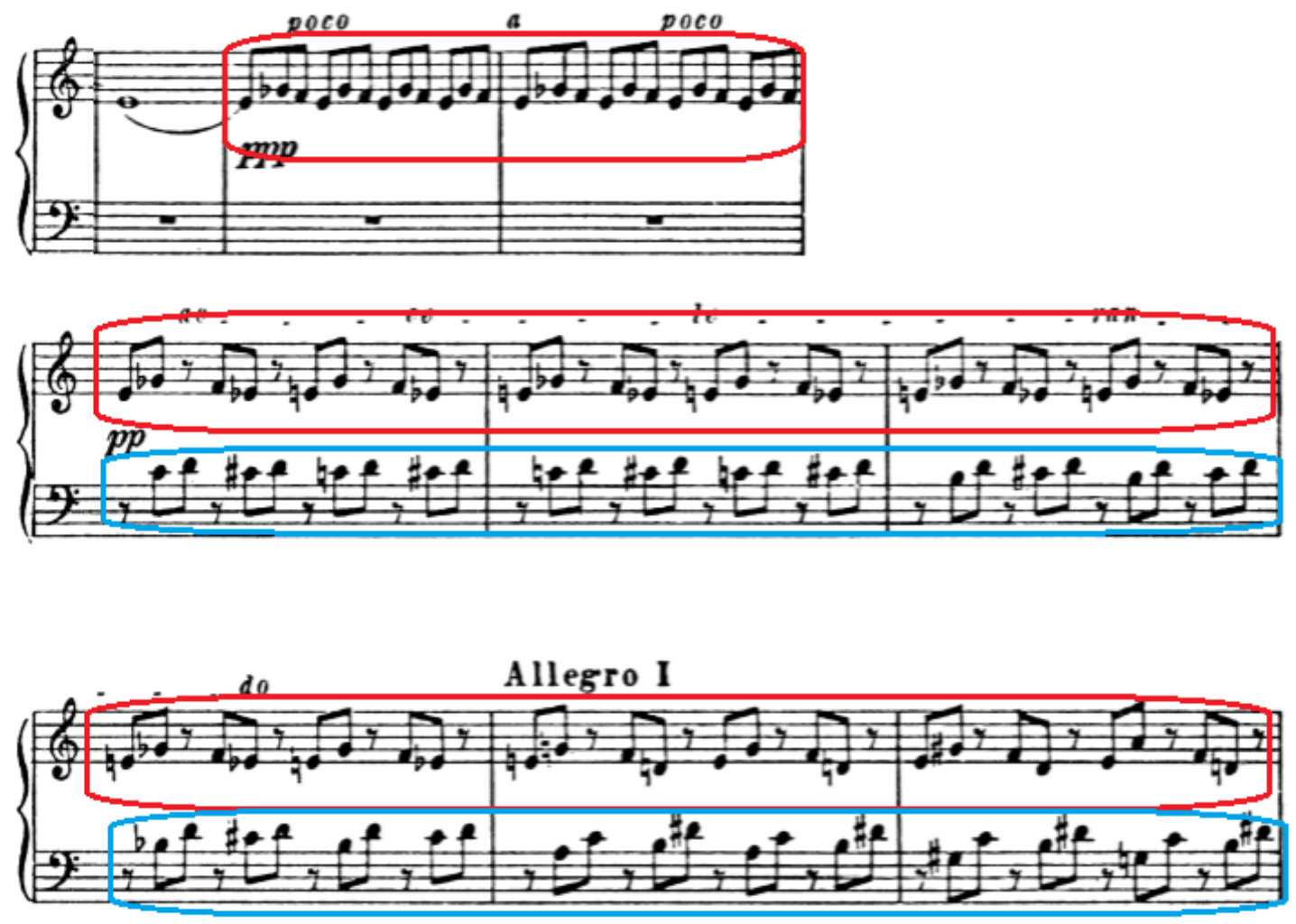

Example 57: mm. 154-162

(3) Modern Dynamic Signs

Prokofiev employed frequent accents and forte-piano markings in this sonata. He put accents on almost every strong beat in measures 1-6. Emphasizing the accents in measure 1 for both hands may make it easier to control the power of the fingers in the following two measures, which lead to theme I. After playing the first accented notes, it is best to play with a relaxed wrist and strong touch from the fingertips. The left hand in measures 3-4 has accented first notes which are essential to the following four notes. It can be challenging to play the accented first notes strongly and then to release the fingers to manage the following four notes. 

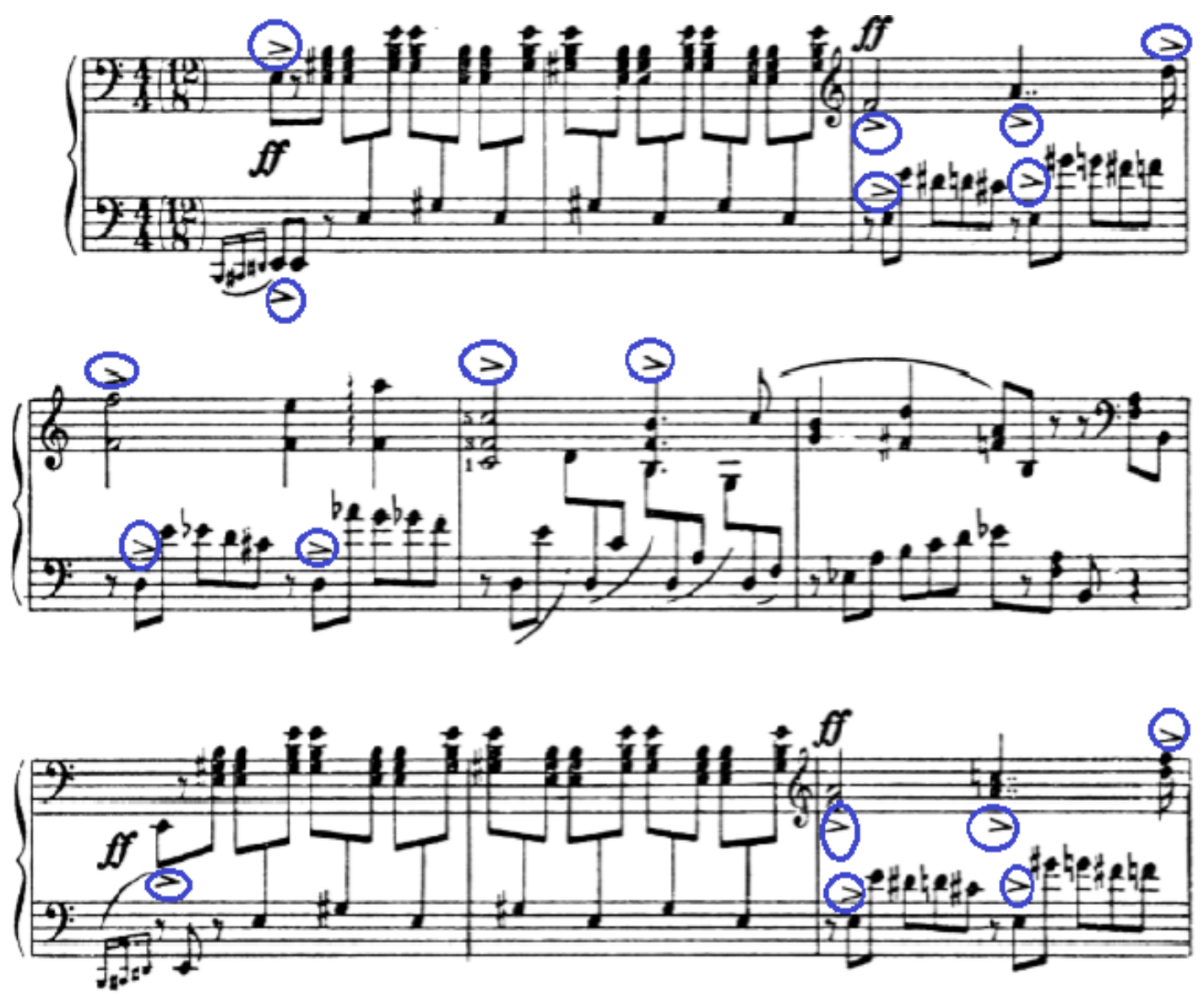

Example 58: mm. 1-9

The same principle can be applied in measures 9-12. The texture is thicker than in the beginning of the piece. The upper voice of the right hand should sing out above the lower voice in the thirds.

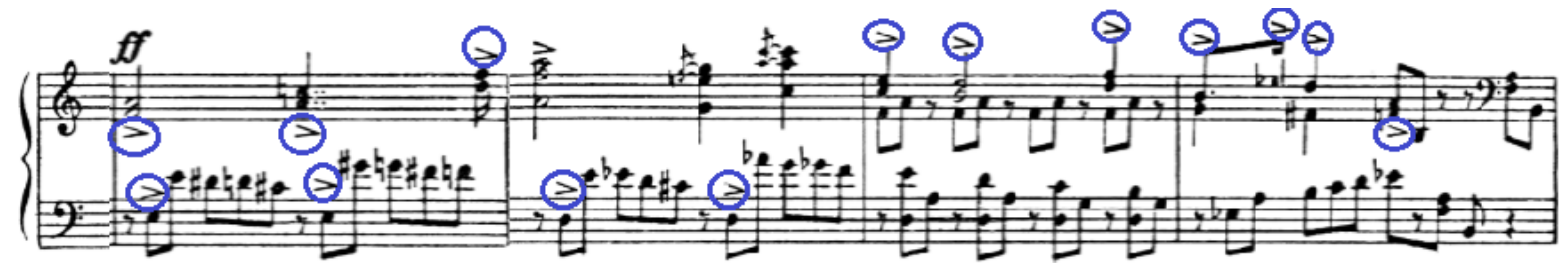

Example 59: mm. 9-12

The $f p$ sign in measures $23-25$ is a very significant point of performance for this sonata. One should play the $f p$ notes loudly with a short pedal, taking the next notes much more gently and without 
pedal. The performer needs a good sense of dynamic control to manage such rapid changes effectively.

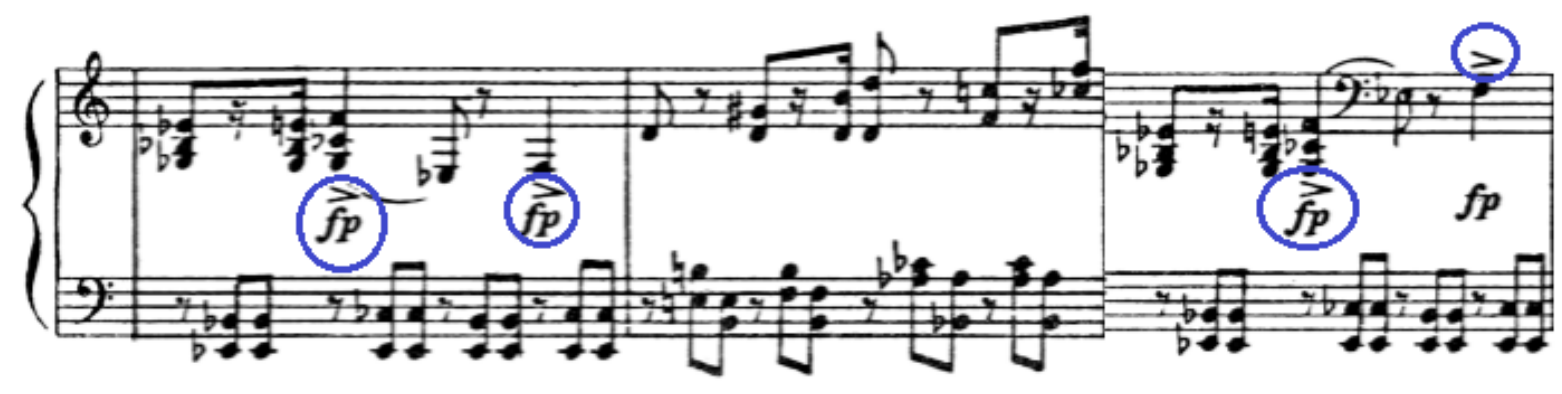

Example 60: mm.23-25

In measures 52-53, a released shoulder, arm, and wrist can help both hands play the constant accents. The poco ritardando sign in the next measure is preparation for the next section.

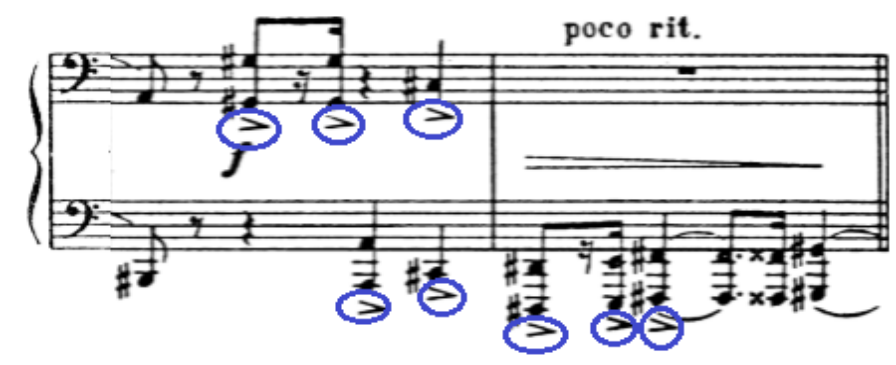

Example 61: mm.52-53

Prokofiev used continuous accents in measures 96-98. They are transformed from theme I. In addition to the fortissimo marks, all the notes bear accents and should be expressed in a dry and strong tone. 


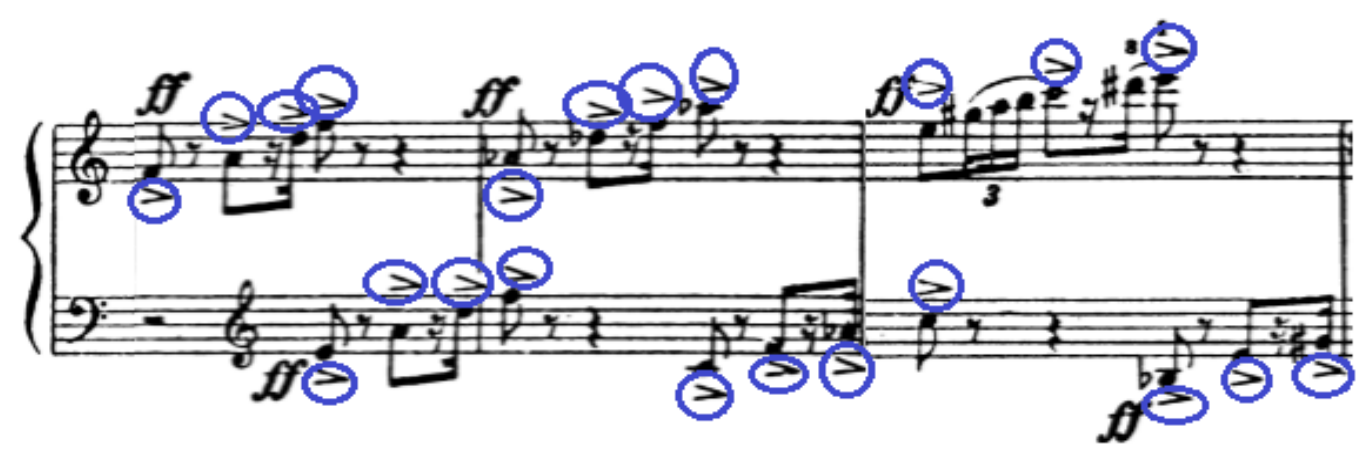

Example 62: mm. 96-98

Measures 103-104 have accented F's in the inner voice at a low position. It strongly suggests the sound of a drum above the ostinato in chromatic thirds.

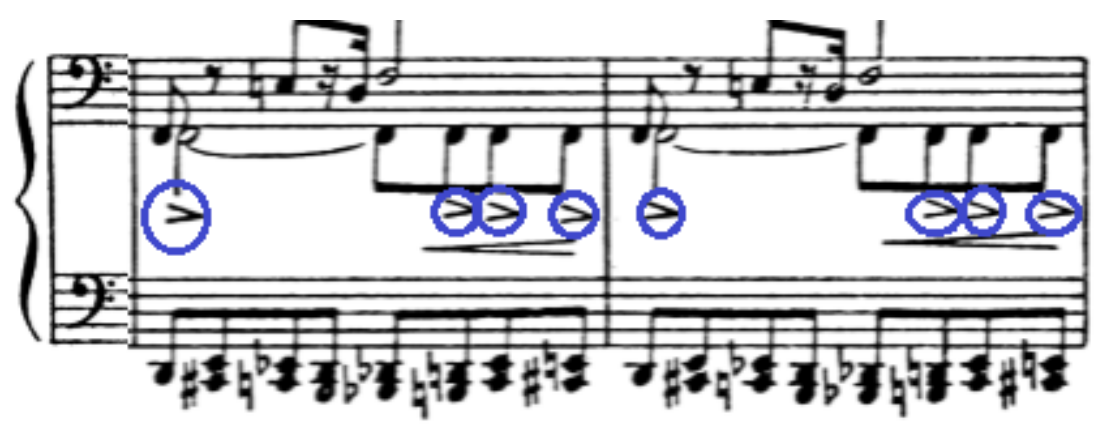

Example 63: mm. 103-104

Measures 146-151 present a combination of arpeggios in the right hand and continuing parallel first-inversion chords in the left hand. The dynamic sign fff with con elevazione indicates that the combination must be expressed with energy. The right hand should lean toward the right side, in order to play the melody in the top voice. The arpeggios at the beginning of the measure should be sounded evenly and freely, directed toward the highest note. The inner voice of the right hand presents repeated sixteenth notes, which can be played evenly as an accompanying part of the melody. 

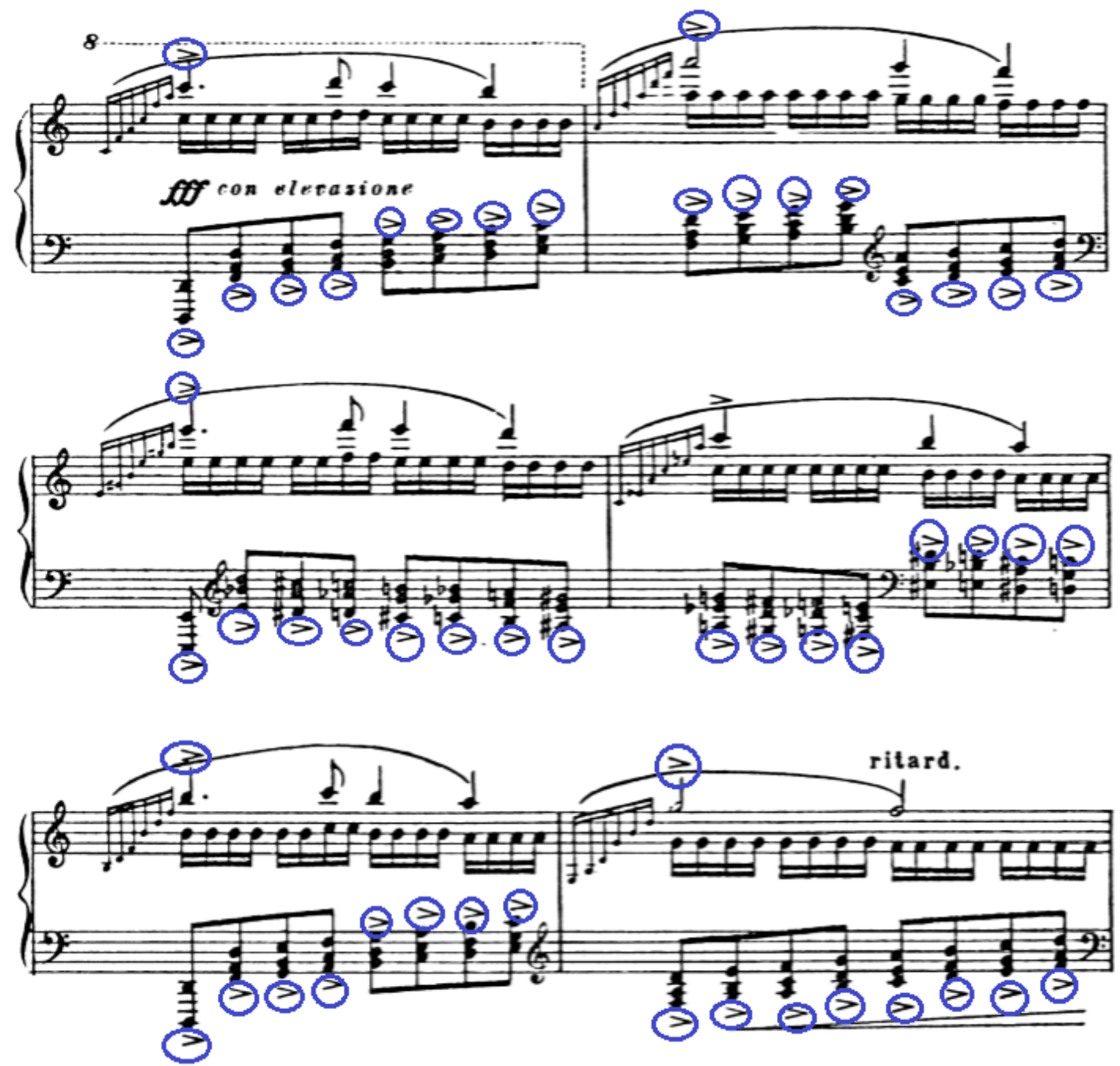

Example 64: mm. 146-151

The accents in measures 213-216 appear in the inner voice. By his quasi tromba indication, Prokofiev suggests that this voice should sound like a trombone.

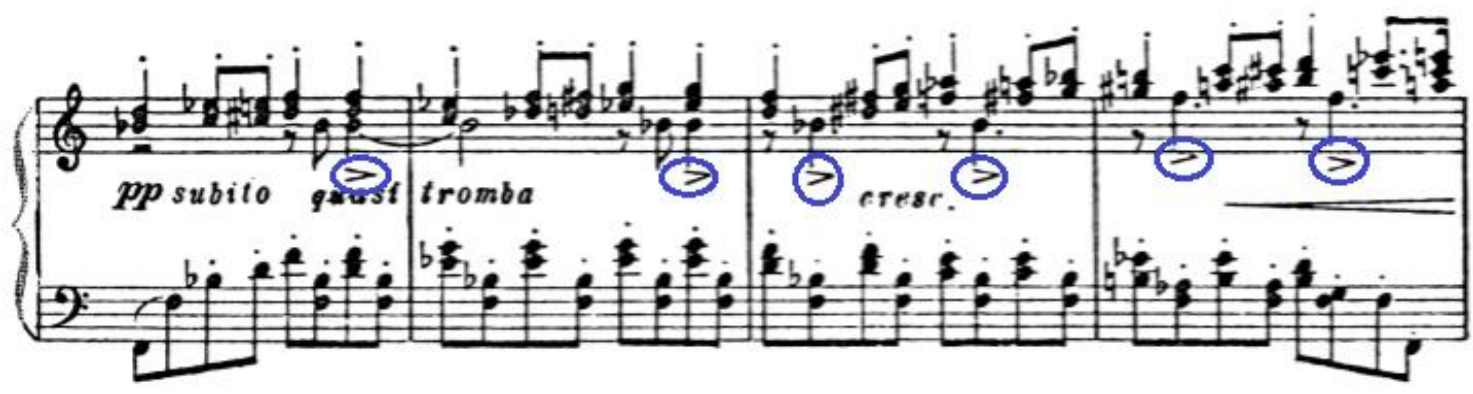

Example 65: mm. 213-216 
Measures 229-231 present a passage with sforzandos and accents, approaching the end of the sonata. They suggest both tension and a dry sound, and applying short, precise touches of pedal can help the notes which have sforzandos.

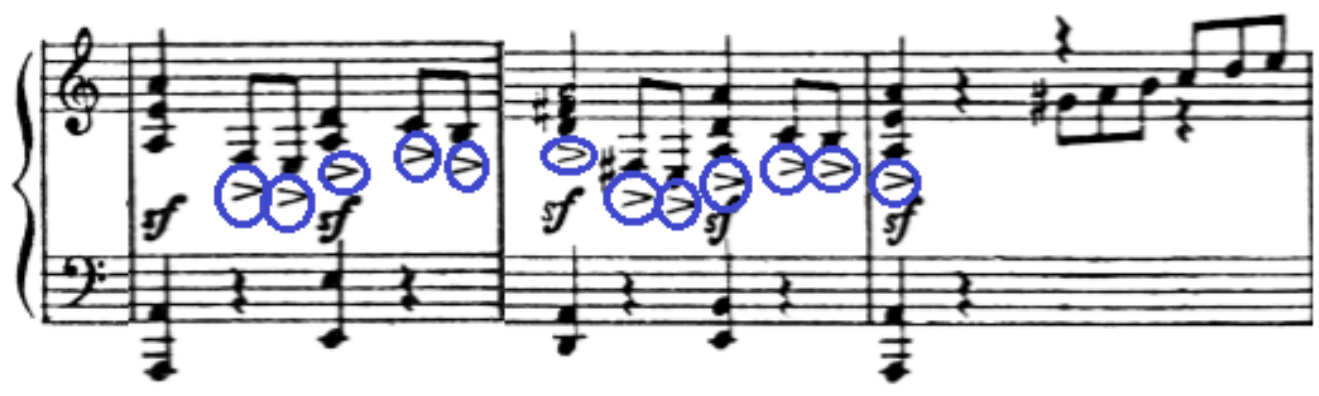

Example 66: mm. 229-231

(4) Abrupt changes of dynamics and tempos

Abrupt changes of dynamics and tempos occur frequently in this sonata. In measures 13-16, we find $f f$, diminuendo, $p$, and $m f$, all within four measures. This active material connects Theme I to Transition Theme II.

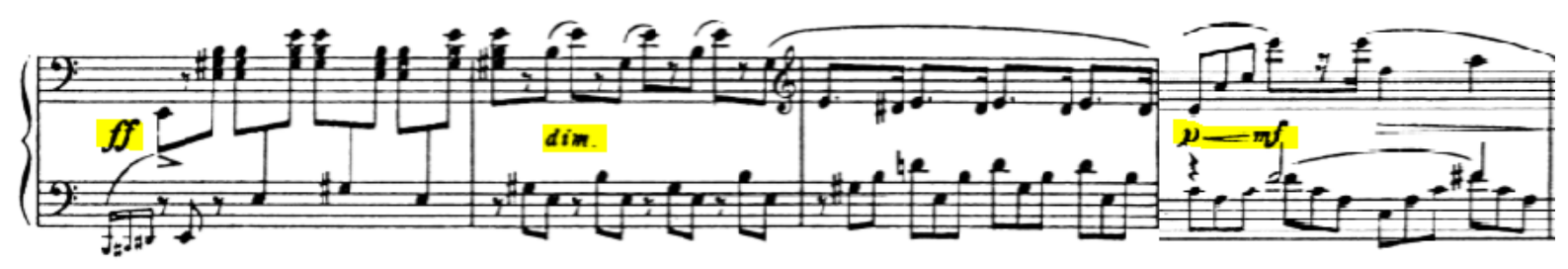

Example 67: mm. 13-16

Measures 22-24 also show that Prokofiev used frequent dynamic changes.

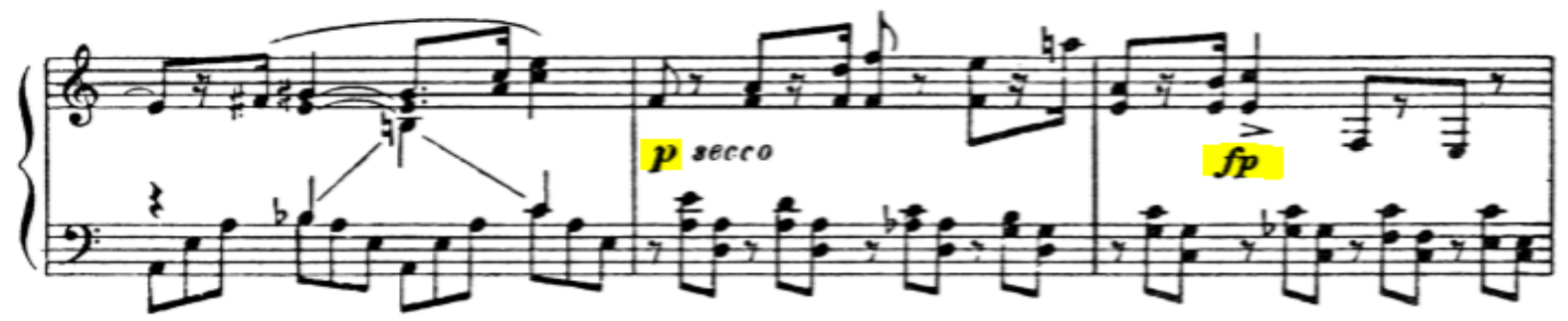

Example 68: mm. 22-24 
The $f$ sign in measure 52 is replaced by $p p$ in measure 54 , along with a tempo change. The performer needs to manage these large shifts in dynamics and tempo within a brief time span. The ritardando is essential and one needs to anticipate the new tempo ahead of time.
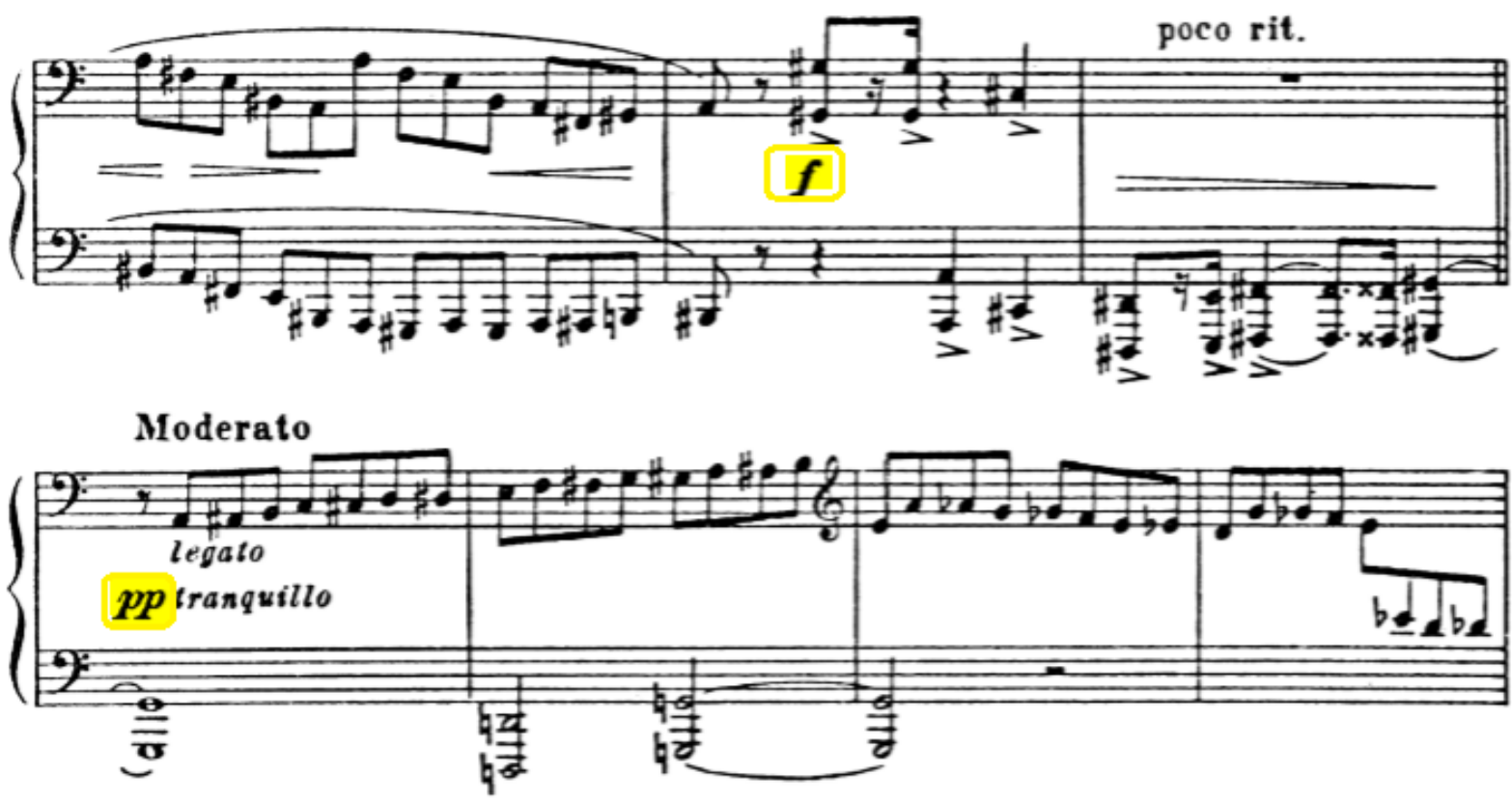

Example 69: mm. 51-57

Prokofiev specifies ritardando assai and $p p$ in measures 91-93, followed in the next bar by sudden changes, both in dynamics and in tempo. The only break between the two sections is a quarter rest on the downbeat of measure 94, but the performer must convey an instantaneous shift in mood from a lyrical line to an almost violent modern line. 

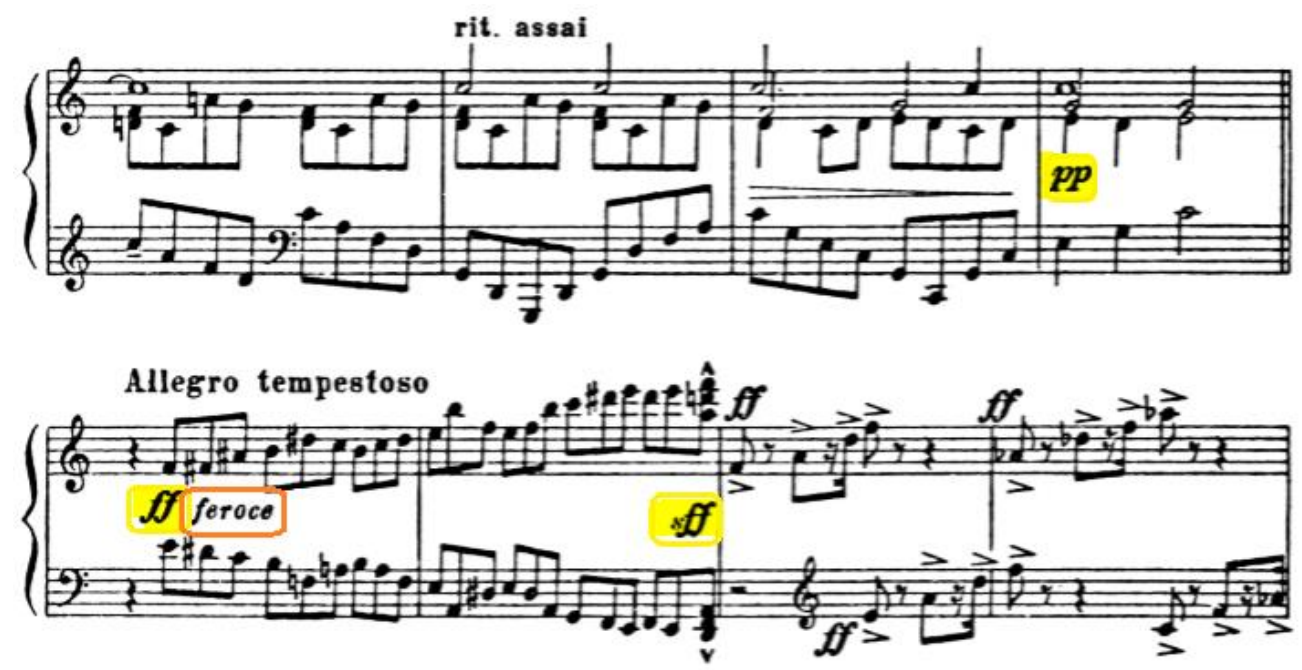

Example 70: mm. 90-97

We find another abrupt alteration of tempo and dynamic in measures 120-123. Prokofiev changes the tempo from allegro to moderato by means of a ritardando in measure 122 . The dynamic change is from $f$ to $p$. These factors help to create a huge mood swing from grotesque and vigorous to lyrical.

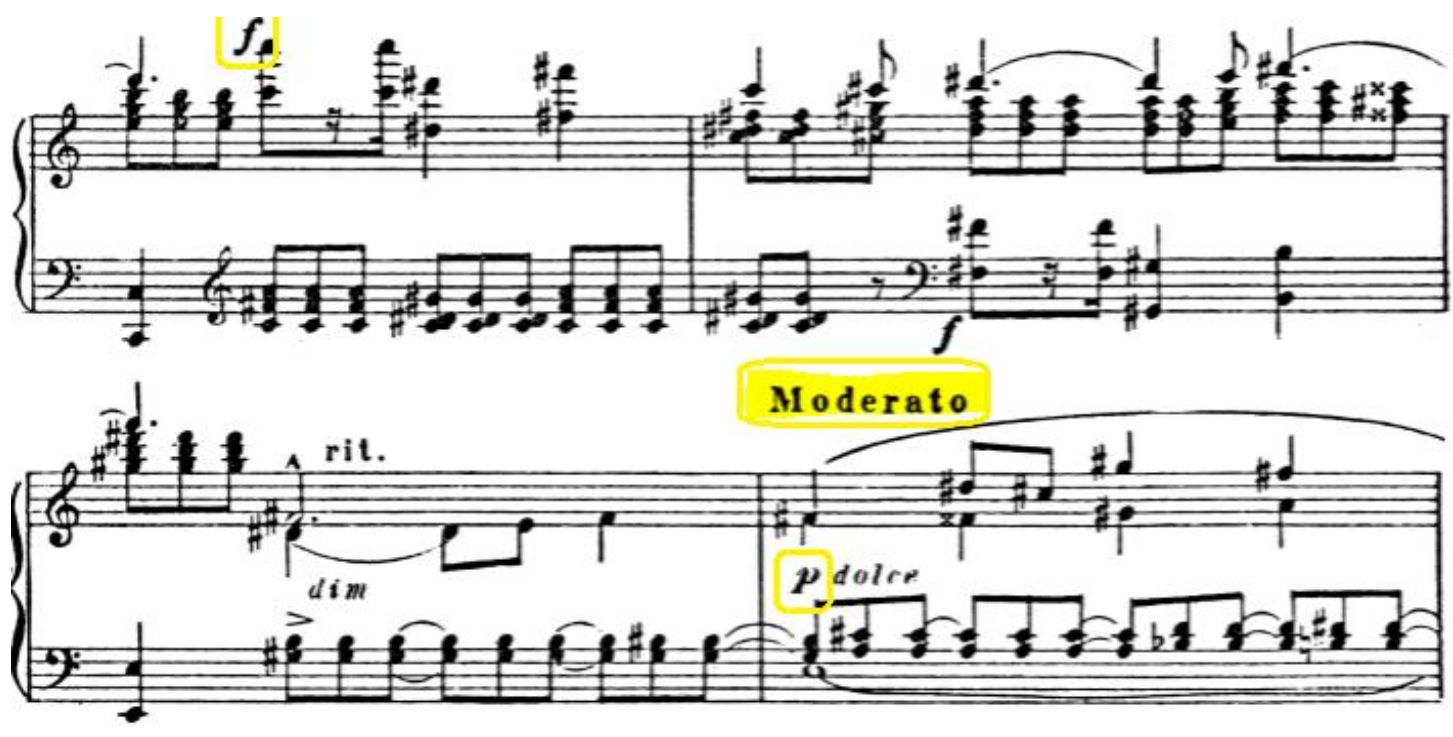

Example 71: mm. 120-123 
Another tempo change appears in measure 128, going from moderato to più lento. The new character indication is pp dolcissimo.

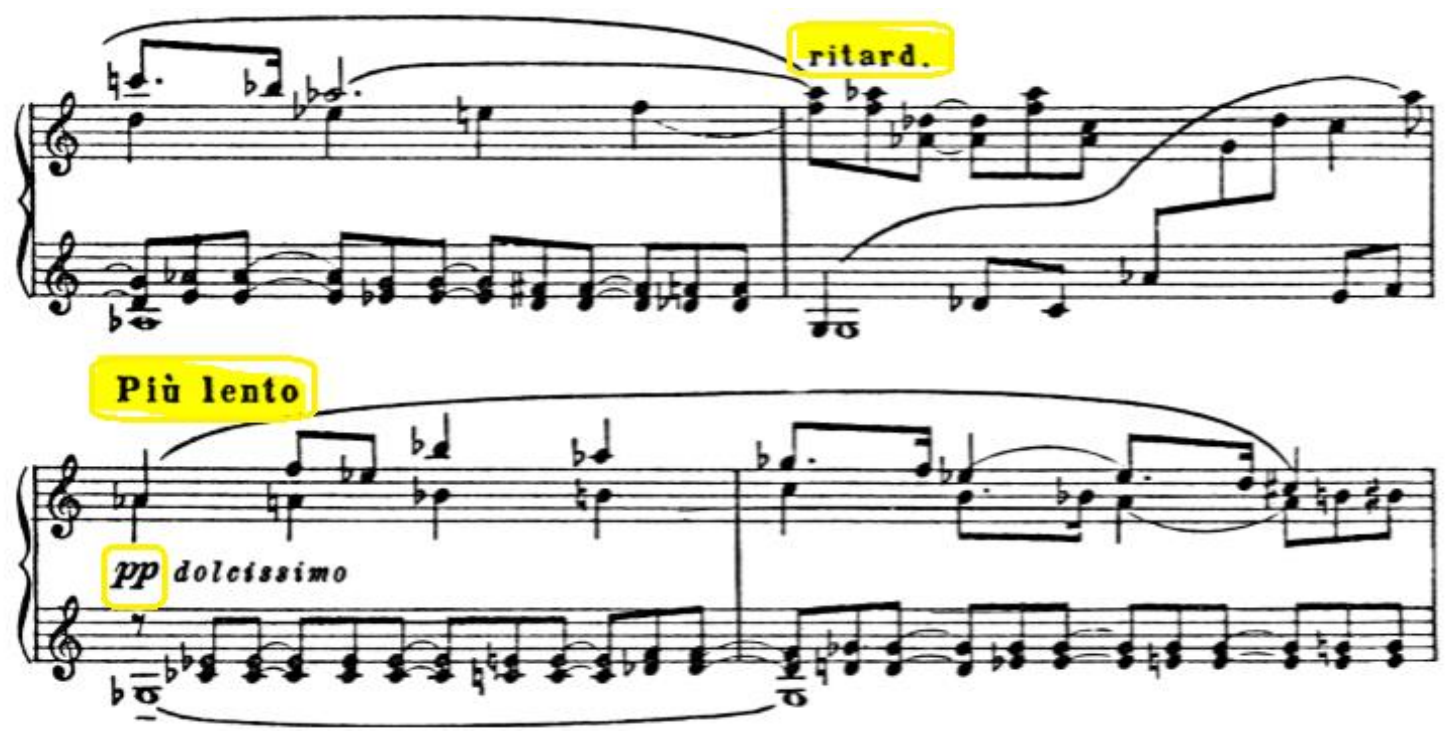

Example 72: mm. 126-129

As part of the recapitulation, the direction poco a poco accelerando begins in measure 155 and ends in measure 160; Allegro I appears in measure 161. One needs a clear plan to spread the tempo change gradually throughout the six measures; hearing two-bar phrase units can help. 

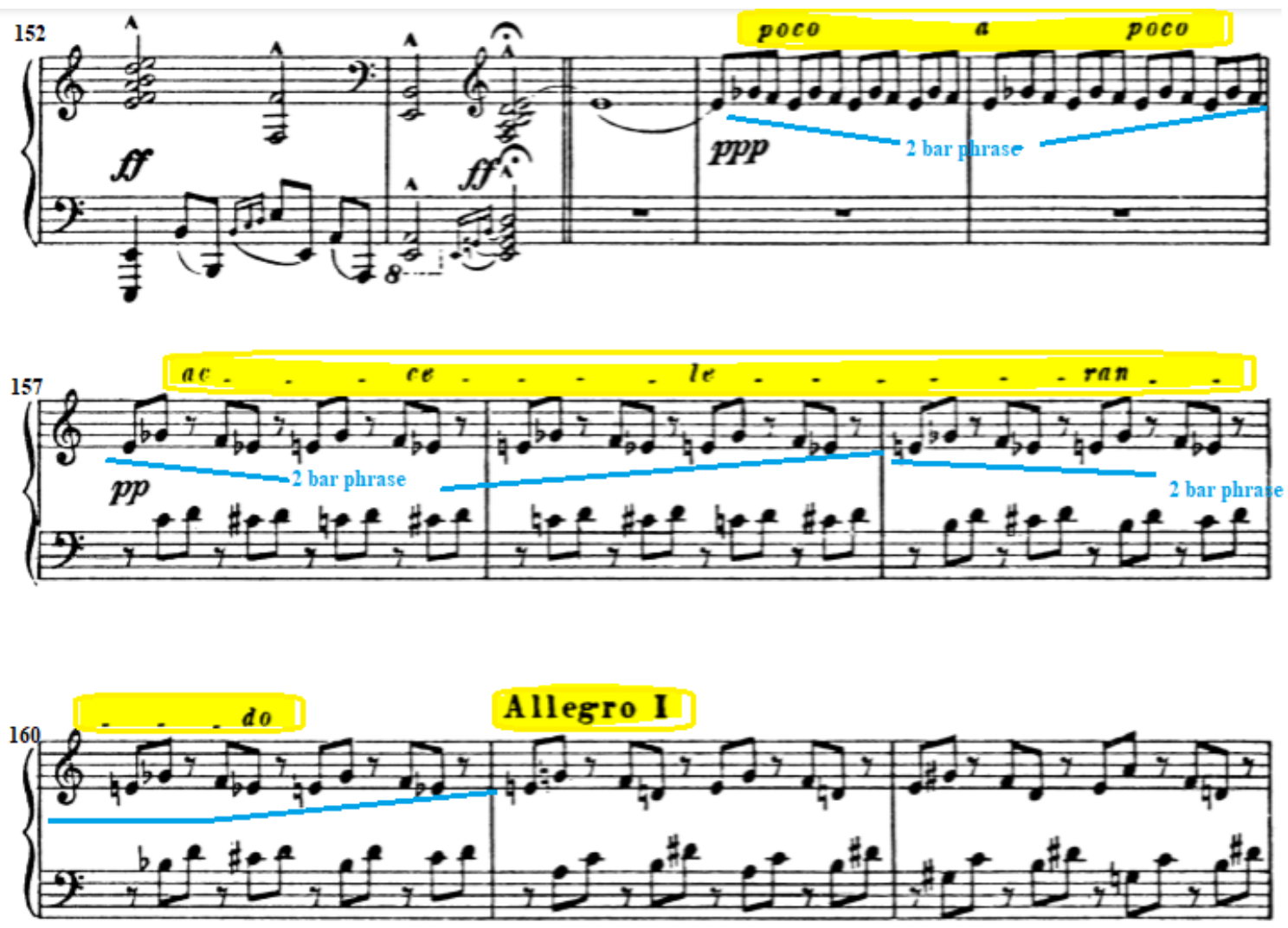

Example 73: mm. 152-162

We find yet another tempo and dynamic change in measure 205, as the prevailing $f$ dynamic gives way to $p p$ and the tempo changes to poco più mosso. The rhythmic divisions of the beat also shift from triplets to eighth notes and managing so many rapid changes can be challenging. 

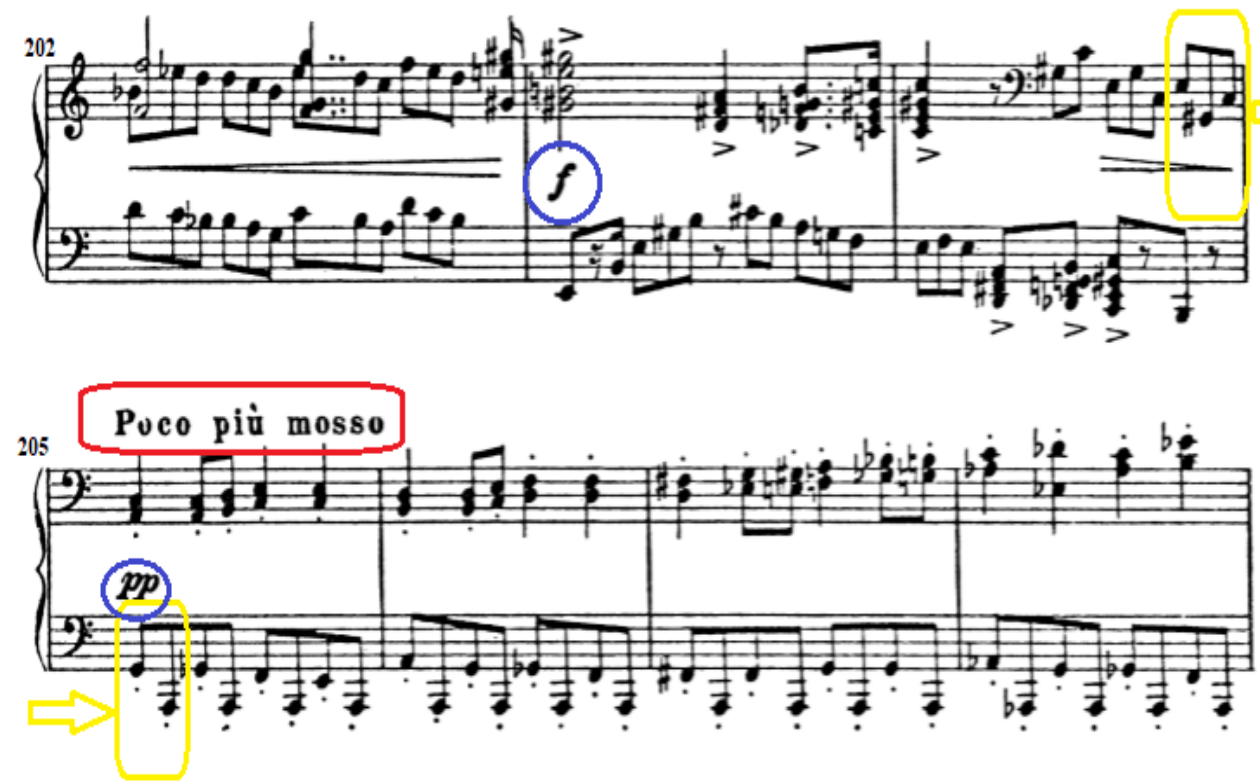

Example 74: mm. 202-208

(5) Wide Leaps and Trills

Prokofiev also used wide leaps and trills in composing this sonata. There is a five-octave span from the lowest note to the highest note in measures 105-106. This part is one of the most difficult spots in this sonata. In measure 105, the ascending arpeggio in the right hand consists of four beats of sixteenth notes. The first note, F, is the center of this passage. That first note can be heavy, with a deep pedal. The sixteenth notes in this passage should be practiced slowly, for evenness, perhaps with an accent on the first sixteenth note of every beat. For performance, the performer should recall that Prokofiev indicates accents only on the downbeats. 

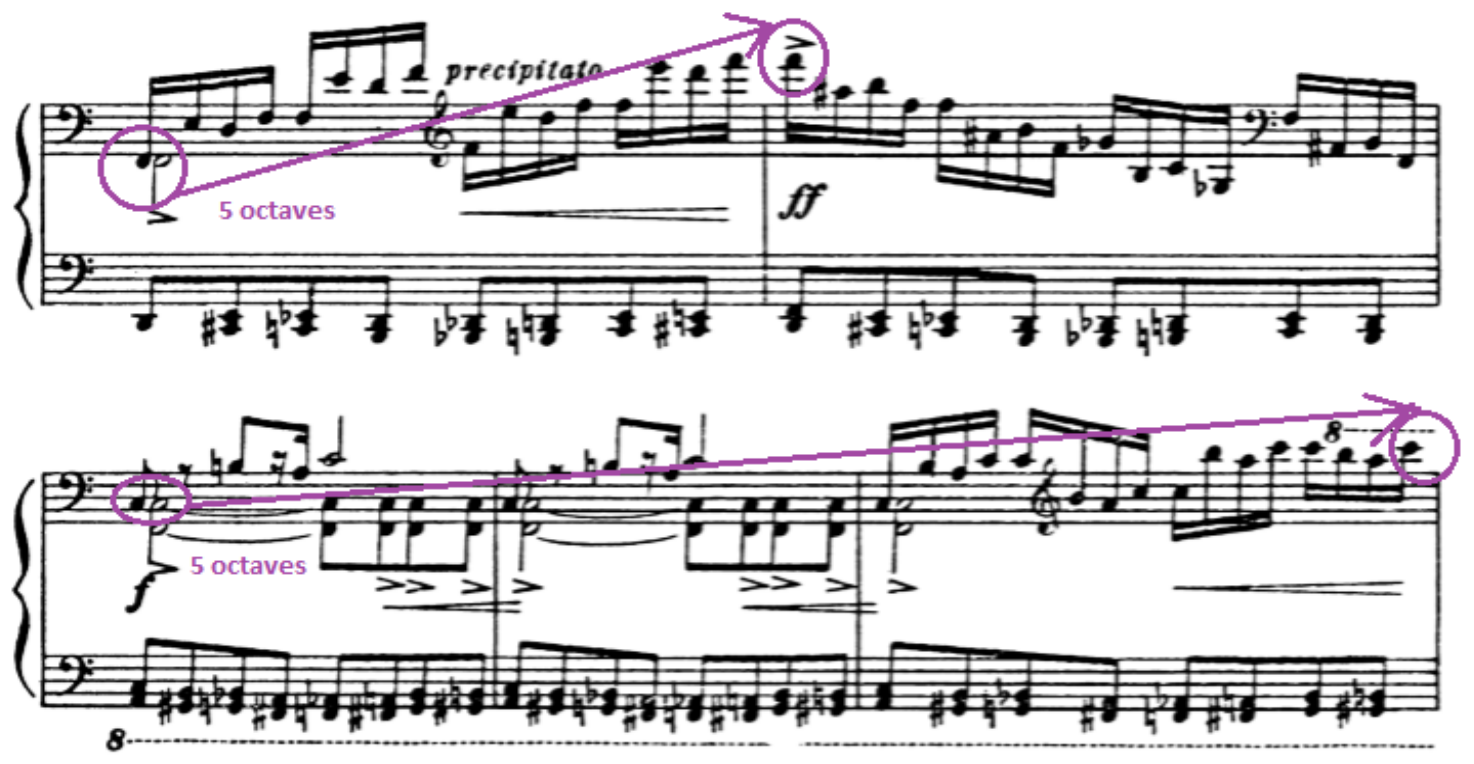

Example 75: mm. 105-109

Prokofiev specifies written-out trills in measures 111-113. Be careful with the last beats of mm. 111 and 112, so as not to add an extra beat to the left hand. Also observe the slurs in the left hand during mm. 112-113.

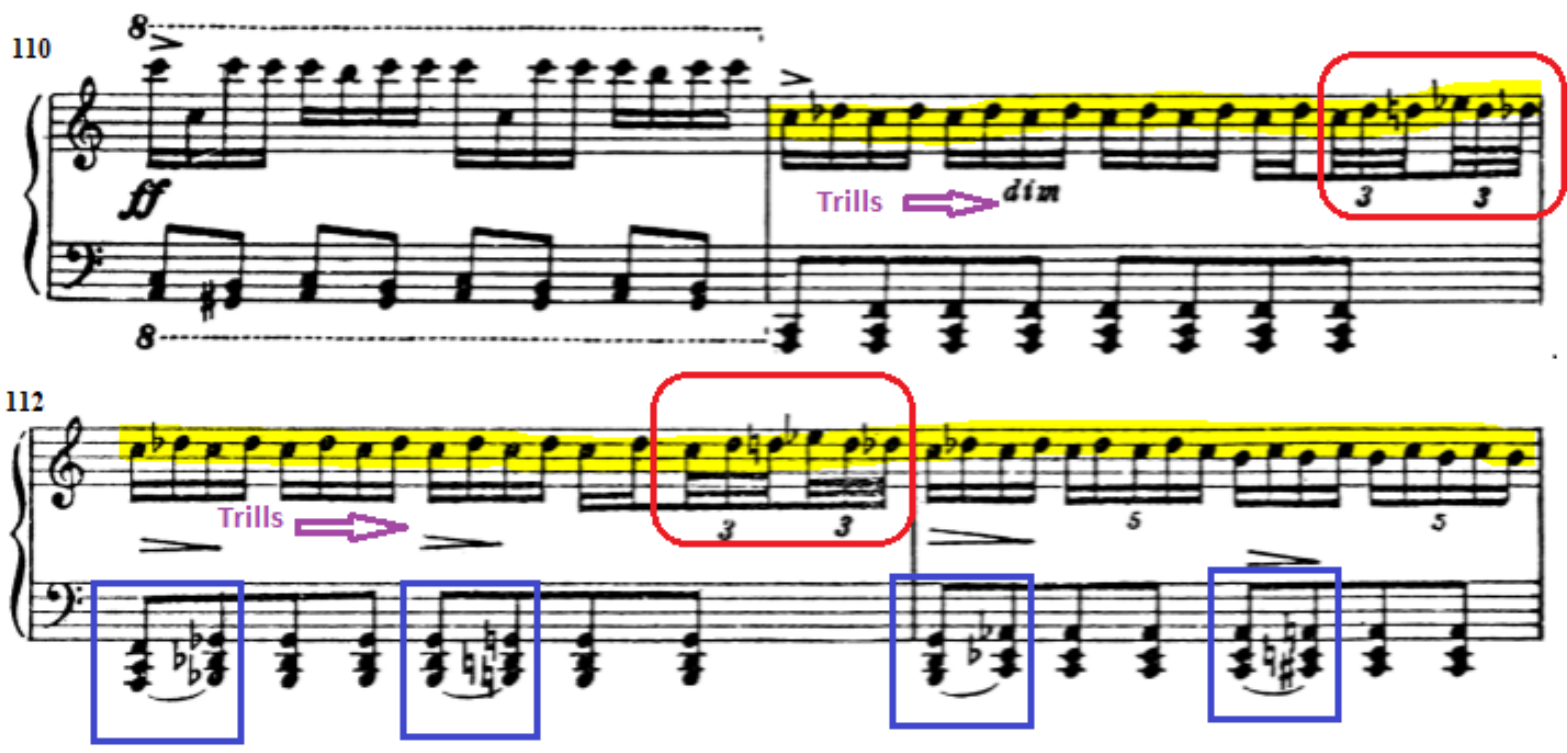

Example 76: mm. 110-113 
To play measures 140-145 effectively, one must carefully observe where the melody is located within the complex texture. The passage displays a range of more than five octaves, including hand crossings.

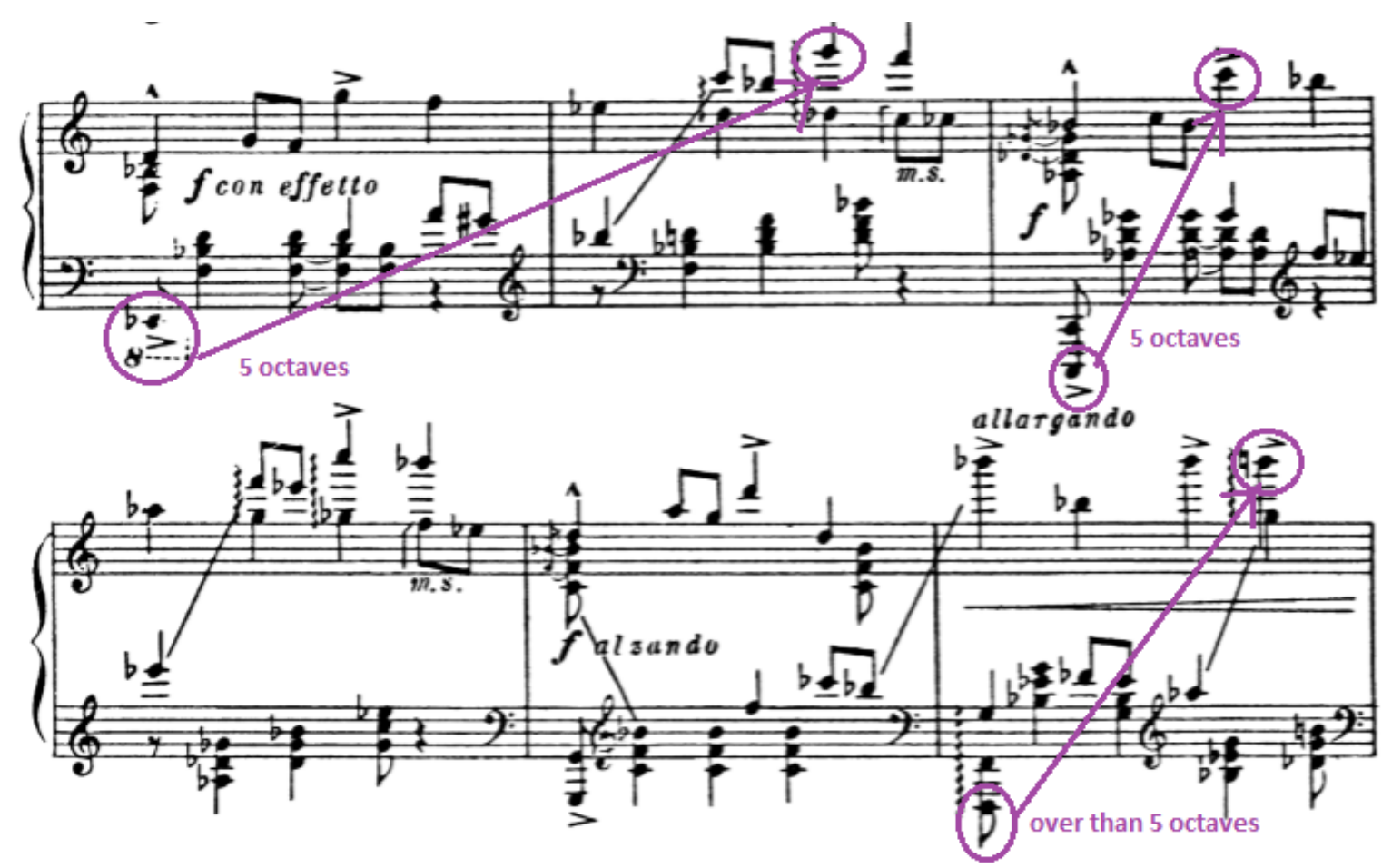

Example 77: mm. 140-145

Measures 146-147 display parallel first-inversion chords in the left hand. Each is accented and the left hand covers a four-octave range in these two bars. At the same time, the right hand negotiates grace-note arpeggios across a three-octave range, along with repetition of notes in the inner voice and the melody in the top voice. It is challenging to control so many notes in distinct textures. The next two measures also give parallel minor seventh chords to the left hand; these move downward chromatically. 

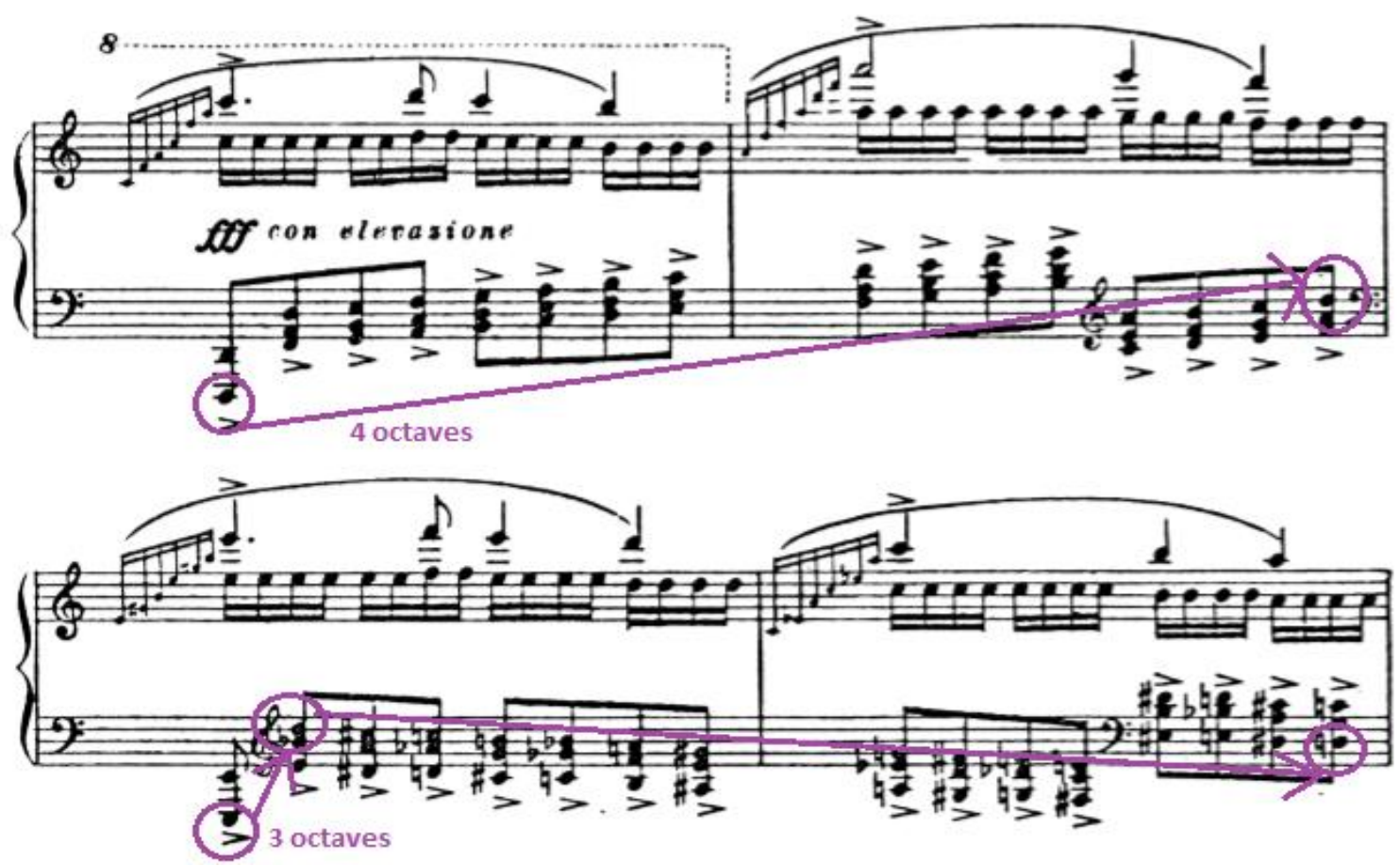

Example 78: mm. 146-149

\section{The Toccata Line}

Prokofiev's toccata line appears in measures 114-117, in the inner voices of both hands. It is easy to play these sixteenth notes too loudly, potentially overpowering the main melody, which is in the top voice.
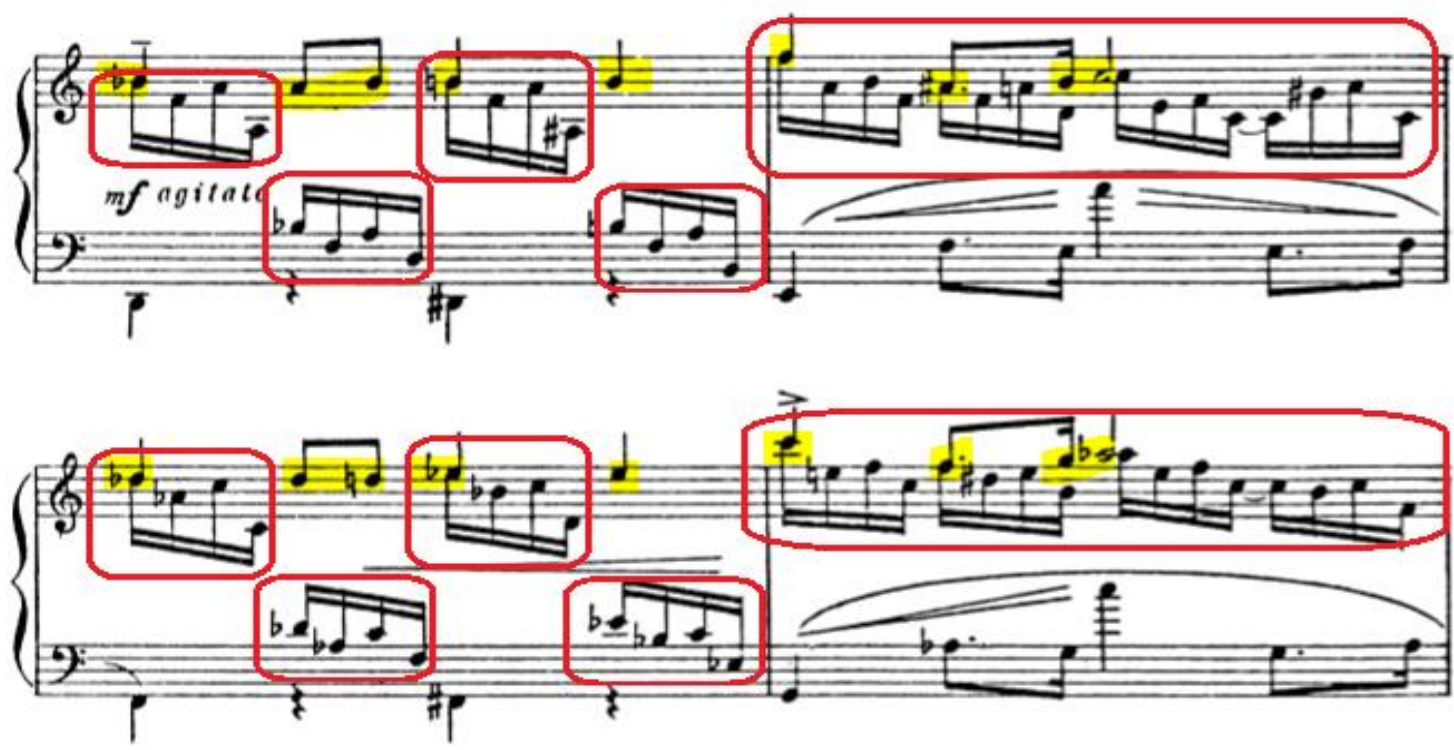

Example 79: mm. 114-117 
In measures 146-151, the inner voice in the right hand also shows the toccata line. These sixteenth notes are not the melody, but serve as an accompanying part; as such, they must be relatively light within the fff dynamic. The only possible fingering is to use the right thumb for the repeated notes.
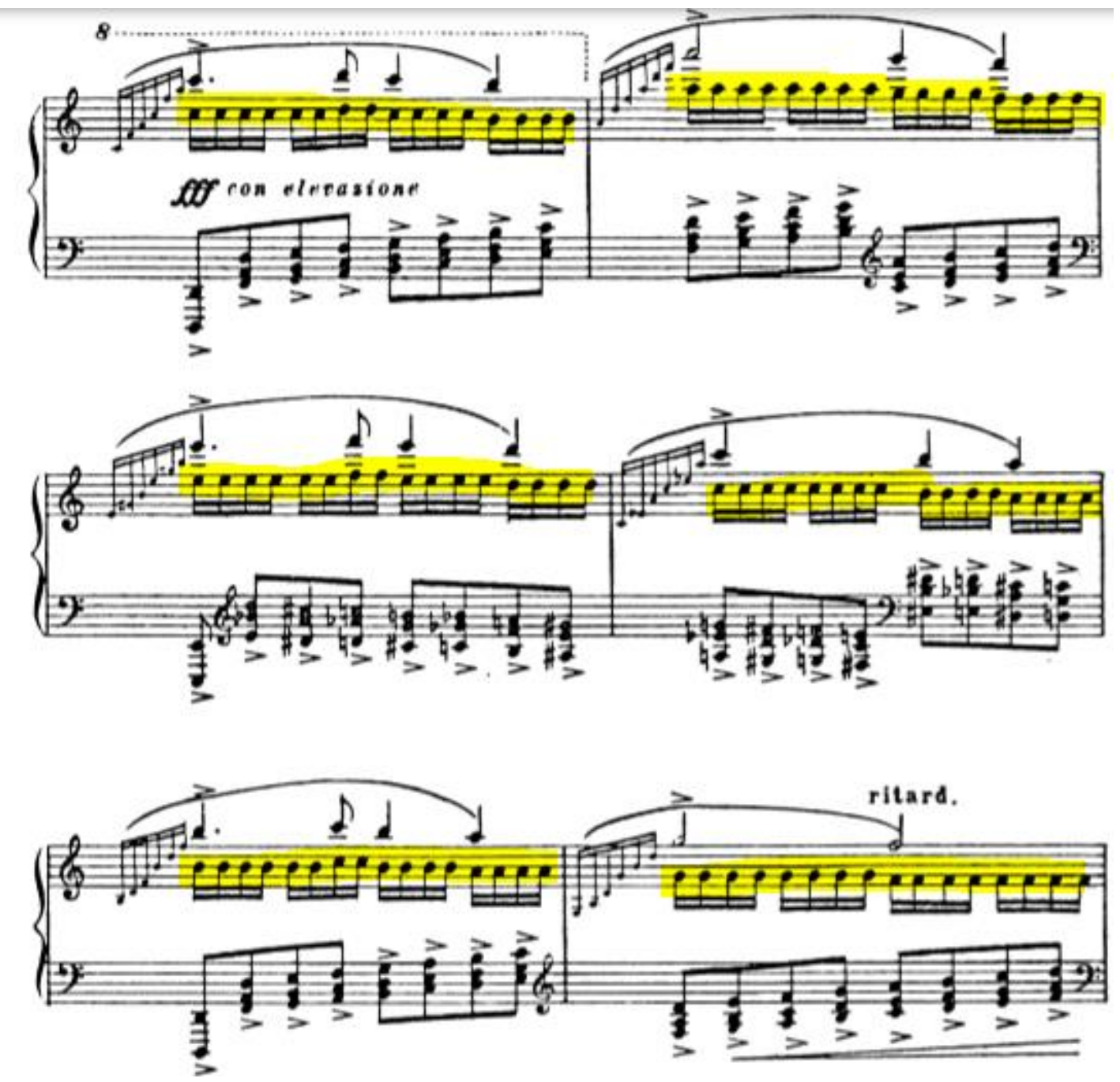

Example 80: mm. 146-151

\section{Pedaling}

Most sections of this sonata do not need much pedal. To show a "Percussive" effect, which is one of Prokofiev's self-described characteristics, it is important to play with less pedal than usual.

Example 72 suggests a pedaling strategy for the opening of the sonata, mm. 1-6. One wants pedal for the ff dynamic, but each application can be short, to convey clarity and dryness. 

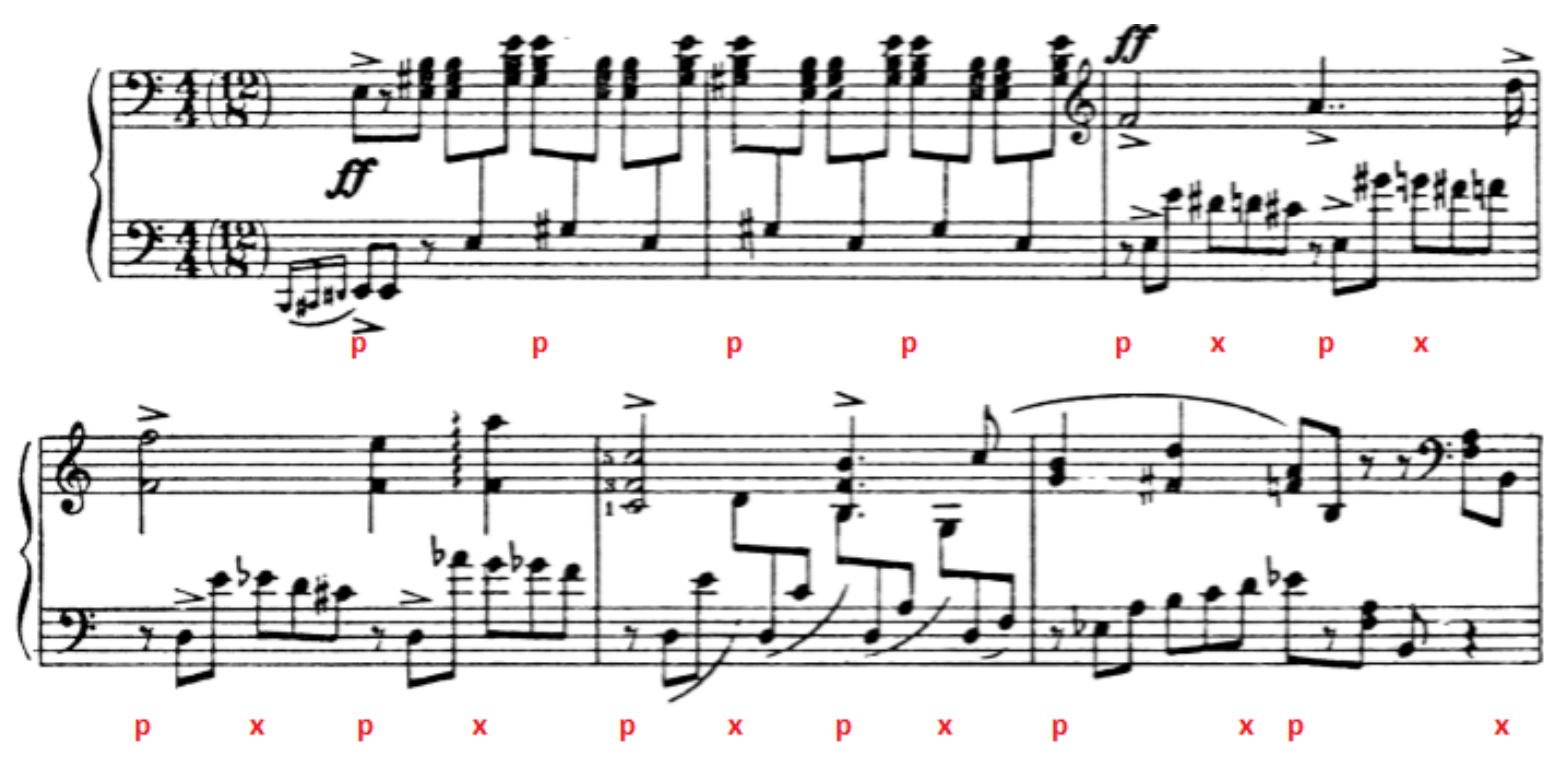

Example 81: mm. 1-6

\section{Fingering}

Many parts of this sonata are difficult to play without effective fingering choices. In order to play smoothly in fast tempos, it is beneficial and efficient to work out fingerings before practicing passagework. Following, in examples 73-80, are examples that have been helpful to me in this piece.
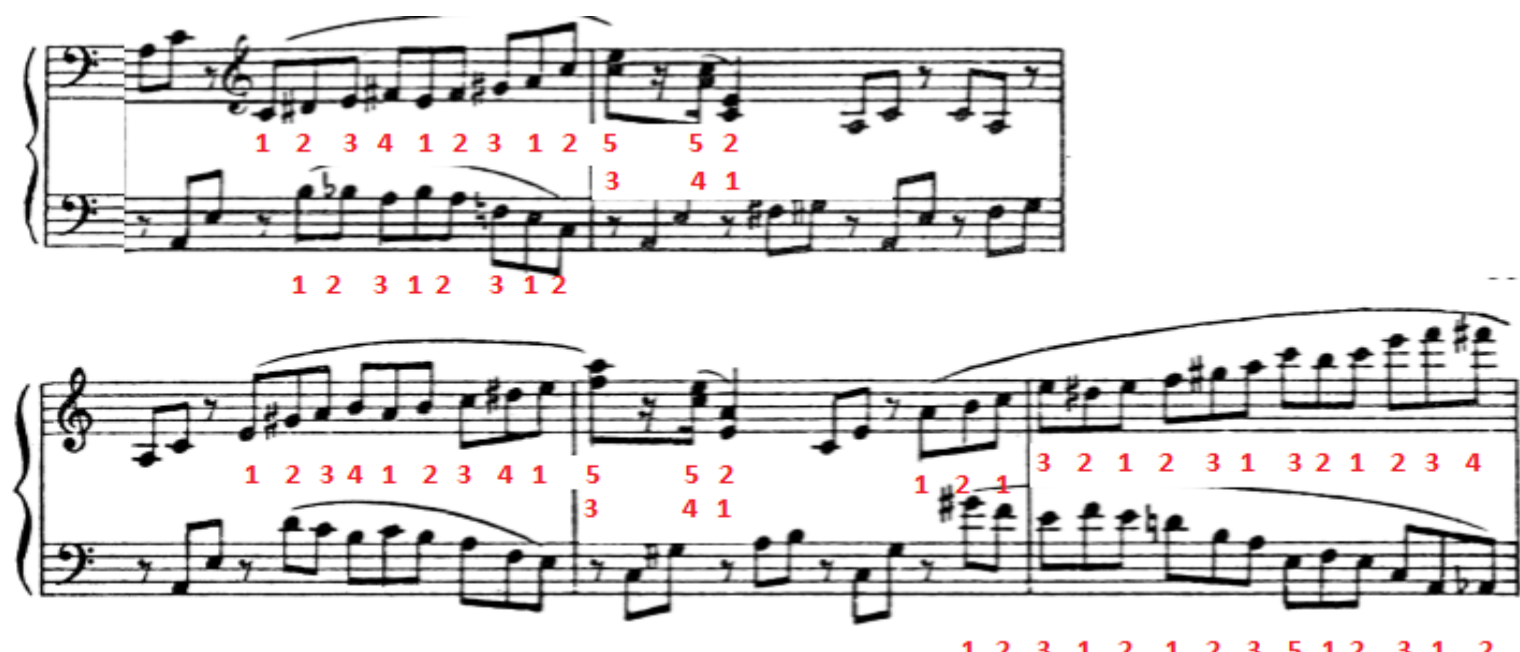

Example 82: mm. 29-33 

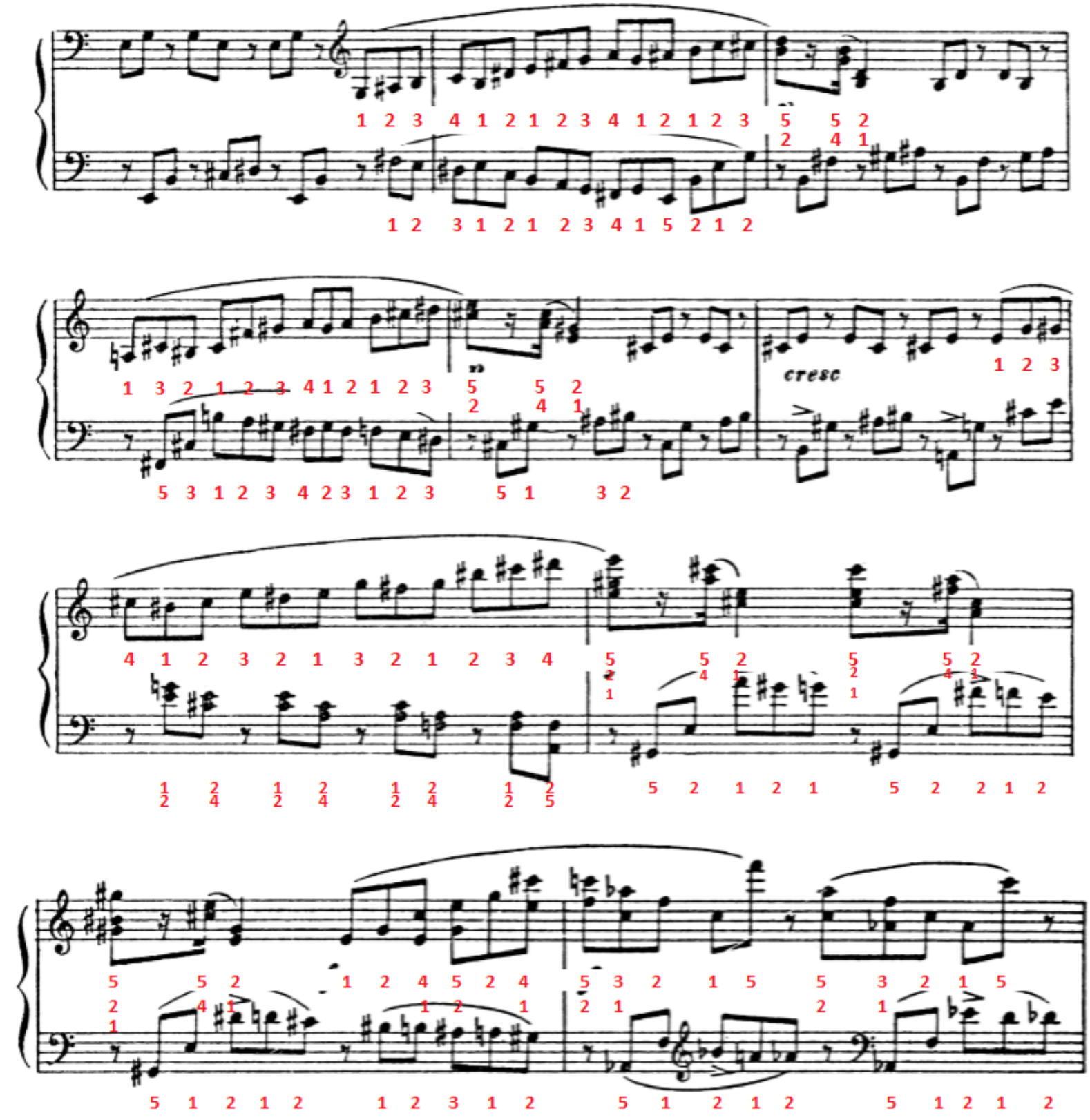

Example 83: mm. 37-46 

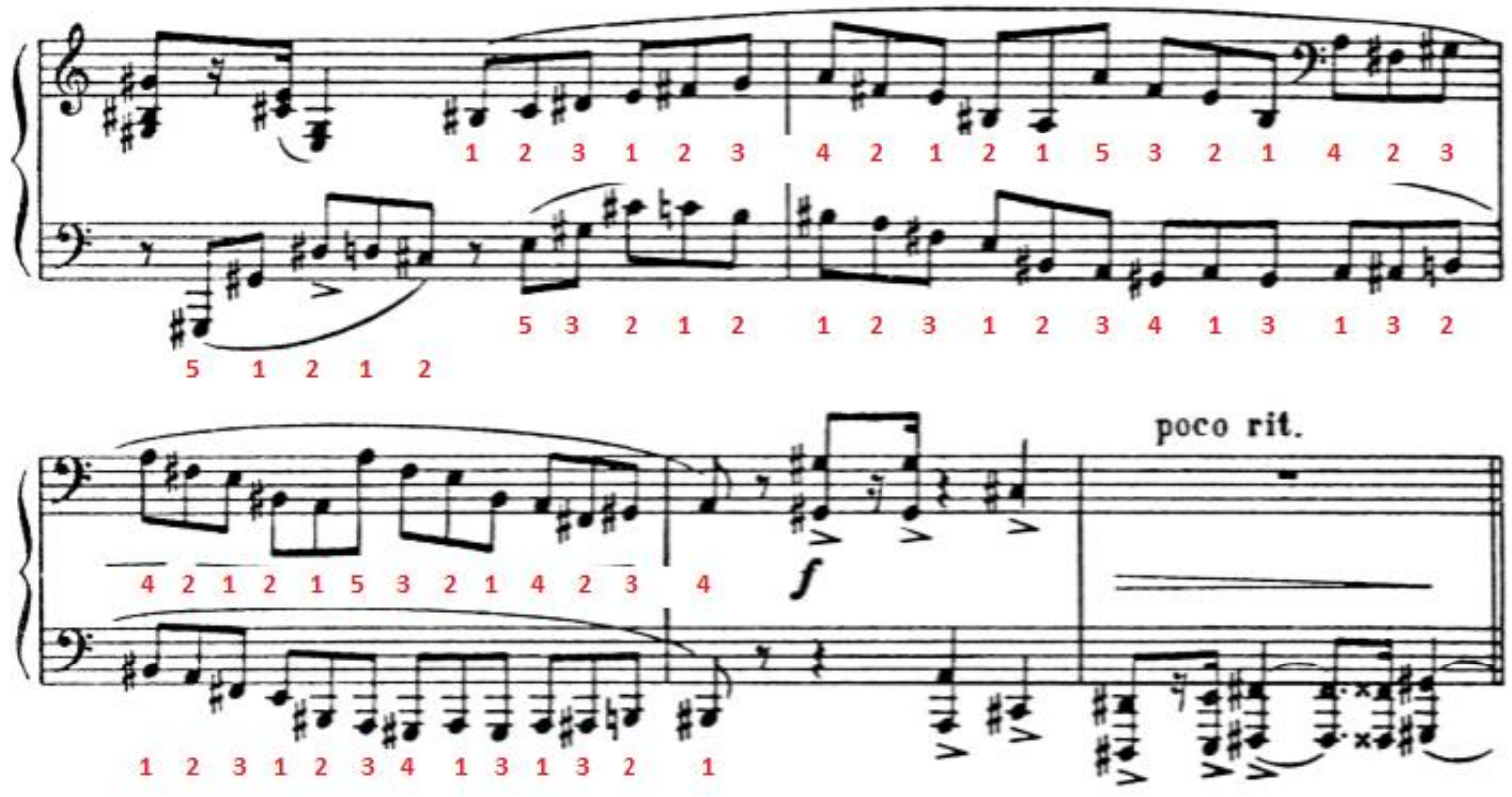

Example 84: mm. 49-52

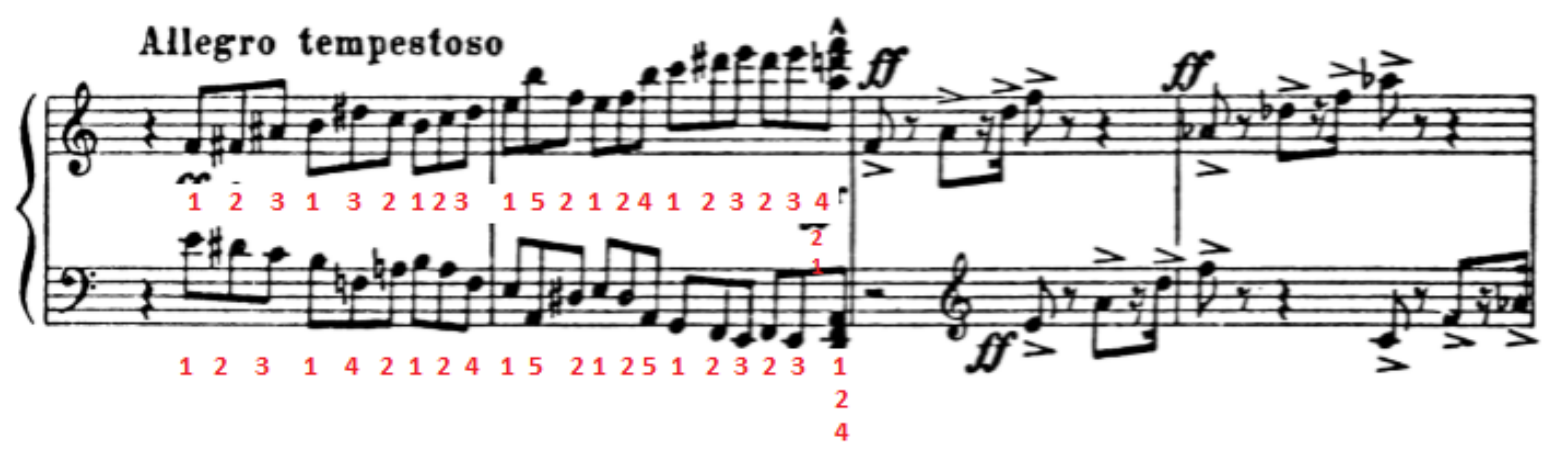

Example 85: mm. 94-95 

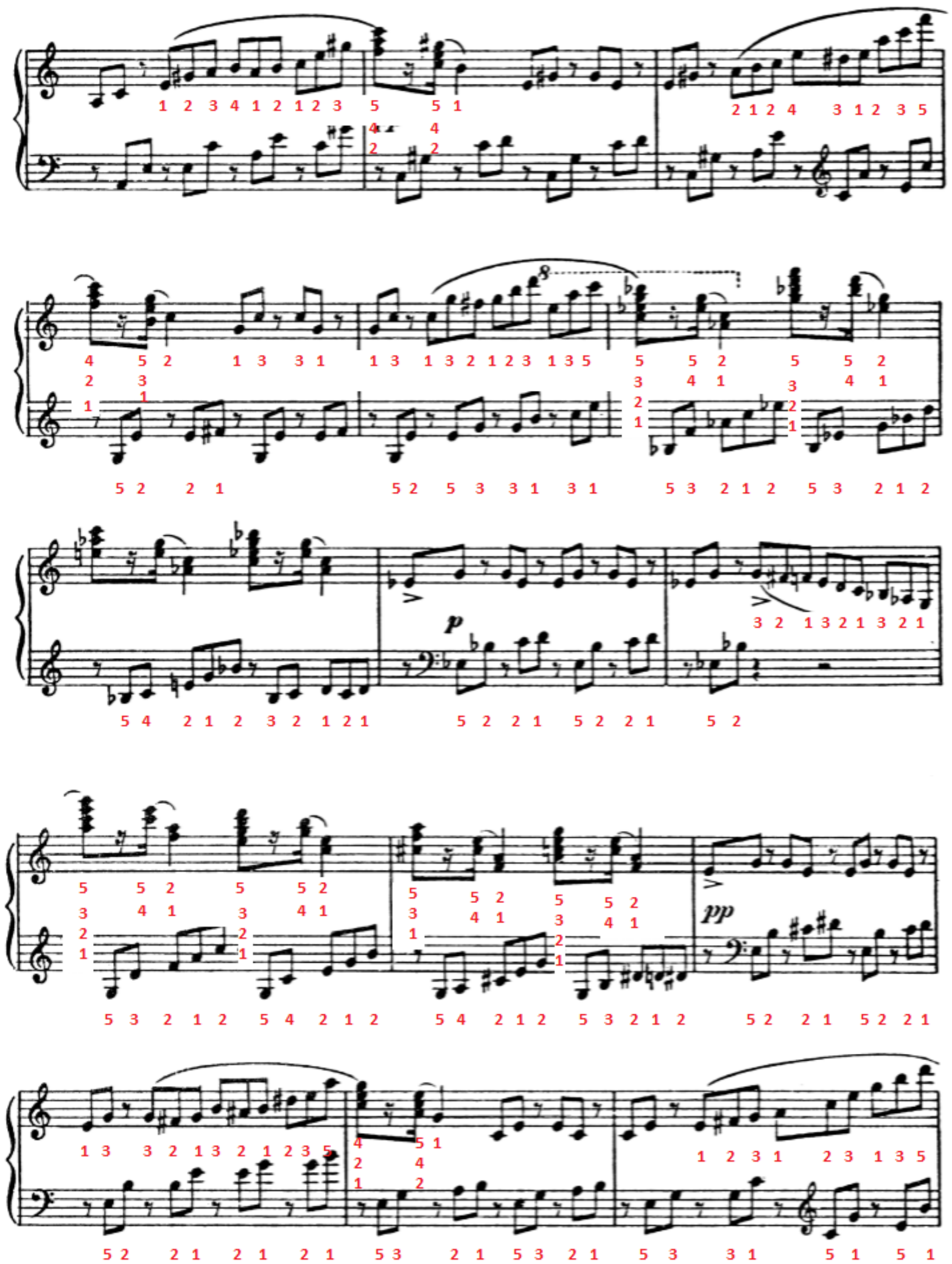

Example 86: mm. 166-180 

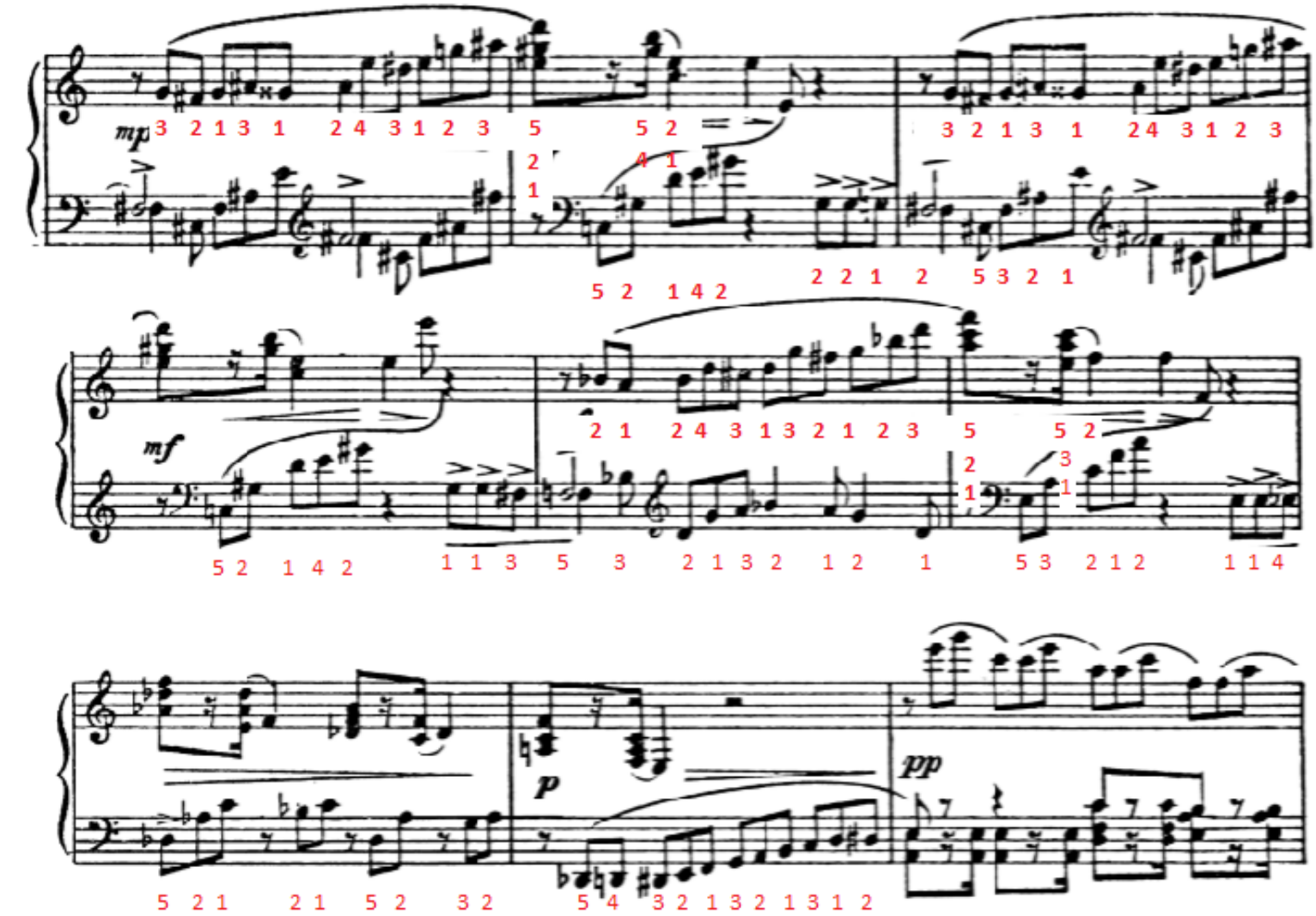

Example 87: mm. 181- 189
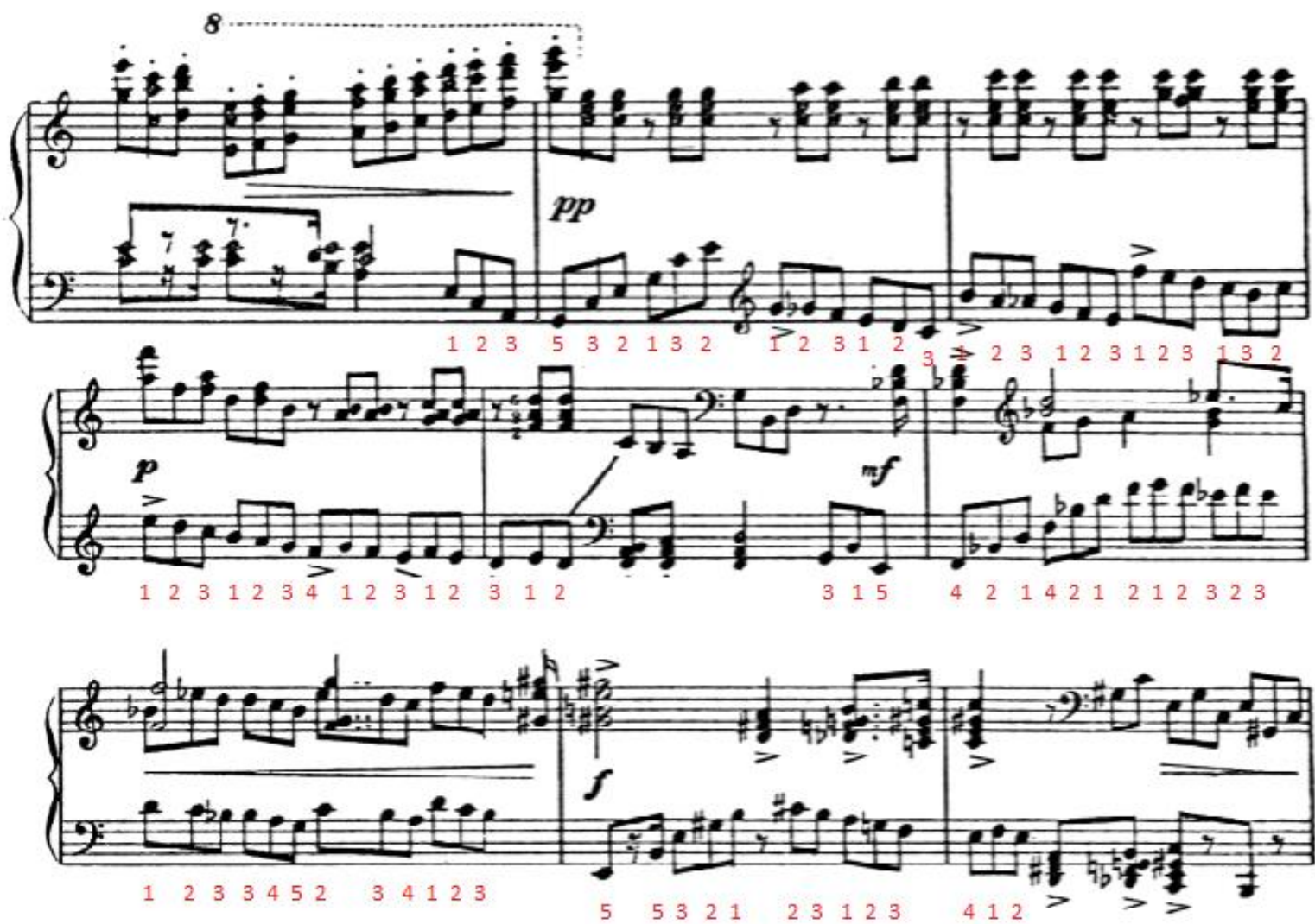

Example 88: mm. 196-204 


\section{Chapter 5. Conclusion}

Among Prokofiev's nine complete piano sonatas, the Third Piano Sonata was written in 1917 as a one-movement work; it is also the shortest among his piano sonatas. It can be a great showcase both for the performer and also for the five compositional characteristics Prokofiev describes for his own music: the lyrical line, the grotesque line, the classical line, the modern line, and the toccata line.

Regarding the classical line, Prokofiev employs the sonata-allegro structure, which is a traditional classical form. This sonata consists of two contrasting themes employed in the form of Exposition-Development-Recapitulation-Coda. Theme I appears fortissimo, displaying contrast between a diatonic progression in the right-hand melody and a chromatic progression in the left hand. Theme II is much more lyrical, sempre dolce, and presents an eighth-note (duple) division of the quarter beat, in sharp contrast to the driving triplets of Theme I. In the Development, Prokofiev creates transformations of each theme. Triplet rhythms appears throughout the work, providing unity. Prokofiev uses Alberti bass, ostinato, and traditional formulas which represent his classical line.

Aspects of Prokofiev's “modern” line appear in the structure of the Recapitulation: Unlike most traditional forms, in Prokofiev's hands this sonata does not present Theme I in the Recapitulation. Chromatic and diatonic melodies appear simultaneously in many parts of this sonata. The combination of motoric rhythms, two-against-three conflicts, triplets, dotted-eighth-and-sixteenth patterns, along with the chromatic progression of chords conveys a modern and innovative effect. Intervals of seconds and sevenths, wide leaps, transpositions, and chromatic thirds appear frequently in this sonata.

These features figure prominently for any pianist preparing this work for performance. The work requires a strong rhythmic sense and virtuoso technical accomplishment. Prokofiev often treats the piano as a percussion instrument, creating effects that are both challenging and enjoyable to play.

Prokofiev's Piano Sonata no. 3, op. 28, provides many opportunities for pianists to improve and display their skill while exploring twentieth-century compositional style. Most of all, it is a worthwhile and effective piece that is enjoyable to hear and to play. 


\section{SELECTED BIBLIOGRAPHY}

\section{BOOKS}

Berman, Boris. Pianist's Bench. New Haven and London: Yale University Press, 2000.

Berman, Boris. Prokofiev's Piano Sonatas. New Haven and London: Yale University Press, 2008.

Minturn, Neil. The Music of Sergei Prokofiev. New Haven and London: Yale University, 1997.

Morgan, Robert P. Twentieth-Century Music. New York: W.W. Norton \& Company, 1991.

Nice, David. Prokofiev From Russia to The West 1891-1935. New Haven and London: Yale

University Press, 2009.

Prokofiev, Sergei. Prokofiev By Prokofiev - A Composer's Memoir- London and Sydney: Macdonald General Books Macdonald and Jane's, 1979.

\section{DISSERTATIONS AND THESES}

Chae, Roia. "A Study on The Analysis of Prokofiev's Piano Sonata no. 3, op. 28 Which Shows The Development of Sonata." (M.M. Thesis, Yonsei University, Seoul, 2003).

Chang, Ya-Liang. "A Study and Performer's Analysis of Piano Sonatas by Béla Bartók and Sergei Prokofiev." (D.M.A. Dissertation, University of Cincinnati, 2000).

Hong, Soo Kyung, "A Study on the Piano Sonata No. 3 in a minor by Sergei Prokofiev: focusing on construction and musical expression." (M.M. Thesis, Sejong University, 2007).

Juan, Shu-Fen. "Variants of Sonata Form as Seen Alban Berg's Piano Sonata Op. 1 and Sergei Prokofiev's Piano Sonata No. 3 in A Minor, Op. 28." (D.M.A. Diss., Coral Gables, 2006).

Kim, Namhee. "A Study of the Pedaling of S. Prokofiev Piano Sonata No. 3, Op. 28.” (M.M. Thesis, Jeonbuk National University, Jeonju, 1997).

Lee, Eun Hee. "An Analytic Study on the Sergei Prokofiev Piano Sonata No. 3, Op. 28." (M.M. Thesis, Hanyang University, Seoul, 2009).

Lee, Yunjeong. "Analytic Study on the Piano Sonata No. 3 in a minor Op. 28 by Sergey Prokofiev." (M.M. Thesis, Joongang University, Seoul, 2002).

Markovic, Nikola. "Freedom in Interpretation and Piano Sonata No. 7 By Sergei Prokofiev -A Comparison of Two Approaches to Piano Interpretation-." (M.M. Thesis, University of Adger, Kristiansand, Norway, 2012). 
Martin, Rebecca Gena. "The Nine Piano Sonatas of Sergei Prokofiev.” (D.M.A. Diss., University of Kentucky, Lexington, 1982).

Oh, Youngsuk. “(A) Study of Piano Sonata Op. 28, No. 3, Composed by Sergey Prokofiev.” (M.M. Thesis, Anyang University, Anyang, 2003).

Rifkin, Deborah Anne. “Tonal Coherence in Prokofiev's Music: A Study of The Interrelationships of Structure, Motives, and Design.” (Ph.D. Diss., University of Rochester, Rochester, 2000).

Tsai, Chia-hui, “Sonata Form Innovations in Prokofiev's Nine Piano Sonatas.” (D.M.A. Diss., University of Cincinnati, 2003).

Westfall, David. "Three One-Movement Sonatas of The Russian Silver Age: A Comparative Study." (D.M.A. Diss., University of Hartford, West Hartford, 2008).

Woo, Jinkyung. "Research on Piano Sonata No. 3, Op. 28 by Sergey Prokofiev." (M.M. Thesis, Catholic University of Korea, Bucheon, 2008).

\section{JOURNALS}

Bass, Richard. "Prokofiev's Technique of Chromatic Displacement." Music Analysis, Vol. 7, No. 2 (Jul. 1988), pp. 197-214.

O’Shea, Gary. ““A Permanent Influence': Beethoven's Impact on Prokofiev's Piano Writing.” The Musical Times (Autumn 2015), pp. 49-62.

Rifkin, Deborah. “A Theory of Motives for Prokofiev's Music.” Music Theory Spectrum 26 (2004), pp. 265-290. 